Illinois State University

ISU ReD: Research and eData

Theses and Dissertations

$10-29-2018$

\title{
Synthesis And Characterization Of A Series Of Vanadium(iv) Complexes With The Kläui Ligand
}

Xiao Wu

Illinois State University, wuxiao0314@163.com

Follow this and additional works at: https://ir.library.illinoisstate.edu/etd

Part of the Chemistry Commons

\section{Recommended Citation}

Wu, Xiao, "Synthesis And Characterization Of A Series Of Vanadium(iv) Complexes With The Kläui Ligand" (2018). Theses and Dissertations. 1023.

https://ir.library.illinoisstate.edu/etd/1023

This Thesis is brought to you for free and open access by ISU ReD: Research and eData. It has been accepted for inclusion in Theses and Dissertations by an authorized administrator of ISU ReD: Research and eData. For more information, please contact ISUReD@ilstu.edu. 


\title{
SYNTHESIS AND CHARACTERIZATION OF A SERIES \\ OF VANADIUM(IV) COMPLEXES WITH \\ THE KLÄUI LIGAND
}

\begin{abstract}
XIAO WU
107 Pages

Cyclopentadienyltris (dibutyl phosphito- $P$ ) cobaltate, $\left\{\left(\mathrm{C}_{5} \mathrm{H}_{5}\right) \mathrm{Co}\left[(\mathrm{OR})_{2} \mathrm{PO}\right]_{3}\right\}^{-}(\mathrm{R}=\mathrm{Bu})$, is a tripodal ligand and also called Kläui ligand $(\mathrm{R}=\mathrm{Bu})$. The synthesis and characterization of several vanadium(III) and vanadium(IV) complexes containing Kläui ligand ( $\mathrm{R}=\mathrm{Bu})$ as the catalytic models to catalyst the oxidation reaction of 3,5-di-tert-butylcatechol (3,5-DTBC) to 3,5-di-tertbutyl-o-benzoquinone (3,5-DTBQ) are detailed here. Chapter II details the synthesis of the supersandwiches and Kläui ligand $(\mathrm{R}=\mathrm{Bu})$. Chapter III details the synthesis of vanadium monomeric complexes containing Kläui ligand $(\mathrm{R}=\mathrm{Bu})$. Chapter IV details the vanadium dimeric bridging complexes synthesized by different vanadium monomers from Chapter III. Chapter V details the catalytic activities of these vanadium complexes.

KEYWORDS: Kläui ligand; tridentate oxygen ligand; vanadium; oxalate bridge; phosphonate bridge; catalyst
\end{abstract}


SYNTHESIS AND CHARACTERIZATION OF A SERIES

OF VANADIUM(IV) COMPLEXES WITH

THE KLÄUI LIGAND

XIAO WU

A Thesis Submitted in Partial
Fulfillment of the Requirements
for the Degree of
MASTER OF SCIENCE
Department of Chemistry
ILLINOIS STATE UNIVERSITY

2018 
(C) 2018 Xiao Wu 
SYNTHESIS AND CHARACTERIZATION OF A SERIES

OF VANADIUM(IV) COMPLEXES WITH

THE KLÄUI LIGAND

XIAO WU

COMMITTEE MEMBERS:

Craig C. McLauchlan, Chair

Christopher G. Hamaker

Jun-Hyun Kim 


\section{ACKNOWLEDGMENTS}

I would like to thank Illinois State University, the American Chemical Society Petroleum Research Fund, the National Science Foundation, the Kurz scholarship, the Illinois State University Department of Chemistry and Graduate Program. I would especially like to thank my family and loved ones, Dr. Christopher Hamaker for teaching me everything I know about inorganic chemistry and crystallography, and Dr. Craig McLauchlan who has been a mentor to me throughout my time as a graduate student.

X. W. 


\section{CONTENTS}

Page

ACKNOWLEDGMENTS

CONTENTS

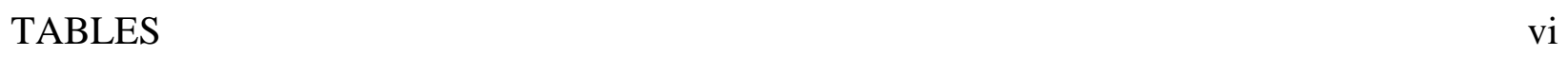

FIGURES

SCHEMES

CHAPTER I: INTRODUCTION 1

CHAPTER II: SYNTHESIS AND CHARACTERIZATION OF SUPERSANDWICH

$\left(\mathrm{CpP}{ }^{\mathrm{OBu}} \mathrm{Co}\right)_{2} \mathrm{M}(\mathrm{M}=\mathrm{Co}, \mathrm{Ni}, \mathrm{V}=\mathrm{O})$ AND THE NEW KLÄUI LIGAND (CpP $\left.{ }^{\mathrm{OBu} C o}\right)^{-} \quad 23$

$\begin{array}{ll}\text { Abstract } & 23\end{array}$

$\begin{array}{ll}\text { Introduction } & 23\end{array}$

$\begin{array}{ll}\text { Experimental } & 25\end{array}$

$\begin{array}{ll}\text { General considerations } & 25\end{array}$

Bis[cyclopentadienyltris(dibutyl phosphito- $P$ )cobalt- $O, O$ ’, $O$ ”]

cobaltate(II), (CpP $\left.{ }^{\mathrm{OBu}} \mathrm{Co}\right)_{2} \mathrm{Co}(2) \quad 26$

Sodium cyclopentadienyltris(diethyl phosphito- $P$ )

cobaltate, $\mathrm{Na}\left(\mathrm{CpP}^{\mathrm{OEt}} \mathrm{Co}\right)(3) \quad 26$

Sodium cyclopentadienyltris(dibutyl phosphito- $P$ )

$\begin{array}{ll}\text { cobaltate, } \mathrm{Na}\left(\mathrm{CpP}^{\mathrm{OBu}} \mathrm{Co}\right)(\mathbf{4}) & 27\end{array}$

Bis[cyclopentadienyltris(dibutyl phosphito- $P$ )cobalt- $O, O^{\prime}, O^{\prime}$ ]

nickelate(II), (CpP $\left.{ }^{\mathrm{OBu}} \mathrm{Co}\right)_{2} \mathrm{Ni}(5) \quad 27$

Bis[cyclopentadienyltris(dibutyl phosphito-P)cobalt- $O, O$ ', $O$ ’] 
oxovanadate(IV), (CpP $\left.{ }^{\mathrm{OBu}} \mathrm{Co}\right)_{2} \mathrm{~V}=\mathrm{O}$ (6)

Bis[cyclopentadienyltris (dibutyl phosphito- $P$ ) cobalt- $O, O$ ', $O$ ’]

cobaltate(III) hexanchloroantimonate, $\left[\left(\mathrm{CpP}{ }^{\mathrm{OBu}} \mathrm{Co}\right)_{2} \mathrm{Co}\right] \mathrm{SbCl}_{6}$ (7)

Results and Discussion

Syntheses

Characterization

CHAPTER III: SYNTHESIS AND CHARACTERIZATION OF SERIES VANADIUM PRECURSORS CONTAINING THE KLÄUI LIGAND (CpP $\left.{ }^{\mathrm{OBu}} \mathrm{Co}\right)^{-}$

Abstract

Introduction

Experimental

General considerations

$\mathrm{VOCl}_{2}$

$\left[\left(\mathrm{CpP}{ }^{\mathrm{OBu}} \mathrm{Co}\right) \mathrm{VOCl}_{2} \mathbf{( 8 )}\right.$

$\left(\mathrm{CpP}{ }^{\mathrm{OBu}} \mathrm{Co}\right) \mathrm{VCl}_{2}(\mathrm{DMF})$ (9)

$\left(\mathrm{CpP} \mathrm{PBu}^{\mathrm{Bu}}\right) \mathrm{VO}(\mathrm{acac})(\mathbf{1 0})$

Results and Discussion

Syntheses

Characterization

CHAPTER IV: SYNTHESIS AND CHARACTERIZATION OF SERIES VANADIUM

DIMERS CONTAINING THE KLÄUI LIGAND (CpPOBuCo)-

Abstract

Introduction 
$\begin{array}{ll}\text { Experimental } & 53\end{array}$

$\begin{array}{ll}\text { General considerations } & 53\end{array}$

$\left(\mathrm{CpP} \mathrm{PBu}^{\mathrm{Ou}}\right)_{2}[\mu-\mathrm{ox}] \mathrm{V}_{2} \mathrm{O}_{2}$ (11) 53

$\left[\left(\mathrm{CpP}^{\mathrm{OBu}} \mathrm{Co}\right) \mathrm{V}(\mathrm{O})\left(\mu-\mathrm{O}_{2} \mathrm{PPh}_{2}\right)\right]_{2} \mathbf{( 1 2 )} \quad 53$

Results and Discussion $\quad 53$

$\begin{array}{ll}\text { Syntheses } & 53\end{array}$

$\begin{array}{ll}\text { Characterization } & 56\end{array}$

CHAPTER V: OXIDATIVE CATALYTIC ACTIVITY OF SERIES VANADIUM

COMPLEXES CONTAINING THE KLÄUI LIGAND (CpP $\left.{ }^{\mathrm{OBu}} \mathrm{Co}\right)^{-} \quad 59$

$\begin{array}{ll}\text { Abstract } & 59\end{array}$

$\begin{array}{ll}\text { Introduction } & 59\end{array}$

$\begin{array}{ll}\text { Experimental } & 60\end{array}$

$\begin{array}{ll}\text { General considerations } & 60\end{array}$

$\begin{array}{ll}\text { Calibration } & 60\end{array}$

$\begin{array}{ll}\text { Catalytic activity } & 61\end{array}$

$\begin{array}{ll}\text { Results and Discussion } & 61\end{array}$

$\begin{array}{ll}\text { Conclusion } & 64\end{array}$

$\begin{array}{ll}\text { Future Works } & 64\end{array}$

$\begin{array}{lr}\text { REFERENCES } & 66\end{array}$

$\begin{array}{ll}\text { APPENDIX A. IR SPECTRA } & 74\end{array}$

$\begin{array}{ll}\text { APPENDIX B. RAMAN SPECTRA } & 89\end{array}$

$\begin{array}{ll}\text { APPENDIX C. NMR SPECTRA } & 93\end{array}$ 


\section{TABLES}

Table

Page

1. $\mathrm{P}=\mathrm{O}$ Stretching Frequencies of Supersandwich Complexes 35

2. Magnetic Susceptibilities of Supersandwich Complexes 35

3. IR and Raman Spectroscopy of the Three Kläui Ligands 37

4. ${ }^{31}$ P NMR Chemixal Shift Correlation of the Three Kläui Ligands 39

5. $\mathrm{P}=\mathrm{O}$ Stretching Frequencies of Selected Vanadium Monomer Complexes 46

6. P-O Stretching Frequencies of Selected Vanadium Monomer Complexes 48

7. UV-Vis Spectra Data of Vanadium Precursors Containing the Kläui Ligand 51

8. $\mathrm{P}=\mathrm{O}$ Stretching and $\mathrm{V}=\mathrm{O}$ Stretching Frequencies of Selected Vanadium

Dimeric Complexes with Oxalate Bridge 58

9. Turnover Frequencies (TOF) of Product by Employing Vanadium

Precursors and Vanadium Dimers Containing the Kläui Ligand as Catalysts 


\section{FIGURES}

Figure

Page

1. Extended Solid of $\mathrm{V}_{2} \mathrm{O}_{5}$ and Structure of $\mathrm{PO}_{4}{ }^{3-}$ and $\mathrm{VO}_{4}{ }^{3-}$ Ions

2. Structure of Phosphate Ion $\left(\mathrm{PO}_{4}{ }^{3-}\right)$ (a) and Orthovanadate $\left(\mathrm{VO}_{4}{ }^{3-}\right)$ (b)

3. 3D Structure Model of $\mathrm{VOPO}_{4} \cdot 2 \mathrm{H}_{2} \mathrm{O}$ with $\mathrm{PO}_{4}$ Tetrahedra Linked

to $\mathrm{VO}_{6}$ Octahedra Center

4. The Host Structure of $\mathrm{VOPO}_{4} \cdot 2 \mathrm{H}_{2} \mathrm{O}$

5. Dimensional Reduction of a Framework of Corner-sharing Octahedra

6. Hexanuclear Vanadium (V) Cluster (VO) $6\left(\mathrm{O}_{3} \mathrm{POSiMe}_{3}\right)_{8} \mathrm{Cl}$

7. Structure of Vanadyl Pyrophosphate (VO) ${ }_{2} \mathrm{P}_{2} \mathrm{O}_{7}$

8. Hydrotris(pyrazolyl)borate Ligand, $\mathrm{Tp}^{-}$

9. Three-dimensional Cubic Cage Model of Tetravanadium-phosphorus Complexes

10. Thermal Ellipsoid Plot (30\%) of Dinuclear V(IV) Complexes $\left[\mathrm{LVO}\left(\mu-\left(\mathrm{C}_{6} \mathrm{H}_{5} \mathrm{O}\right)_{2} \mathrm{PO}_{2}\right)\right]_{2}$

11. Structure of the Kläui Ligand, $\left(\mathrm{CpP}^{\mathrm{OR}} \mathrm{Co}\right)^{-}$, or $\left(\mathrm{L}^{\mathrm{OR}}\right)^{-}$

12. Nomenclature of Organophosphorus Ligands

13. Thermal Ellipsoid Plots of the Core Structure for Four Unique

Dimeric Components of the Hexanuclear Cluster

$\mathrm{H}_{2} \mathrm{O} \subset\left[t-\mathrm{Bupz}\left(\mu-\mathrm{C}_{6} \mathrm{H}_{5} \mathrm{OPO}_{3}\right) \mathrm{VO}_{6}\left(\mathrm{H}_{2} \mathrm{O}\right)_{2}-2 \mathrm{CH}_{3} \mathrm{CH}_{2} \mathrm{OH}\right.$

14. Classification Scheme for Cyclic $(\mathrm{O}=\mathrm{V})(\mathrm{OPO})_{2}(\mathrm{~V}=\mathrm{O})$ Bridging

Units in Vanadyl Phosphate Systems

15. The Structure of Co-supersandwich

16. Structures of Supersandwich Complexes with Different Oxidation States 
17. Supersandwiches with Metal Centers, Ni(II) and V(IV)

18. The Comparison among the IR Spectra of these Three Supersandwich Complexes

19. Stacked ${ }^{1}$ H NMR 400.13 MHz Spectra of Cp Rings of the Three Kläui Ligands

20. Possible Structures of compound (8)

21. UV-Vis Spectra of $\left[\left(\mathrm{CpP}{ }^{\mathrm{OBu}} \mathrm{Co}\right) \mathrm{VOCl}\right]_{2}$ (8)

22. The Overlay IR Spectra of $\mathrm{Na}_{2} \mathrm{C}_{2} \mathrm{O}_{4}$ and $\left(\mathrm{CpP}{ }^{\mathrm{OBu}} \mathrm{Co}\right)_{2}[\mu-\mathrm{ox}] \mathrm{V}_{2} \mathrm{O}_{2}$ (11)

23. The Overlay IR Spectra of Diphenyl Phosphate and $\left[\left(\mathrm{CpP}^{\mathrm{OBu}} \mathrm{Co}\right) \mathrm{V}(\mathrm{O})\left(\mu-\mathrm{O}_{2} \mathrm{PPh}_{2}\right)\right]_{2}$ (12) Showed at $700-3000 \mathrm{~cm}^{-1}$ Range

25. The Absorbance of the Product 3,5-DTBQ Formation Shown at Different Conditions 


\section{SCHEMES}

Scheme

Page

1. Deprotonation Reactions of Vanadate in Aqueous Solution 4

2. Oxidation of Butane under Molecular $\mathrm{O}_{2}$ by a $\mathrm{VOPO}_{4}$ Catalyst 5

3. Formula of Dimensional Reduction 99

4. Scheme for Preparation of $\mathrm{L}^{\mathrm{OEt}} \mathrm{Ti}^{\mathrm{IV}}$ Phosphato Complexes in Aqueous Media 16

5. General Reaction Scheme to Afford Target Vanadium (III) Clusters 18

6. General Reaction Scheme to Afford Target Vanadium (IV) Molecules 19

7. Oxidation of 3,5-di-tert-butylcatechol 22

8. The Proposed Synthetic Scheme Co-supersandwich ( $\left.\mathrm{CpP}{ }^{\mathrm{OBu}} \mathrm{Co}\right)_{2} \mathrm{Co}$ (2)

and the Butyl Kläui Ligand $\left(\mathrm{CpP}^{\mathrm{OBu}} \mathrm{Co}\right)^{-} \quad 30$

9. Synthesis Scheme of Co(III)-supersandwich Salt

$\left[\left(\mathrm{CpP}^{\mathrm{OBu}} \mathrm{Co}\right)_{2} \mathrm{CoSbCl}_{6}\right](7)$

10. Synthesis Scheme of Vanadium Precursors Containing the Kläui Ligands 41

11. Synthesis Scheme of (CpP $\left.{ }^{\mathrm{OBu}} \mathrm{Co}\right)_{2}[\mu-\mathrm{ox}] \mathrm{V}_{2} \mathrm{O}_{2}$ (11)

12. Synthesis Scheme of $\left[\left(\mathrm{CpP}{ }^{\mathrm{OBu}} \mathrm{Co}\right) \mathrm{V}(\mathrm{O})\left(\mu-\mathrm{O}_{2} \mathrm{PPh}_{2}\right)\right]_{2}$ (12) 56 


\section{CHAPTER I: INTRODUCTION}

Vanadium is a trace element that may be beneficial to humans and other living organisms (1-6). It presents at very low concentrations $\left(<10^{-8} \mathrm{M}\right)$ in all cells in plants and animals. Very pure vanadium rarely occurs in nature and it is always found with other elements. Approximately 85\% of vanadium produced is used as ferrovanadium or as a steel additive. It is quite reactive with oxygen, nitrogen, and carbon. The common oxidation states of vanadium are V(III), V(IV) and $\mathrm{V}(\mathrm{V})$, and the color varies with the oxidation state. V(III) complexes are air-sensitive. They are often green when dissolving in water as $\mathrm{V}^{3+}$. Vanadium(IV) complexes are stable in air. The formation of $\mathrm{V}(\mathrm{IV})$ complexes are usually $\mathrm{VO}^{2+}$ in aqueous solution (vanadyl) and appear blue. As for vanadium(V) complexes, they are also air stable and exist as $\mathrm{VO}_{2}{ }^{+}$or $\mathrm{VO}_{3}{ }^{-}$(vanadate) and appear yellow in aqueous solution. Vanadium oxides and vanadium halides as well as many other vanadium complexes have many applications in our life (4-7). The coordination chemistry of vanadium involves stereochemically flexible-coordination geometries ranging from four-, six-,

seven- to eight-coordination, which are thermodynamically plausible $(3,6,8)$ and are well-used in both academic and industrial settings.

The redox interchange charges, whether $\mathrm{V}(\mathrm{V}) / \mathrm{V}(\mathrm{IV})$ orV(IV)/V(III), increase the versatility of this element in the biological milieu as contributions for proteins and other organelles as well as catalysts for oxidation reactions in industry (6,9-11). The catalytic activities of vanadium complexes have significant advanced in last few decades. Vanadium complexes have already been extensively applied as catalysts or catalyst precursors for reactions including alkane oxidation reactions $(9,12-14)$ to give alcohols and ketones; halogenations to generate organohalides $(15-17)$; and carboxylation to form carboxylic acids (18-20). Owing to the high affinity for oxygen, vanadium can behave as a Lewis acid because of its low radius/charge ratio (21-23), thus it plays 
a crucial role in catalysis or as the promoter for oxidation reactions(24-28). The catalytic oxidations can be performed by a variety of oxygen donors, like $\mathrm{O}_{2}$ and $\mathrm{H}_{2} \mathrm{O}_{2}$ in both liquid systems or support systems (29-32). The use of these oxidizing reagents is attractive from environmental and economic aspects. Many vanadium complexes have already been well-used in industrial process. One example of vanadium catalysis is vanadium pentaoxide $\left(\mathrm{V}_{2} \mathrm{O}_{5}\right)$ (structure shown in Figure 1 (33)). It is widely used in the Contact process (34) (oxidation of $\mathrm{SO}_{2}$ to produce $\mathrm{SO}_{3}$ ) as well as the oxidation of ethanol to form ethanal (35). Another well-characterized industrial vanadium catalyst is vanadium phosphate $\left(\mathrm{VOPO}_{4}\right)$ (structure shown in Figure 2 and Figure 3) in the production of maleic anhydride (MA). 


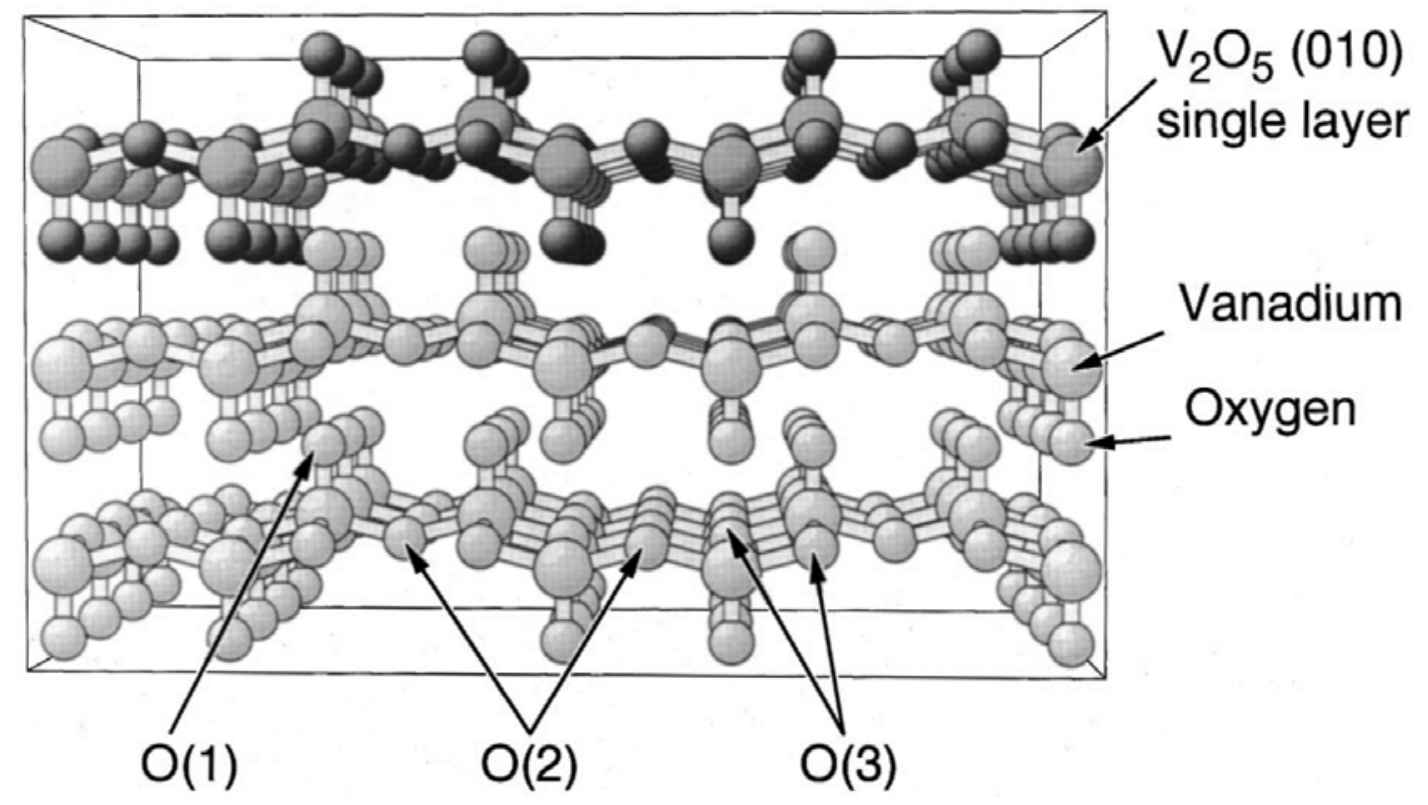

Figure 1. Extended Solid of $\mathrm{V}_{2} \mathrm{O}_{5}$ and Structure of $\mathrm{PO}_{4}{ }^{3-}$ and $\mathrm{VO}_{4}{ }^{3-}$ Ions. (a) The extended solid of $\mathrm{V}_{2} \mathrm{O}_{5}$. Three types of oxygen: (1) mono-coordinated oxygen atoms connect to vanadium atoms; (2) double-coordinated oxygen atoms bridge two ribbon; (3) triple-coordinated oxygen within the ribbon. Modified with permission from (33).

Vanadium has very rich chemistry involving phosphates. Orthovanadate $\left(\mathrm{VO}_{4}{ }^{3-}\right.$ ) (shown in Figure 2 (a)) which is isostructural to the phosphate ion $\left(\mathrm{PO}_{4}{ }^{3-}\right)$ (shown in Figure 2 (b)) acts as a competitive inhibitor of human alkaline phosphatases (36). The pKa values of $\mathrm{VO}_{4}{ }^{3-}$ are similar to the pKa values of $\mathrm{PO}_{4}{ }^{3-}$ as well as performs analogically in the deprotonation reactions, shown in Scheme 1 (Eq (1) - (3)) (37). In addition, phosphate and its derivatives can coordinate to vanadium metal centers to form extended vanadium phosphate materials (38). The magnetic properties of these vanadium-phosphate materials can be partially attributed to oxidation states of vanadium, thus, are very useful to contribute to the mechanism of catalysis for industrial oxidation reactions with those extended lattice structures. 


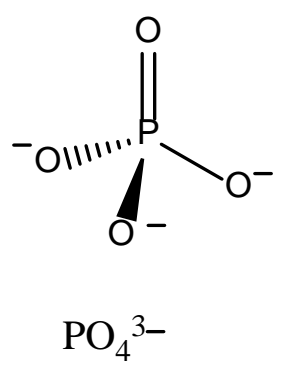

(a)

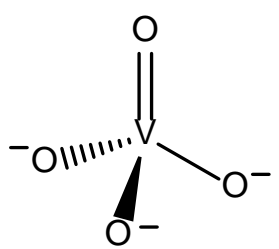

$\mathrm{VO}_{4}{ }^{3-}$

(b)

Figure 2. Structure of Phosphate Ion $\left(\mathrm{PO}_{4}{ }^{3-}\right)$ (a) and Orthovanadate $\left(\mathrm{VO}_{4}{ }^{3-}\right)$ (b).

Scheme 1. Deprotonation Reactions of Vanadate in Aqueous Solution. The pKa values for phosphate ions are 2.1, 7.2 and 12.7 (equations are not shown) (37).

$$
\begin{aligned}
& \mathrm{H}_{3} \mathrm{VO}_{4}+\mathrm{H}_{2} \mathrm{O} \leftrightharpoons \mathrm{H}_{2} \mathrm{VO}_{4}^{-}+\mathrm{H}_{3} \mathrm{O}^{+} \quad p K_{a}=3.5 \\
& \mathrm{H}_{2} \mathrm{VO}_{4}^{-}+\mathrm{H}_{2} \mathrm{O} \leftrightharpoons \mathrm{HVO}_{4}^{2-}+\mathrm{H}_{3} \mathrm{O}^{+} \\
& \mathrm{HVO}_{4}^{2-}+\mathrm{OH}^{-} \leftrightharpoons \mathrm{VO}_{4}^{3-}+\mathrm{H}_{2} \mathrm{O} \quad \mathrm{p} K_{a}=12.5
\end{aligned}
$$

As mentioned before, vanadium phosphate is a well-studied catalyst. It has been established as a selective hydrocarbon oxidation catalyst for more than 40 years (39-41). The primary use in industry involves the production of maleic anhydride (MA) from $n$-butane (42), shown in Scheme 2. This reaction is important because MA can be used as an intermediate in the production of many useful organic molecules, including fumaric acid as a food addictive, pharmaceuticals and styrenemaleic anhydride (SMA) copolymers (43). This reaction is the only example of a practical industrial reaction involving alkane oxidation. The selectivity of this reaction is around $65 \%-70 \%$ under typical industrial conditions (less than $2 \mathrm{~mol} \%$ n-butane in air, with conversion from 70 to $85 \%$ between 400 and $450{ }^{\circ} \mathrm{C}$ ). The different crystalline, polymorphic and hydrated phases of $\mathrm{VOPO}_{4}$ have been extensively studied (44-46). The active phase of the VPO catalyst is vanadyl pyrophosphate $(\mathrm{VO})_{2} \mathrm{P}_{2} \mathrm{O}_{7}$ with $\mathrm{P}: \mathrm{V}$ atomic ratio around $1: 1$. The average oxidation states of vanadium in equilibrated VPO catalysts is typically $4.00-4.03$ (47-48). The overall oxidation 
state can vary depending on the ratio of +4 and +5 oxidation states found within the lattice which may affect the activity and selectivity of the catalyst. However, even though structure and preparation of $\mathrm{VOPO}_{4}$ as a catalyst are well understood, the mechanism is unclear and thus raises many. This catalytic reaction has led to many confusions of the nature of the active phase in nbutane oxidation. The identification of the active sites involved in the different steps of the reaction are still a challenge.

Scheme 2. Oxidation of Butane under Molecular $\mathrm{O}_{2}$ by a $\mathrm{VOPO}_{4}$ Catalyst.

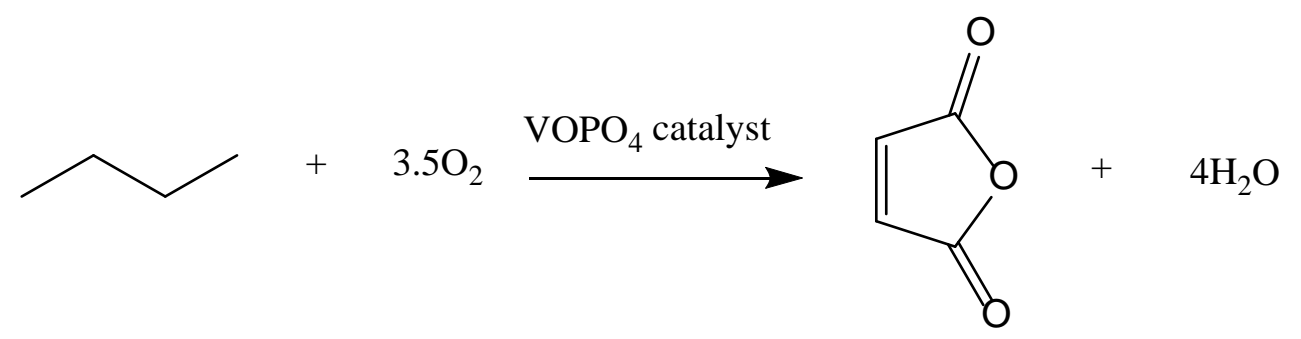

$\mathrm{VOPO}_{4}$ is often hydrated with the formula $\mathrm{VOPO}_{4} \cdot \mathrm{H}_{2} \mathrm{O}$ (49). The X-ray crystal structure of VOPO $4 \cdot 2 \mathrm{H}_{2} \mathrm{O}$ shows an infinite lattice of $\mathrm{PO}_{4}$ tetrahedra linked to $\mathrm{VO}_{6}$ octahedra by sharing the phosphate oxygen atoms according to Nakamarua (49) and Tieze (50), shown in Figure 3. The VO6 octahedra do not exist as ideal or perfectly symmetrical octahedra and are highly distorted. The distorted shape arises from the electronics of the metal centers. The very short $\mathrm{V}-\mathrm{O}(4)$ distance, $1.567(5) \AA$, is interpreted as confirmation of the existence of the cation $\mathrm{VO}^{3+}$. $\mathrm{O}(2)$ and $\mathrm{O}(3)$ belong to the two water molecules with longer $\mathrm{V}-\mathrm{O}$ bonds compare to others. 


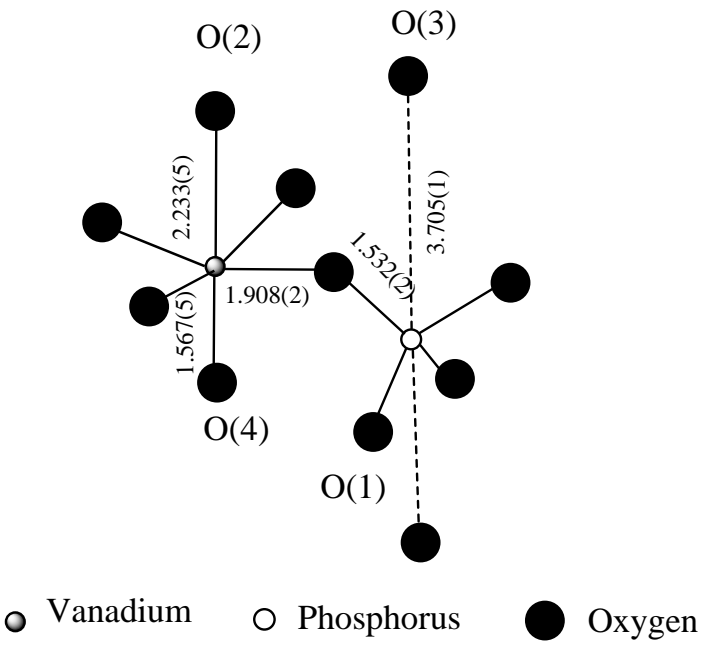

Figure 3. 3D Structure Model of $\mathrm{VOPO}_{4} \cdot 2 \mathrm{H}_{2} \mathrm{O}$ with $\mathrm{PO}_{4}$ Tetrahedra Linked to $\mathrm{VO}_{6}$ Octahedra Center. The bond lengths are shown in the Figure (50).

Tachez et al. (51) presented the results of structure refinement of the deuterated compound $\mathrm{VOPO}_{4} \cdot 2 \mathrm{D}_{2} \mathrm{O}$ based on neutron powder diffraction data. The host structure of vanadyl phosphate consists of infinite sheets of distorted $\mathrm{VO}_{6}$ octahedra and $\mathrm{PO}_{4}$ tetrahedra linked by shared $\mathrm{O}$ atoms, shown in Figure 4 (a). The oxygen atom of one water molecule is attached to vanadium atom to complete the $\mathrm{VO}_{6}$ octahedra geometry and the second water is hydrogen bonded to $\mathrm{PO}_{4} \mathrm{O}$ atoms and to the first water molecule. The water molecules link these sheets together, creating a regular network of hydrogen bridges in the interlayer space, shown in Figure 4 (b). 


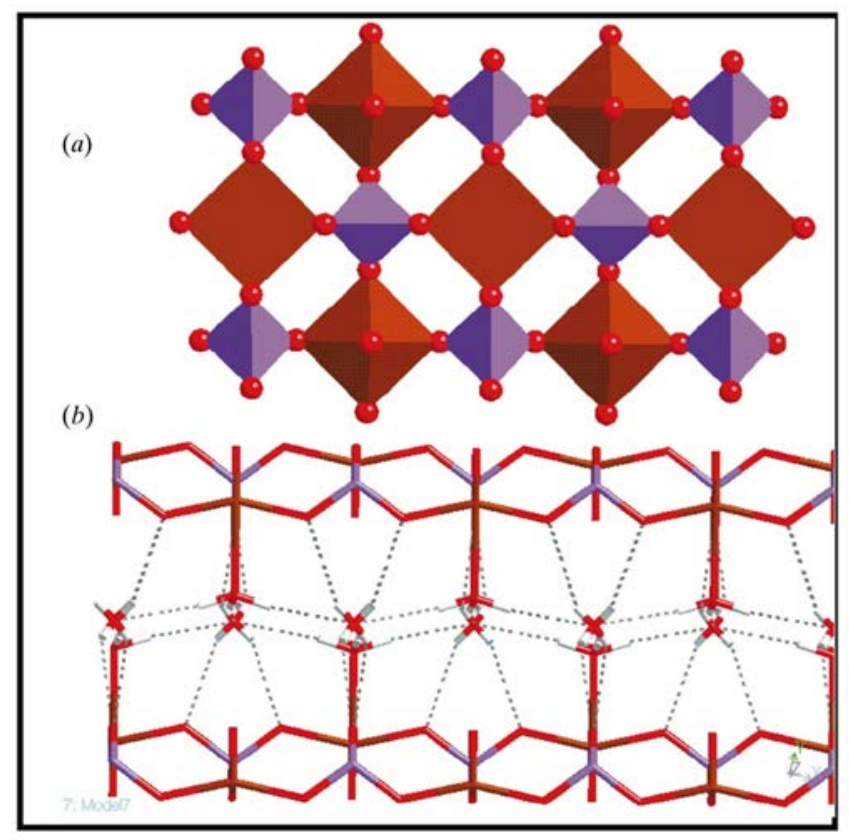

Figure 4. The Host Structure of $\mathrm{VOPO}_{4} \cdot 2 \mathrm{H}_{2} \mathrm{O}$. (a) view of the host layer $\mathrm{VOPO}_{4}$ consists of infinite sheets of distorted $\mathrm{VO}_{6}$ octahedra and $\mathrm{PO}_{4}$ tetrahedra linked by shared $\mathrm{O}$ atoms. (b) side view into the interlayer arrangement of water molecules with two differently bonded water molecules in the interlayer space. Modified with permission from (52).

The combination of the extended lattice, variation in oxidation states and identification of the active catalytic species makes it hard to study mechanistically. Scientists focus on employing structural models and functional models to mimetic $\mathrm{VOPO}_{4}$ catalysts (53). To achieve this goal, our group employed a technique called “dimensional reduction”, which is a practical formalism for manipulating solid structures, shown in Scheme 3 and Figure 5 (54-56). This formalism first described how the metal-anion (M-X) framework of a parent compound $\mathrm{MX}_{\mathrm{x}}$, dismantled upon reaction with an ionic reagent $A_{a} X$ to produce daughter product $A_{n a} M X_{x+n}$. The added anions terminate $\mathrm{M}-\mathrm{X}-\mathrm{M}$ bridges and yield a less tightly connected framework, which retains the metal coordination geometry and polyhedron connectivity of the parent structure. This formalism is a thought experiment. The ion $\mathrm{A}$ in the dimensional reduction agent $\mathrm{A}_{\mathrm{a}} \mathrm{X}$ is the charge-balancing 
counterion and much more electropositive than $\mathrm{M}$, which will not form strong covalent bonds with anions. An example of how dimensional reduction works is shown in Figure 5. MX 3 framework (1) has $\mathrm{MX}_{6}$ octahedral linked in three dimensions via shared corners. The insertion of $\mathrm{A}_{\mathrm{a}} \mathrm{X}$ will reduce the dimension and lead to a framework $\mathrm{A}_{2} \mathrm{MX}_{4}$ (2) which has two-dimensional sheets of corner-sharing octahedra and the counterion A residing between the layers. Further insertion of $\mathrm{A}_{\mathrm{a}} \mathrm{X}$ will lead to the framework $\mathrm{A}_{2 \mathrm{a}} \mathrm{MX}_{5}$ (3) which has one-dimensional chains of corner-sharing octahedra. The final product is framework $\mathrm{A}_{3 a} \mathrm{MX}_{6}(4)$ with discrete octahedral $\left[\mathrm{MX}_{6}\right]^{\mathrm{z}-}$. Using this technique, we can have a deep understanding of the structure of $\mathrm{VOPO}_{4}$ by obtaining representative structural and functional models that have finite size and infinite lattice solid-state structure. 
Scheme 3. Formula of Dimensional Reduction. $\mathrm{MX}_{\mathrm{x}}$ is the parent compound, $\mathrm{A}_{\mathrm{a}} \mathrm{X}$ is the counterion and $\mathrm{A}_{n a} \mathrm{MX}(\mathrm{x}+\mathrm{n})$ is the daughter product.

$$
M X_{x}+n A_{a} X \rightarrow A_{n a} M X_{x+n}
$$


Figure 5. Dimensional Reduction of a Framework of Corner-sharing Octahedra. Modified with permission from (55).

According to Tenne and co-workers (57), the formation of equivalent stable structures in the layered semiconductor tungsten disulfide have arrangement of atoms in variety of polyhedral and 
cylindrical in tungsten disulfide layers after heating of thin tungsten film in an atmosphere of hydrogen sulfide. Later, Thorn and co-workers applied "dimensional reduction” to vanadium complexes (58). They demonstrated the concept of utilizing single molecular clusters as precursors to complex oxide catalyst systems (59). They synthesized and characterized layered vanadium phosph(on)ates with hexanuclear and tetranuclear vanadium(V) clusters which yielding cubic and tetrahedrally distorted species. These compounds contain pentavalent vanadium centers which are capable of oxidization of at least one hydrocarbon. One of these complexes synthesized by Thorn is hexanuclear vanadium $(\mathrm{V})$ cluster $(\mathrm{VO})_{6}\left(\mathrm{O}_{3} \mathrm{POSiMe}_{3}\right)_{8} \mathrm{Cl}(58)$, shown in Figure 6. The phosphate environment in this compound is similar to surface structure of vanadyl pyrophosphate (VO) ${ }_{2} \mathrm{P}_{2} \mathrm{O}_{7}$ (60-62) (shown in Figure 7) and may lead to particularly reactive sites, thus important for the selective oxidation reactions. Even these clusters synthesized by Thorn have different geometry compared to our clusters, this concept of representing an extended structure with a finite model is still very similar to our goal. 


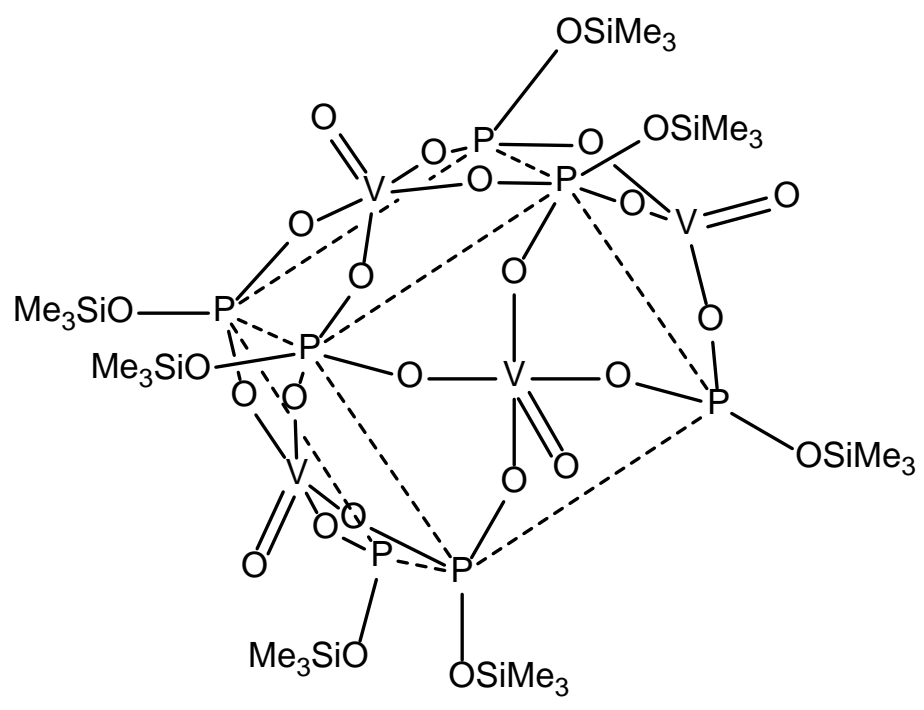

Figure 6. Hexanuclear Vanadium(V) Cluster $(\mathrm{VO})_{6}\left(\mathrm{O}_{3} \mathrm{POSiMe}\right)_{8} \mathrm{Cl}$. Th cubic structure is described by Thorn (58). Dashed lines outline the cubic "framework" of the cluster. The $\mathrm{Cl}$ in the cubic center is omitted for clarity.
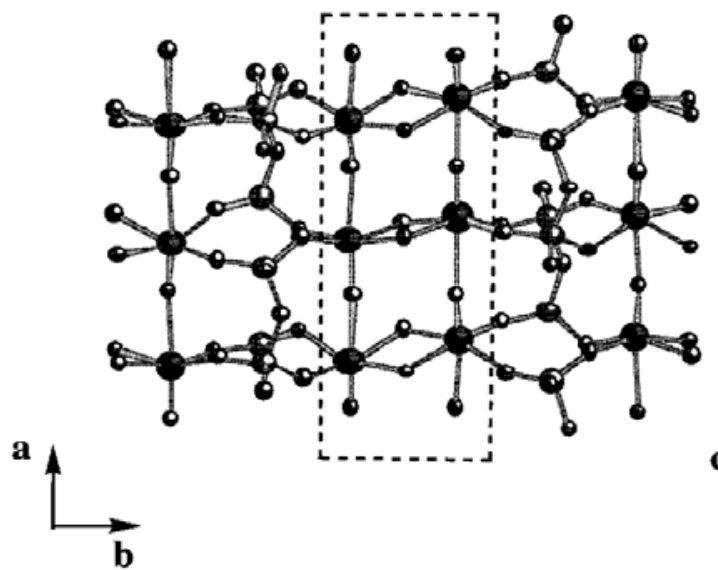

(a)

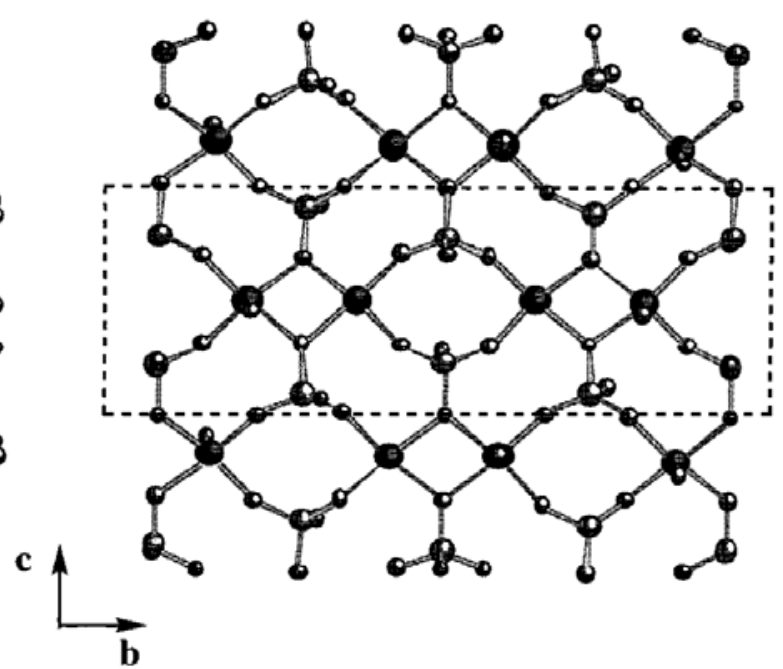

(b)

Figure 7. Structure of Vanadyl Pyrophosphate $(\mathrm{VO})_{2} \mathrm{P}_{2} \mathrm{O}_{7}$. The edge-sharing vanadium-oxygen octahedra are interconnected by pyrophosphate groups. Modified with permission from (60).

Further interest arises from the small possible cage-like vanadium phosphate clusters that have been observed to form around a variety of template molecules or ions. Carrano and co-workers 
employed a nitrogen tridentate ligand, hydridotris(pydazolyl)borate, $\mathrm{HB}(\mathrm{pz})_{3}{ }^{-}$or $\mathrm{Tp}^{-}$, shown in Figure 8, to synthesize and characterize vanadium clusters $(59,63-65)$. $\mathrm{Tp}^{-}$ligand can serve as a facially coordinating, anionic six-electron donor (66-68). It can bind to the vanadium via three nitrogen atoms. With three other oxygen atoms from phosphate moieties binding to the vanadium metal center, a $\mathrm{VN}_{3} \mathrm{O}_{3}$ octahedra- $\mathrm{PO}_{4}$ tetrahedra core can be constructed. One example of those vanadium(III) clusters containing $\mathrm{VN}_{3} \mathrm{O}_{3}-\mathrm{PO}_{4}$ core is shown in Figure 9 (69). Another example is $\left[\mathrm{LVO}\left(\mu-\left(\mathrm{C}_{6} \mathrm{H}_{5} \mathrm{O}\right)_{2} \mathrm{PO}_{2}\right)\right]_{2}$, also synthesized by Carrano and co-workers, shown in Figure $10(70)$. These kinds of host-guest structures with high specificities for guest molecules or ions based on vanadium phosphate cluster hosts are useful to explore the catalytic activities and can be used in biological phosphate systems.

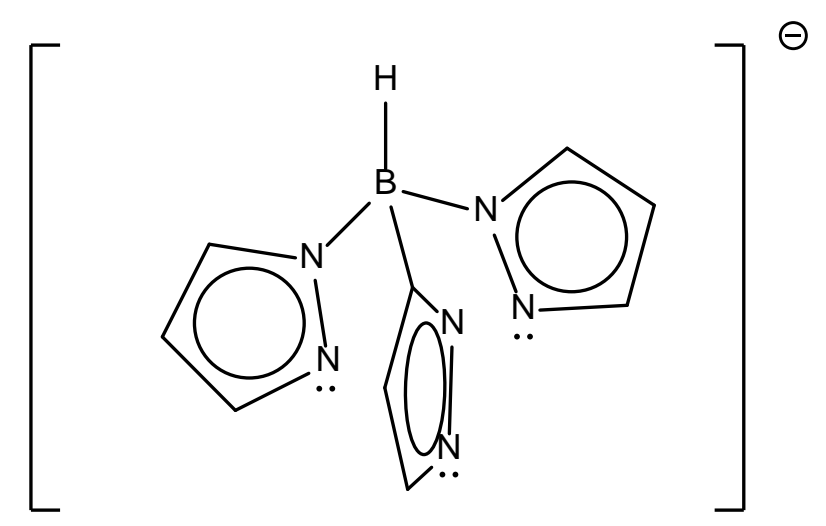

Figure 8. Hydrotris(pyrazolyl)borate Ligand, $\mathrm{Tp}^{-}$. The nitrogen atoms are electron rich and can donate 2 electrons to the metal center. 


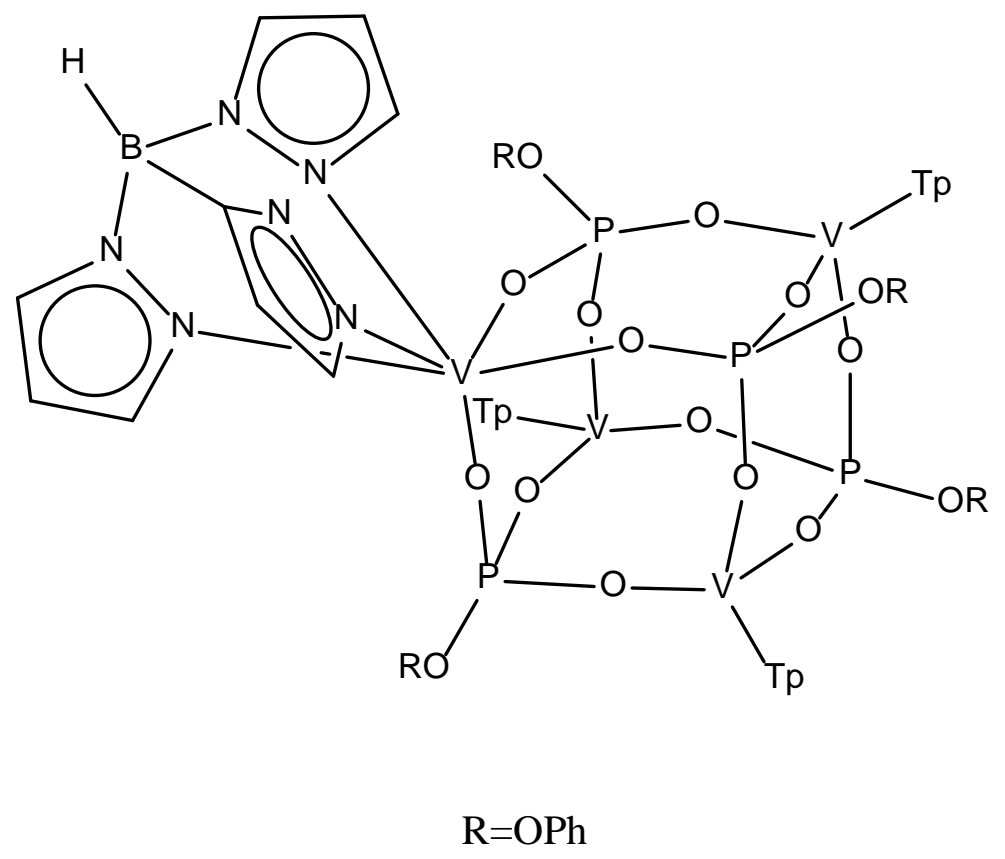

Figure 9. Three-dimensional Cubic Cage Model of Tetravanadium-phosphorus Complexes. The cubic structure is described by Carrano and co-workers (69). Each coordinating phosphate is capable of bridging to two other $\mathrm{TpV}(\mathrm{III})^{2+}$ moieties. 




Figure 10. Thermal Ellipsoid Plot (30\%) of Dinuclear V(IV) Complexes [LVO $(\mu-$ $\left.\left.\left(\mathrm{C}_{6} \mathrm{H}_{5} \mathrm{O}\right)_{2} \mathrm{PO}_{2}\right)\right]_{2}$. The vanadium metal centers are distorted octahedral coordination geometries and bridged by oxygen atoms of the two diphenyl phosphate groups. Modified with permission from (70).

Recall that our proposed model should have vanadium metal centers in an octahedral ligand field bounded by oxygen atoms of phosphates and share the catalyst's structural features as well as electronic and catalytic qualities. Unlike the cage-like, Tp-type vanadium phosphate clusters, our model structure should contain the $\mathrm{PO}_{4}$ tetrahedra link to the $\mathrm{VO}_{6}$ octahedra, complete with the distorted geometry, and the metal centers in the V(IV) oxidation state. In this vein, we employed a ligand called Kläui ligand, $\eta^{5}$-cyclopentadienyltris-(dialkylphosphito-P) cobaltate(III), $\left(\mathrm{CpP}^{\mathrm{OR}} \mathrm{Co}\right)^{-}$, or $\left(\mathrm{L}^{\mathrm{OR}}\right)^{-}$, shown in Figure 11. It is the first example of a monoanionic tridentate oxygen ligand with $\mathrm{C}_{3 \mathrm{v}}$ symmetry. This ligand shares the same properties with $\mathrm{Tp}^{-}$ligand:

- They have the abilities to occupy three cis- coordination sites on the metal and leave open another three cis- coordination sites for ancillary ligands to complete a distorted octahedral environment around the metal center. 
- They are able to stabilize the oxidation state of metal centers.

- They are easy to synthesize.

With the Kläui ligand, we can control the metal center’s oxidation state and coordinating nature. More importantly, we can achieve the goal to model vanadium-phosphate complexes with the core of $\mathrm{VO}_{6}$ octahedra linked with $\mathrm{PO}_{4}$ tetrahedra.
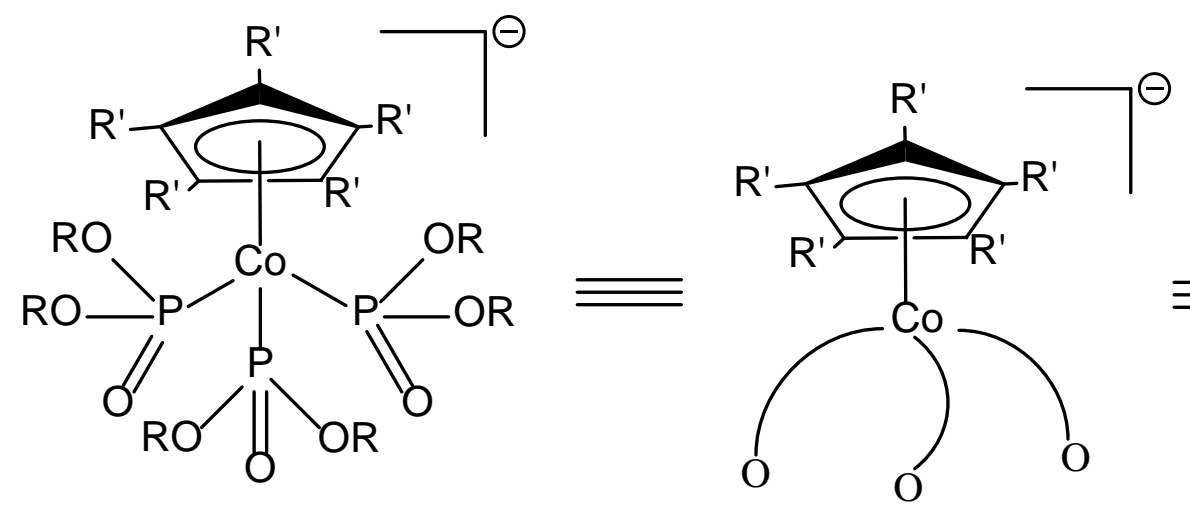

$$
\begin{aligned}
& \bar{\equiv}\left(\mathbf{L}^{\mathbf{O R}}\right)^{-} \\
& \mathrm{R}=\mathrm{Me}, \mathrm{Et}, \mathrm{Bu},{ }^{\mathrm{i}} \mathrm{Pr} \\
& \mathrm{R}^{\prime}=\mathrm{H}, \mathrm{CH}_{3}
\end{aligned}
$$

Figure 11. Structure of the Kläui Ligand, $\left(\mathrm{CpP}^{\mathrm{OR}} \mathrm{Co}\right)^{-}$, or $\left(\mathrm{L}^{\mathrm{OR}}\right)^{-}$.

The Kläui ligands share the similar structure to half-sandwich complexes (71-74). Half sandwich complexes are also called piano-stool compounds. They share the common structure with $\mathrm{C}_{5} \mathrm{H}_{5}$-ring bonded on one side and three ligands bonded on the other side, which follows the 18 electrons rule. They are often good nucleophiles that react with Brønsted acids under mild condition. The Kläui ligand is monoanionic, facially coordinating and tridentate, binding through three oxygen atoms. Despite Kläui ligand's hardness and strong $\pi$-donor strength, it is compatible with both hard and soft metal ions, exhibiting interesting organometallic chemistry (75). It can stabilize a variety of organometallic fragments in high oxidation states that have not been previously stabilized by other oxygen donor ligands. Many researchers are focused on the organometallic chemistry of the Kläui ligand. Leung and co-workers employed Titanium(IV) to synthesize phosphorus complexes (76), shown in Scheme 4. They found the $\mathrm{L}^{\mathrm{OE}} \mathrm{Ti}^{\mathrm{IV}}$ phosphate can catalyze sulfides with $t$-BuOOH but not olefins. Other applications of metal complexes with 
the Kläui ligand have been found in electrocatalysis (77), organic transformations $(75,78)$, homogeneous catalysis (79) and catalytic polymerization (80).

Scheme 4. Scheme for Preparation of $\mathrm{L}^{\mathrm{OEt}} \mathrm{Ti}^{\mathrm{IV}}$ Phosphato Complexes in Aqueous Media. Treatment of titanyl sulfate in dilute sulfuric acid with 1 equiv of $\mathrm{NaL}^{\mathrm{OEt}}$ and excess amount of $\mathrm{Na}_{3} \mathrm{PO}_{4}$ yield the yellow product $\left[\left(\mathrm{LoEtTi}_{3}(\mu-\mathrm{O})_{3}\left(\mu-\mathrm{PO}_{4}\right)\right](76)\right.$.



Our project focuses on modeling complexes containing vanadium with organophosphorus ligands. Use of the phosph-(on/in)ates to bridge the metal centers completes the typical vanadium phosphorus model with $\mathrm{PO}_{4}$ tetrahedra linked to $\mathrm{VO}_{6}$ octahedra. At this point, it is important to explain organophosphorus compounds and their derivatives, phosph-(on/in)ates. Organophosphorus derivatives, shown in Figure 12, are commonly used as ligands in coordination chemistry (81) because they are both sterically and electronically tunable on a metal center. The simplest and most-used phosphorus ligand in organometallic chemistry is the phosphine, $\mathrm{PR}_{3}$. The first catalytic example of a phosphine complex, $\left[\mathrm{Rh}\left(\mathrm{PPh}_{3}\right)_{3} \mathrm{Cl}\right]$, was been characterized by Wilkinson (82) and his coworkers for hydrogenation reactions, transition metal complexes, and then commonly used in organic synthesis (83). This catalytic example attracted much interest in 
exploration of the catalytic activities of phosphorus containing complexes. Later, the phosphorustype ligand with general formula $\left(\mathrm{P}=\mathrm{O}(\mathrm{OR})\left(\mathrm{OR}{ }^{\prime}\right)\right.$ ) was widely studied and has been discussed for many purposes in scientific communications $(41,81)$. We employed $\left(\mathrm{P}=\mathrm{O}(\mathrm{OR})\left(\mathrm{OR}{ }^{\prime}\right)\right)$ phosphonate to synthesize cobalt-phosphonate complexes (Kläui ligand) as our ligand to maintain the charge balance. In addition, we employed phosphonate and phosphinate as the phosphorus bridge to link the vanadium centers.

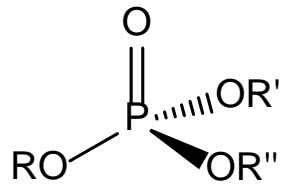

Phosphate<smiles>[R][Po]([R])(=O)=O</smiles>

Phosphonate

$$
\begin{aligned}
& \mathrm{R}=\mathrm{H}, \text { Alkyl, aryl } \\
& \mathrm{R}=\mathrm{H}, \text { Alkyl, aryl } \\
& \text { R"=H, Alkyl, aryl }
\end{aligned}
$$<smiles>[R][P+]([R])([R])=O</smiles>

Phosphinate

Figure 12. Nomenclature of Organophosphorus Ligands.

Our group had characterized a series of vanadium complexes $(4,84-87)$ containing $\left(\mathrm{CpP}^{\mathrm{OMe}} \mathrm{Co}\right)^{-}$ and $\left(\mathrm{CpP}^{\mathrm{OEt}} \mathrm{Co}\right)^{-}$before. Weberski and co-workers started from vanadium(III) precursors and further synthesized cage-like tetravanadium clusters, shown in Scheme 5. These tetravanadium clusters share the core with $\mathrm{PO}_{4}$ tetrahedra linked to $\mathrm{VO}_{6}$ octahedra. The $\left(\mathrm{CpP}{ }^{\mathrm{OEt}} \mathrm{Co}\right)^{-}$is more desirable in this capacity as its oxygen-binding mode yields the pursued geometry and composition. 
Scheme 5. General Reaction Scheme to Afford Target Vanadium(III) Clusters.

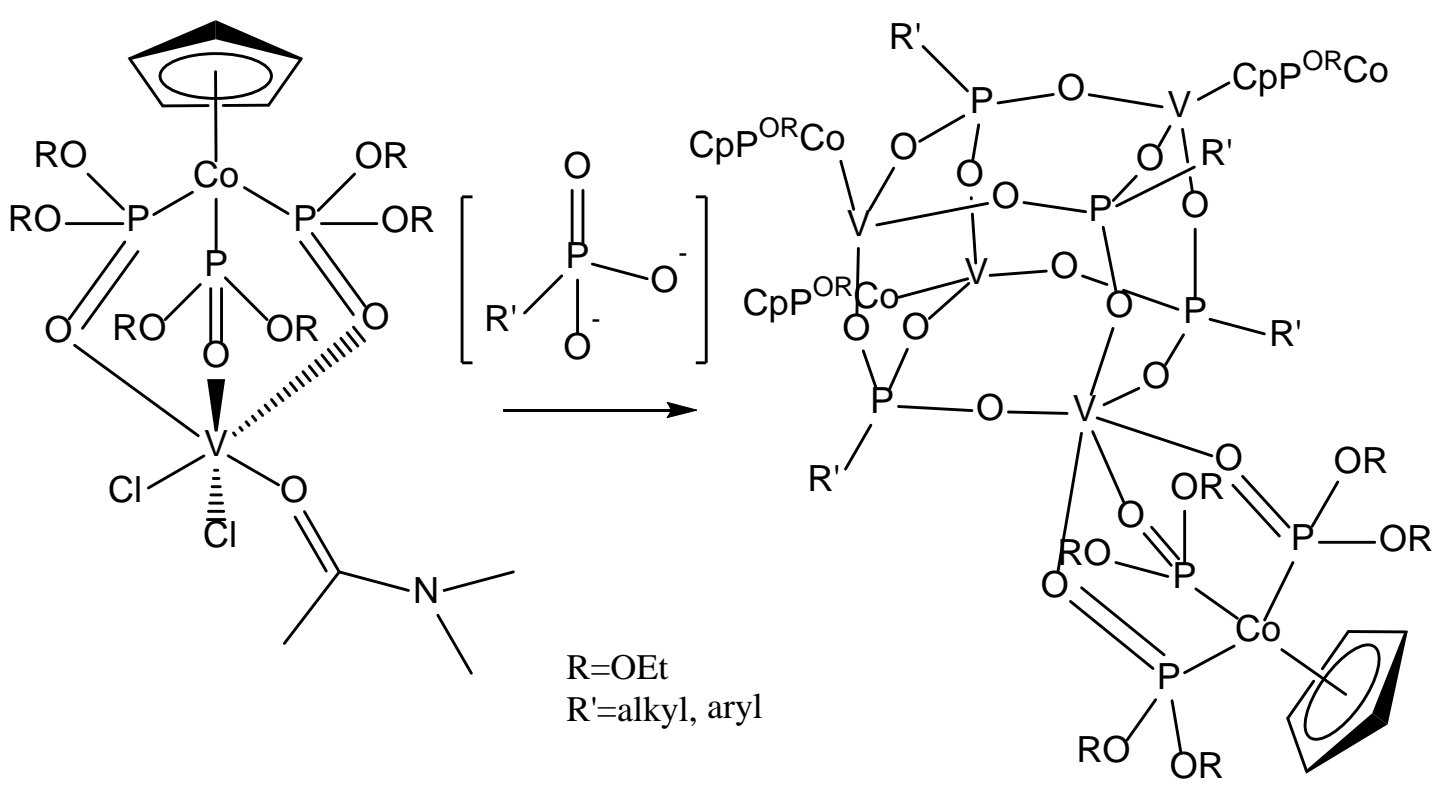

However, owing to the oxophilicity of vanadium(III), these vanadium(III) clusters must be kept under inert atmosphere. Otherwise, they will quickly oxidize to the vanadium(IV) species. Several vanadium(IV) molecules were synthesized by Anderson and co-workers in our group starting from vanadium(III) precursors $(84-86,88)$. One example is shown in Scheme 6. These complexes are dinuclear vanadium complexes, with two vanadium centers linked with phosph-(on/in)ates bridging. These complexes share the same basic structural framework with dimeric $\mathrm{V}_{2} \mathrm{O}_{4} \mathrm{P}_{2}$ core. The bridging nature of the phosph-(on/in)ates moieties allows for systematic classification of the $\mathrm{V}-(\mathrm{OPO})_{2}-\mathrm{V}$ core implemented by Carrano and co-workers (70). 
Scheme 6. General Reaction Scheme to Afford Target Vanadium(IV) Molecules. The starting compound is a V(III) monomer. Under the atmosphere, it will react with phosph-(on/in)ate salts to form V(IV) dimeric compounds.



All these vanadium(IV) complexes have a core with a $(\mathrm{O}=\mathrm{V})(\mathrm{OPO})_{2}(\mathrm{~V}=\mathrm{O})$ ring $(64,70,84$ 86,89) and varying groups on the aryl moieties attached to the phosphorus atom. According to Carrano and co-workers, there are four unique dimeric components in a hexanuclear vanadium(IV) cluster, $\left.\mathrm{H}_{2} \mathrm{O} \subset\left[t-\mathrm{Bupz}\left(\mu-\mathrm{C}_{6} \mathrm{H}_{5} \mathrm{OPO}\right)_{3}\right)\right]_{6}\left(\mathrm{H}_{2} \mathrm{O}\right)_{2}-2 \mathrm{CH}_{3} \mathrm{CH}_{2} \mathrm{OH}$ (70), shown in Figure 13. The water molecule in this compound is the most important factor in producing the conformation of the $(\mathrm{O}=\mathrm{V})(\mathrm{OPO})_{2}(\mathrm{~V}=\mathrm{O})$ ring of the cluster. Recent years have seen many vanadyl phosphate compounds in the form of both extended solids and discrete, template-centered clusters (90-92). Carrano and co-workers further established a more systemic classification scheme for 
cyclic $(\mathrm{O}=\mathrm{V})(\mathrm{OPO})_{2}(\mathrm{~V}=\mathrm{O})$ bridging units in vanadyl phosphate systems, shown in Figure 14, with the potential ring geometry with cis/trans configuration occupying the central position.
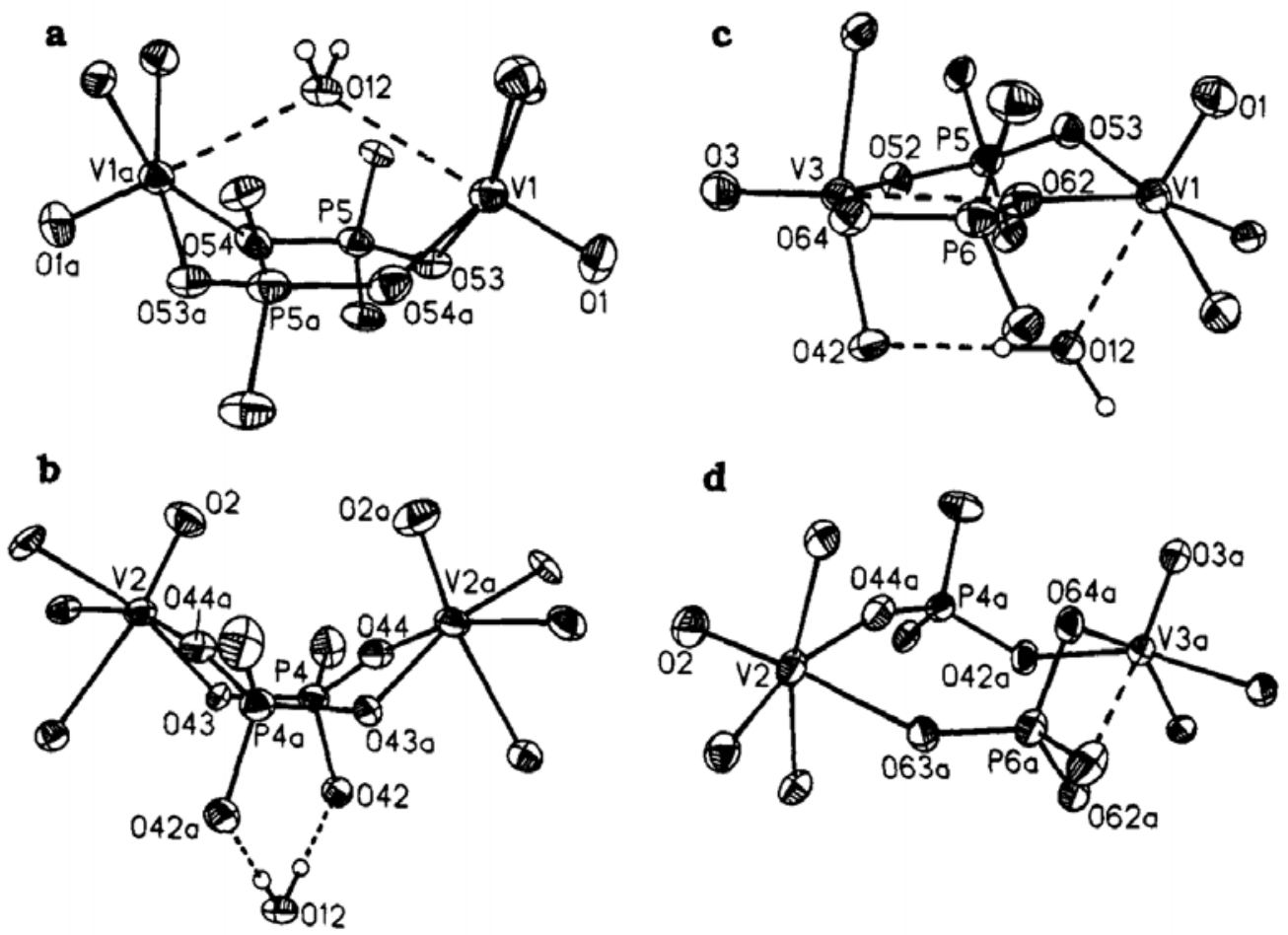

Figure 13. Thermal Ellipsoid Plots of the Core Structure for Four Unique Dimeric Components of the Hexanuclear Cluster $\mathrm{H}_{2} \mathrm{O} \subset\left[t-\mathrm{Bupz}\left(\mu-\mathrm{C}_{6} \mathrm{H}_{5} \mathrm{OPO}_{3}\right) \mathrm{VO}\right]_{6}\left(\mathrm{H}_{2} \mathrm{O}\right)_{2}-2 \mathrm{CH}_{3} \mathrm{CH}_{2} \mathrm{OH}$. Modified with permission from (70). 




Figure 14. Classification Scheme for Cyclic $(\mathrm{O}=\mathrm{V})(\mathrm{OPO})_{2}(\mathrm{~V}=\mathrm{O})$ Bridging Units in Vanadyl Phosphate Systems. Name for the four major typed structures are underlined. Modified with permission from (70).

Our group has synthesized series of vanadium-phosph-(on/in)ate dimers with the methyl Kläui ligand $\left(\mathrm{L}^{\mathrm{OMe}}\right)^{-}$and the ethyl Kläui ligand $\left(\mathrm{L}^{\mathrm{OEt}}\right)^{-}$. For these dimeric vanadium complexes, only two vanadium-phosphate bridging cores were found: cis/cis-anti and retracted chair. My work will focus on vanadium- phosph-(on/in)ate bridging complexes with the butyl Kläui ligand, $\left(\mathrm{CpP}^{\mathrm{OBu}} \mathrm{Co}\right)^{-}$or $\left(\mathrm{L}^{\mathrm{OBu}}\right)^{-}$.

Our initial purpose is to establish a system to explore the catalytic mechanism of the $\mathrm{VOPO}_{4}$ catalyst. In order to test whether our structural model is also functional model, investigation into the activity of our model molecules has been conducted using the catalytic oxidation of 3,5-di-tert- 
butylcatechol (3,5-DTBC) to 3,5-di-tert-butyl-o-benzoquinone (3,5-DTBQ) illustrated in Scheme 7. This reaction was not only employed in vanadium catalyst studies, but also in other organometallic catalyst tests (93-96). The methods we used are based on the work of our group (87), Roman with his co-workers (97) and Casellato with his co-workers (98). Our groups studied the catalytic activities of vanadium-Kläui ligand compounds with $\left(\mathrm{L}^{\mathrm{OMe}}\right)^{-}$and $\left(\mathrm{L}^{\mathrm{OEt}}\right)^{-}$previously. The compound ( $\left.\mathrm{CpP}^{\mathrm{OR}} \mathrm{Co}\right) \mathrm{VCl}_{2} \mathrm{DMF}$ was found to be a pre-catalyst for the oxidation of 3,5-DTBC in the presence of peroxide or $\mathrm{O}_{2}$ since it was not stable in solution and could be oxidized to an oxovanadium(IV) species. The diluted 3,5-DTBC solution is light yellow initially. Adding catalyst yields a lightly brown solution, which gradually turned to a dark yellow color, indicative of the increased presence of 3,5-DTBQ.

Scheme 7. Oxidation of 3,5-di-tert-butylcatechol.


UV-Vis spectroscopy will be used to test the catalytic activities of this reaction. The published results showed the maximum UV-Vis absorbance of 3,5-DTBC is at $397 \mathrm{~nm}(87,97)$. So, formation of the quinone can be monitored over time at this wavelength. Through the comparisons of our findings with the current proposed theoretical mechanistic pathway, it serves to elucidate how the reaction works as well as the requisite structural necessary for the catalyst. 


\title{
CHAPTER II: SYNTHESIS AND CHARACTERIZATION OF \\ SUPERSANDWICH, $\left(\mathrm{CpP}^{\mathrm{OBu}} \mathrm{Co}\right)_{2} \mathrm{M}(\mathrm{M}=\mathrm{Co}, \mathrm{Ni}, \mathrm{V}=\mathrm{O})$ \\ AND THE NEW KLÄUI LIGAND (CpP $\left.{ }^{\mathrm{OBu}} \mathrm{Co}\right)^{-}$
}

\begin{abstract}
The scope of this chapter was to synthesize "supersandwich" complexes containing three metal centers as well as a new type of Kläui ligand $\left(\mathrm{CpP}^{\mathrm{OBu}} \mathrm{Co}\right)^{-}$. The new Kläui ligand, $\left(\mathrm{CpP}{ }^{\mathrm{OBu}} \mathrm{Co}\right)^{-}$, can be used to synthesize many other organometallic compounds as catalysts for industrial oxidation of alkanes and other hydrocarbons. The first step in the preparation was the synthesis three-metal-center supersandwich complex $\left(\mathrm{CpP}{ }^{\mathrm{OBu}} \mathrm{Co}\right)_{2} \mathrm{Co}$. Breaking the supersandwich complexes produced the Kläui ligand $\left(\mathrm{CpP}^{\mathrm{OBu}} \mathrm{Co}\right)^{-}$. The Kläui ligand can further react with other metal complexes and replace the metal center to peepare other supersandwich complexes $\left(\mathrm{CpP}^{\mathrm{OBu}} \mathrm{Co}\right)_{2} \mathrm{M}(\mathrm{M}=\mathrm{V}(\mathrm{IV}), \mathrm{Ni}(\mathrm{II}))$.
\end{abstract}

\section{Introduction}

Supersandwich complexes have the two Kläui ligands enclosing a $\left(\mathrm{CpP}^{\mathrm{OR}} \mathrm{Co}\right)_{2} \mathrm{Co}$ and a metal center in a sandwich fashion. Different to sandwich type complexes, which share the $\mathrm{Cp}-\mathrm{M}-\mathrm{Cp}$ structure, supersandwich are more complicated. The three cobalt atoms are linearly arranged and bridged by the phosphonate groups, shown in Figure $15(89,99)$. Two of the cobalt atoms are equivalent, whereas the third one is located at a center of symmetry. The center cobalt is surrounded by six oxygen atoms and fulfill almost an ideal octahedron.

Co-supersandwich complex has a $\mathrm{CoO}_{6}$ core containing a high-spin $\mathrm{Co}(\mathrm{II})$ which accounts for the paramagnetism of the trinuclear complex. The assignment of the oxidation states of the three nuclei are shown below, in Figure 15. The oxidization states of the center Co is +2 and the other 
two are +3 . The crystal structures of $\left(\mathrm{CpP}^{\mathrm{OR}} \mathrm{Co}\right)_{2} \mathrm{Co}$ supersandwich complexes with $\mathrm{R}=$ methyl and ethyl are well studied. The central Co metal is located on the inversion center $(78,89)$.

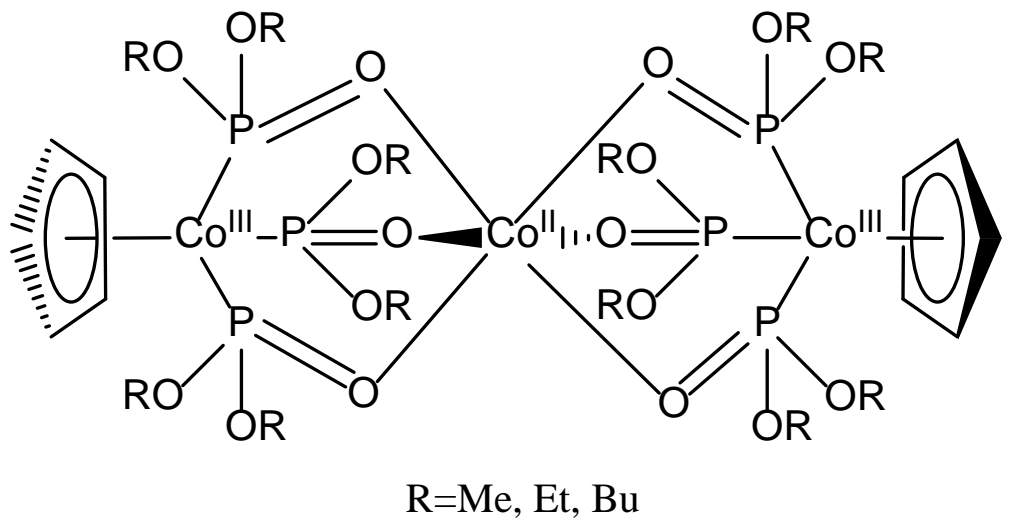

Figure 15. The Structure of Co-supersandwich. The charges of the three Co metals are shown. The R groups varies with Me, Et, Bu.

By breaking the supersandwich complexes, a mono-anionic, tridendate, hard ligand with strong $\pi$-donor strength can be obtained and it is called the Kläui ligand, based on Kläui and co-workers (100-102). Our first goal is to better understand the properties of this butyl Kläui ligand $\left[\left(\mathrm{CpP}^{\mathrm{OBu}} \mathrm{Co}\right)^{-}\right.$or $\left.\mathrm{L}^{\mathrm{OBu}}\right]$. This ligand is further employed to help construct vanadium-phosphorus complexes and fulfill the charge needed, which will be introduced in the next chapter.

The Kläui ligand has unusual ability to form stable complexes with metal ions in virtually any oxidation state. By varying the metal ions, it can generate supersandwich complexes (103), like $\left[\left(\mathrm{CpP}^{\mathrm{OEt}} \mathrm{Co}\right)_{2} \mathrm{M}(\mathrm{III})\right] \mathrm{PF}_{6} \quad(\mathrm{M}=\mathrm{Ti}(\mathrm{III}), \quad \mathrm{V}(\mathrm{III}) \quad$ and $\quad \mathrm{Cr}(\mathrm{III})), \quad\left[\left(\mathrm{CpP}^{\mathrm{OEt}} \mathrm{Co}_{2} \mathrm{Ti}(\mathrm{IV})\right]\left(\mathrm{PF}_{6}\right)_{2} \quad\right.$ and $\left(\mathrm{CpP}{ }^{\mathrm{OEt}} \mathrm{Co}\right)_{2} \mathrm{~V}=\mathrm{O}$, shown in Figure 16. However, these studies explored supersandwich complexes with $\mathrm{R}=\mathrm{Et}$ and there are few reported structures of supersandwich complexes with $\mathrm{R}=\mathrm{Bu}$. In this chapter, several supersandwich complexes with $\mathrm{R}=\mathrm{Bu}$ were synthesized and characterized to help understand the $\mathrm{P}=\mathrm{O}-\mathrm{M}$ interactions in the butyl supersandwich and the role of the butyl Kläui ligand $\left(\mathrm{CpP}^{\mathrm{OBu}} \mathrm{Co}\right)^{-}$in organometallic chelation. 

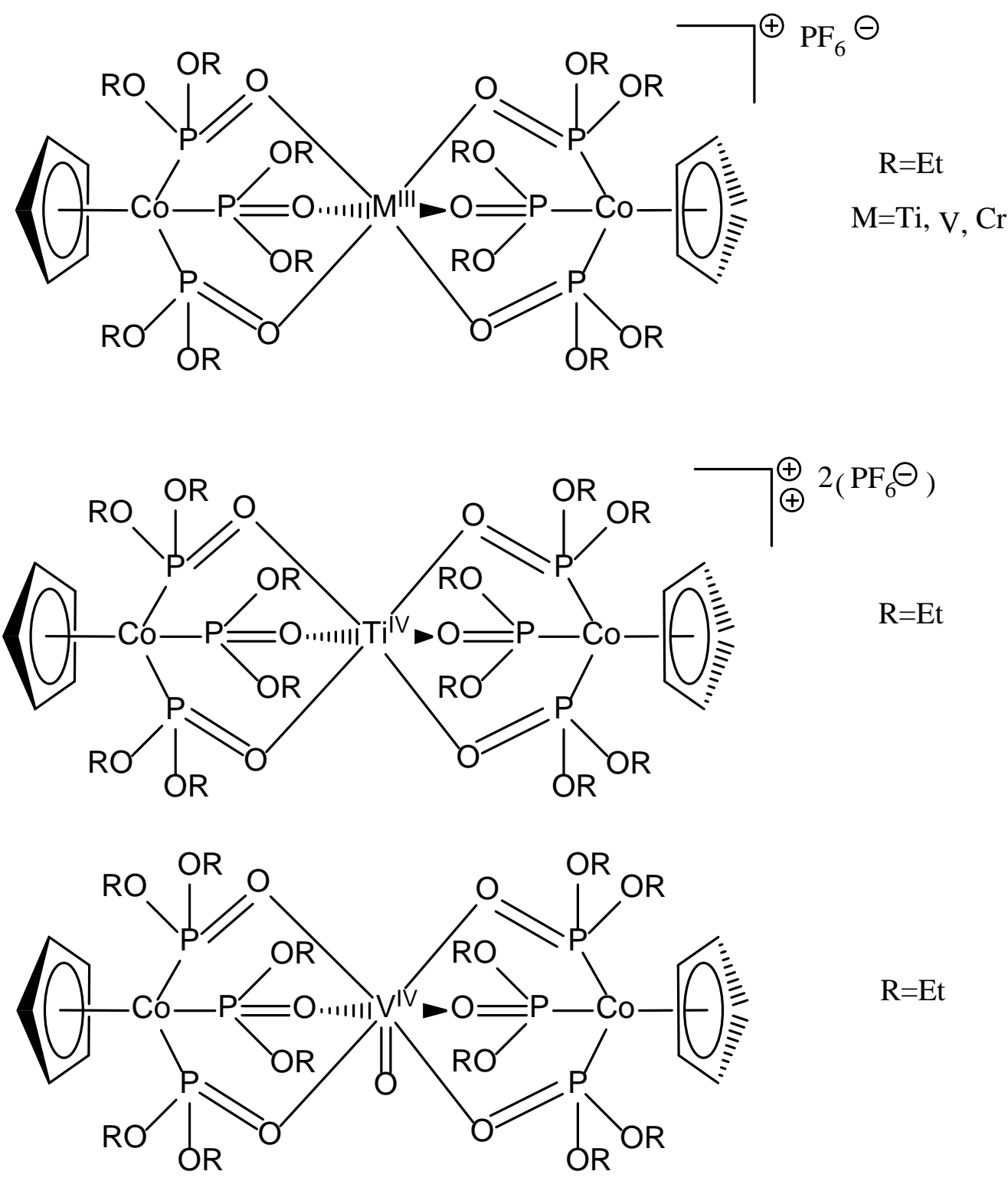

Figure 16. Structures of Supersandwich Complexes with Different Oxidation States.

\section{Experimental}

General considerations. All experimental procedures were performed under ambient condition unless otherwise stated. The compound (1), bis[cyclopentadienyltris(diethyl phosphito-P)cobaltO, O’, O”]cobaltate(II), (CpP $\left.{ }^{\text {OEt }} \mathbf{C o}\right)_{2} \mathbf{C o}$, was synthesized followed by Kläui and repeated by our lab $(87,102)$. The cobaltocene $(98 \%)$ was purchased from Strem Chemicals. dibutyl phosphite (96\%) was purchased from Sigma-Aldrich and deoxygenated before use. Nickel(II) chloride 
( $\mathrm{NiCl}_{6} \cdot \mathrm{H}_{2} \mathrm{O}$, crystals) was purchased from Mallinckrodt AR ${ }^{\circledR}$. Reagent grade methanol (Fisher, 99.9\%), diethyl ether (Sigma-Aldrich, 99.8\%), pentane (Fisher, 99\%) and carbon tetrachloride (Fisher, 99\%) were used as received. Sodium cyanide (Fisher, reagent grade, 98\%). dibutyl ether (99.3\%) and tris(4-bromophenyl)-ammoniumyl hexachloroantimonate $\left(\left[\left(p-\mathrm{BrC}_{6} \mathrm{H}_{4}\right)_{3} \mathrm{~N}\right] \mathrm{SbCl}_{6}\right.$, technical grade) were purchased from Sigma-Aldrich. Infared spectra were collected on a PerkinElmer FT-IR spectrometer as $\mathrm{KBr}$ mulls or $\mathrm{NaCl}$ pellets. ${ }^{1} \mathrm{H}$ NMR, ${ }^{13} \mathrm{C}$ NMR and ${ }^{31} \mathrm{P}$ NMR spectra were collected at $400.13 \mathrm{MHz}, 100.62 \mathrm{MHz}, 161.97 \mathrm{MHz}$ on a Bruker spectrometer and were referenced to residual chloroform (104). Magnetic susceptibility measurements were carried out using a Johnson Matthey magnetic susceptibility balance.

\section{Bis[cyclopentadienyltris(dibutyl phosphito-P)cobalt-O, $\quad O^{\prime}, \quad O$ O']cobaltate(II),} (CpP $\left.{ }^{\mathrm{OBu}} \mathrm{Co}\right)_{2} \mathrm{Co}$ (2). Cobaltocene (5.00 g, $26.4 \mathrm{mmol}$ black crystal) and deoxygenized dibutyl phosphite $(25 \mathrm{~mL})$ was added in a $50 \mathrm{~mL}$ dry Schlenk flask with a stir bar. The reaction was airfree, heated to $160^{\circ} \mathrm{C}$ and stirred for $7 \mathrm{~h}$. The resulting black slurry solution was cooled to room temperature. Methanol $(25.0 \mathrm{~mL})$ was added to afford an orange air-stable precipitate. The product was filtered and washed by methanol and dried overnight resulting in an orange waxy solid. Purification by Soxhlet extraction with diethyl ether yielded $7.59 \mathrm{~g}$ (5.91 mmol, 22.3\%) of orange waxy solid. The melting point of the compound is $122-124{ }^{\circ} \mathrm{C}$. IR( $\left(\mathrm{cm}^{-1}, \mathrm{KBr}\right): 2957 \mathrm{~s}, 2873 \mathrm{~m}$, 1463 m, 1379 m, 1129 vs, 1066 s, 1024 s, 1010 s, 969 s, 960 s, 883 s, 829 s, 783 m, 719 m. Mag. Suscept.: $\mu_{\mathrm{eff}}\left[\mu_{\mathrm{B}}\right]=4.76 ; \chi_{\mathrm{m}}=-1.04 \times 10^{-2} \mathrm{erg} \cdot \mathrm{G}^{-2} \cdot \mathrm{mol}^{-1}\left(\chi_{\mathrm{m}} \mathrm{T}=-3.07\right)$.

\section{Sodium cyclopentadienyltris(diethyl phosphito-P)cobaltate, $\mathrm{Na}\left(\mathrm{CpP}^{\mathrm{OEt}} \mathrm{Co}\right)$ (3). Compound}

(1), ( $\left.\mathrm{CpP}^{\mathrm{OEt}} \mathrm{Co}\right)_{2} \mathrm{Co}(1.290 \mathrm{~g}, 1.14 \mathrm{mmol})$ and sodium cyanide $(0.420 \mathrm{~g}, 8.60 \mathrm{mmol})$ were added into methanol $(50.0 \mathrm{~mL})$. The mixture was stirred for $2 \mathrm{~h}$ and orange clear solution was obtained. Rotary evaporation of the solution produced yellow solid. The solid was extracted by diethyl ether 
and the solvent remained was filtered by gravity filtration. The solvent was rotary evaporated and yield $3.061 \mathrm{~g}$ (5.48 mmol, 64\%) of yellow solid. The melting point of the compound is 138 $141^{\circ} \mathrm{C} . \mathrm{IR}\left(\mathrm{cm}^{-1}, \mathrm{KBr}\right): 3433$ vs, 2975 vs, 2929 m, 2896 m, 1479 w, 1442 m, 1385 s, 1261 w, 1166 vs, 1095 w, 1049 vs, 928 vs, 831 s, 760 s, 727 s. Mag. Suscept.: $\mu_{\mathrm{eff}}\left[\mu_{\mathrm{B}}\right]=0.157 ; \chi_{\mathrm{m}}=-3.59$ x $10^{-4}$ erg. $\mathrm{G}^{-2} \mathrm{~mol}^{-1}\left(\chi_{\mathrm{m}} \mathrm{T}=-0.107\right) .{ }^{1} \mathrm{H}$ NMR (400.13 $\left.\mathrm{MHz}, \mathrm{CDCl}_{3}, \mathrm{ppm}\right): 4.92 \mathrm{~s}, 3.91 \mathrm{multi}, 1.15$ t. ${ }^{31} \mathrm{P}$ NMR (161.97 MHz, CDCl3, ppm): 97.6.

Sodium cyclopentadienyltris(dibutyl phosphito-P)cobaltate, $\mathrm{Na}\left(\mathrm{CpP}{ }^{\mathrm{OBu}} \mathrm{Co}\right)$ (4). A mixture of sodium cyanide (0.804 g, $0.0160 \mathrm{~mol})$ and compound (2), (CpP $\left.{ }^{\mathrm{OBu}} \mathrm{Co}\right)_{2} \mathrm{Co}$ (3.603 g, $\left.2.46 \mathrm{mmol}\right)$, was added to $25.0 \mathrm{~mL}$ methanol. The reaction was stirred for $7 \mathrm{~h}$. The solution was orange and clear after the compounds all dissolved. The solvent was filtrated at reduced pressure and rotary evaporated resulting in an orange oil. The orange oil was extracted by carbon tetrachloride and filtrated by gravity filtration. The remained dark orange solvent was dried by rotary evaporation. The oil remaining was further dried under high vacuum for four days and yield $2.488 \mathrm{~g}$ (3.43 mmol, 69.7\%) of compound. IR( $\left.\mathrm{cm}^{-1}, \mathrm{KBr}\right): 3363$ s, 2958 vs, 2875, vs, 2733 w, 1465 m, 1429 w, 1379 m, 1297 w, 1260 w, 1240 w, 1167 vs, 1067 vs, 1026 vs, 970 vs, 880 vs, 830 s, 786 vs, 715 s. ${ }^{1} \mathrm{H}$ NMR (400.13 MHz, CDCl3): 4.92 s, 3.83 multi, 1.48 six, 1.32 six, 0.87 t. ${ }^{13} \mathrm{C}$ NMR (100.62 MHz, $\left.\mathrm{CDCl}_{3}, \mathrm{ppm}\right):$ 89.39, 62.80, 33.32, 19.34, 13.98. ${ }^{31} \mathrm{P}$ NMR (161.97 MHz, $\left.\mathrm{CDCl}_{3}, \mathrm{ppm}\right): 106.8$.

\section{Bis[cyclopentadienyltris(dibutyl phosphito-P)cobalt-O, $\quad O^{\prime}, \quad O$ ']nickelate(II),} (CpP $\left.{ }^{\mathrm{OBu}} \mathrm{Co}\right)_{2} \mathrm{Ni}$ (5). Compound (4) (0.033g, $0.463 \mathrm{mmol}$ ) was dissolved in $20.0 \mathrm{~mL}$ aqueous methanol (50\%:50\%). Compound (4) was partially dissolved. The mixture was dissolved for $1 \mathrm{~h}$. Addition of nickel(II) chloride caused immediate formation of the yellow insoluble precipitate. The product was centrifuged, washed with water and dried under air for four days, yield $0.220 \mathrm{~g}$ 
(0.15 mmol, 33.0\%) of yellow solid. IR(cm-1, KBr): 2958 s, 2873 m, 1464m, 1398 m, 1129 vs, 1066 s, 1025 s, 1010 s, 969 s, 960 s, 884 s, 830s, 783 m, 719 m.

\section{Bis[cyclopentadienyltris(dibutyl phosphito-P)cobalt-O, O', O”]oxovanadate(IV),}

$\left(\mathbf{C p P}{ }^{\mathrm{OBu}} \mathrm{Co}\right)_{2} \mathrm{~V}=\mathbf{O}$ (6). The synthesis of compound (6) was based on Kläui and co-workers (103).

Compound (4), $\mathrm{Na}\left[\left(\mathrm{CpP}^{\mathrm{OBu}} \mathrm{Co}\right)\right],(0.331 \mathrm{~g}, 0.455 \mathrm{mmol})$ and vanadium(IV) oxide sulfate hydrate (0.091 g, $0.457 \mathrm{mmol}$ ) was dissolved in aqueous methanol (50\%:50\%), the reaction was stirred for $3 \mathrm{~h}$. The product was extracted by hexane. The hexane layer was yellow and the aqueous methanol layer was blue. The hexane layer was collected and evaporated to dryness under vacuum. The resulting waxy crystal was olive green and yield $0.030 \mathrm{~g}(0.02 \mathrm{mmol}, 44 \%)$. IR( $\left.\mathrm{cm}^{-1}, \mathrm{KBr}\right): 2958$ vs, 2901 s, 2873 m, 1563 w, 1464 w, 1381 w, 1259 w. 1129 vs, 1063 vs, 1024 vs, 971 vs, 887 m, $832 \mathrm{~m}, 787 \mathrm{w}$.

Bis[cyclopentadienyltris (dibutyl phosphito-P) cobalt- $O, \quad O$, O"]cobaltate(III) hexanchloroantimonate, $\left[\left(\mathbf{C p P}{ }^{\mathrm{OBu}} \mathrm{Co}\right)_{2} \mathrm{Co}_{\mathbf{S b C l}}\right.$ (7). Compound (2), $\left(\mathrm{CpP}^{\mathrm{OBu}} \mathrm{Co}\right)_{2} \mathrm{Co}(0.776 \mathrm{~g}$, $0.529 \mathrm{mmol})$ and $\left[\left(p-\mathrm{BrC}_{6} \mathrm{H}_{4}\right)_{3} \mathrm{~N}\right] \mathrm{SbCl}_{6}(0.433 \mathrm{~g}, 0.530 \mathrm{mmol})$ were mixed in methylene chloride $(40.0 \mathrm{~mL})$ and yield a dark green solution. The reaction was stirred for 4 hrs under aluminium foil followed by rotary evaporation and yield dark green solid. The solid was extracted by dibutyl ether and washed by methanol and pentane yield $(0.257 \mathrm{~g}, 0.143 \mathrm{mmol}, 27.0 \%)$ dark green powder. IR(cm" $\left.{ }^{-1}, \mathrm{KBr}\right): 2961$ s, 2874 s. 2361s, 1465 w, 1379 w, 1068 s, 1022 s, 973 s, 893 w, 838 w, 789 w. ${ }^{31} \mathrm{P}$ NMR(161.97 MHz, CDCl 3 , ppm): 325.8 .

\section{Results and Discussion}

Syntheses. Supersandwich type of metal complexes with butyl Kläui ligand $\left(\mathrm{CpP}^{\mathrm{OBu}} \mathrm{Co}\right)^{-}$were synthesized based on previously reported supersandwich complexes (102). The previously reported supersandwich complexes have interesting changes in chemical and physical properties 
as the R group varies as well as the metal center varies (101-103). In these complexes, the ligand binds through paired electrons located on three donating oxygen atoms. In this project, butyl supersandwich ( $\left.\mathrm{CpP} \mathrm{PBu}^{\mathrm{OB}} \mathrm{Co}\right)_{2} \mathrm{Co}(2)$ and butyl Kläui ligand $\left(\mathrm{CpP}^{\mathrm{OBu}} \mathrm{Co}\right)^{-}$were synthesized, shown in Scheme 8. The cobaltocene sublimes readily slightly above room temperature and easily reacts with oxygen, thus, the reaction was conducted under Schlenk line using air-free technique. In addition, the deoxygenation of dibutyl phosphite was also necessary before the reaction to prevent the oxidation of cobaltocene. Butyl supersandwich is an orange waxy solid. $\mathrm{Na}\left(\mathrm{CpP} \mathrm{PBu}^{\mathrm{OB}} \mathrm{Co}\right)(4)$ is orange wax. The $\mathrm{NaCN}$ was used to break supersandwich to generate $\mathrm{Na}\left(\mathrm{CpP}{ }^{\mathrm{OBu}} \mathrm{Co}\right)(\mathbf{4})$ and $\left[\mathrm{Co}(\mathrm{CN})_{6}\right]^{3-}$ as a byproduct based on Kläui and co-workers (102). The $\mathrm{NaCN}$ is toxic, so the reaction was carried under fume hood and kept away from acids. Wearing gloves was also necessary in this process. 
Scheme 8. The Proposed Synthetic Scheme Co-supersandwich ( $\left.\mathrm{CpP}^{\mathrm{OBu}} \mathrm{Co}\right)_{2} \mathrm{Co}$ (2) and the Butyl Kläui Ligand ( $\left.\mathrm{CpP}^{\mathrm{OBu}} \mathrm{Co}\right)^{-}$.
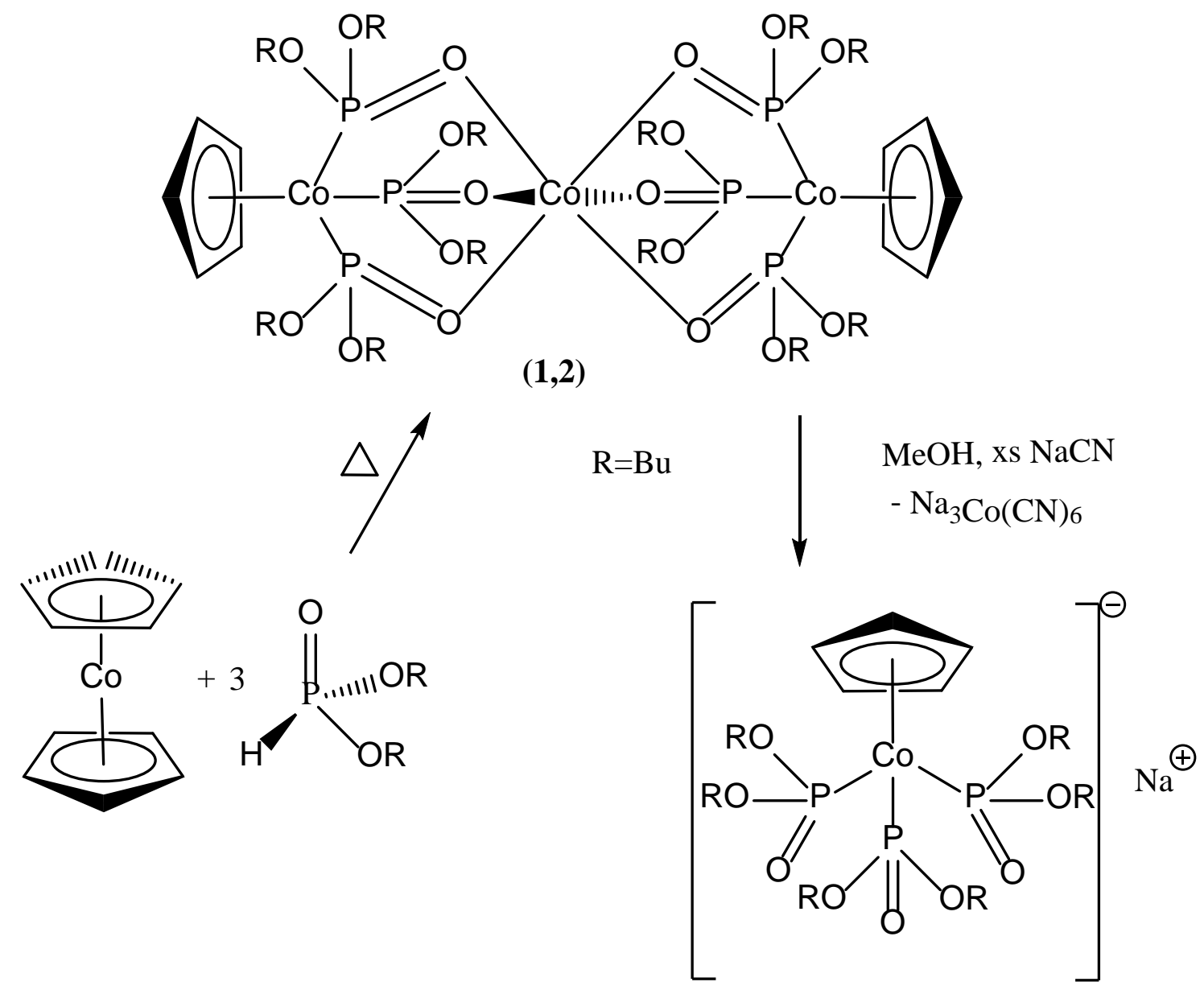

$(3,4)$

$\mathrm{Na}\left(\mathrm{CpP}{ }^{\mathrm{OBu}} \mathrm{Co}\right)(\mathbf{4})$ was employed to synthesize supersandwiches with other metal centers, $\mathrm{Ni}(\mathrm{II})$ and V(IV), based on Kläui and co-workers (102-103), Figure 17. Since butyl Kläui ligand $\left(\mathrm{CpP}{ }^{\mathrm{OBu}} \mathrm{Co}\right)^{-}$is stable in air, all the reactions were conducted under ambient condition. The butyl Kläui ligand $\left(\mathrm{CpP}^{\mathrm{OBu}} \mathrm{Co}\right)^{-}$more favors organic solvent, thus aqueous methanol (50\%:50\%) was employed as the solvent. The resulting compound $\left(\mathrm{CpP}{ }^{\mathrm{OBu}} \mathrm{Co}\right)_{2} \mathrm{Ni}(5)$ is a yellow solid. In the process of mixing the $\mathrm{Na}\left(\mathrm{CpP}^{\mathrm{OBu}} \mathrm{Co}\right)$ (4) and $\mathrm{NiCl}_{2} \cdot 6 \mathrm{H}_{2} \mathrm{O}$, the precipitate formed immediately indicating the strong tendency to form $\left(\mathrm{CpP}^{\mathrm{OBu}} \mathrm{Co}\right)_{2} \mathrm{Ni}$ (5). However, the precipitate suspended all 
around the solution, so centrifugation was necessary to separate the products. For the systhesis of $\left(\mathrm{CpP}{ }^{\mathrm{OBu}} \mathrm{Co}\right)_{2} \mathrm{~V}=\mathrm{O}(\mathbf{6}), \mathrm{VOSO}_{4} \cdot \mathrm{H}_{2} \mathrm{O}$ was less soluble in aqueous methanol, however, after the addition of $\left(\mathrm{CpP}^{\mathrm{OBu}} \mathrm{Co}\right)^{-}$, the reaction became clear and green indicating the occurrence of the reaction.

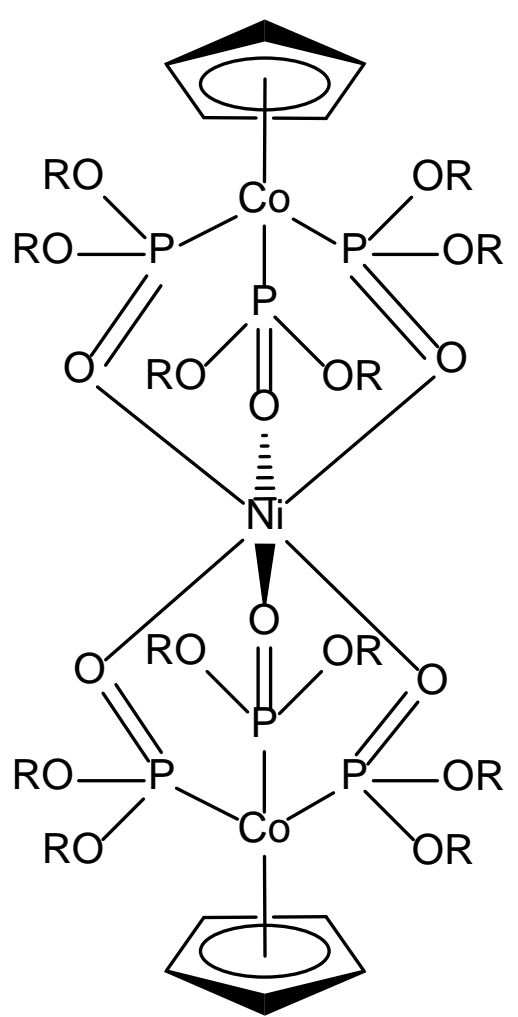

(5) $\mathrm{Ni}(\mathrm{II})$

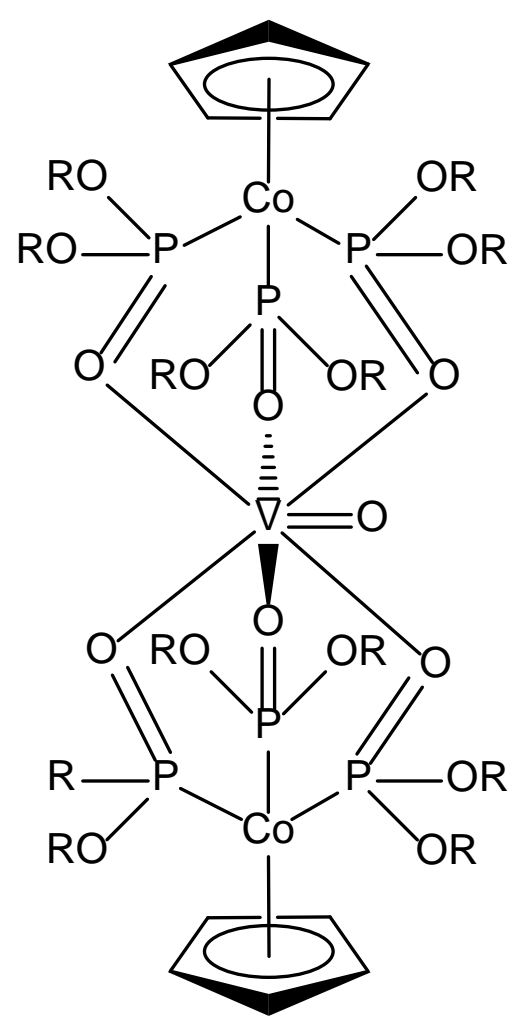

(6) V(IV)

$\mathrm{R}=\mathrm{Bu}$

Figure 17. Supersandwiches with Metal Centers, Ni(II) and V(IV).

Compared to $\left(\mathrm{CpP}^{\mathrm{OMe}} \mathrm{Co}\right)^{-}$and $\left(\mathrm{CpP}^{\mathrm{OEt}} \mathrm{Co}\right)^{-}$, $\left(\mathrm{CpP}^{\mathrm{OBu}} \mathrm{Co}\right)^{-}$is bulkier and more disordered, so the crystallization work was challenging. One way to promote crystallization was to oxidize the center Co(II) metal to go from a molecular species to a salt. A strong oxidization reagent was employed to oxidize $\left(\mathrm{CpP}^{\mathrm{OBu}} \mathrm{Co}\right)_{2} \mathrm{Co}$ (2) to generate oxidized $\mathrm{Co}(\mathrm{III})$ species, shown in scheme 9. The $\left[\left(\mathrm{CpP}^{\mathrm{OBu}} \mathrm{Co}\right)_{2} \mathrm{Co}\right] \mathrm{SbCl}_{6}(7)$ is green solid. The strong oxidizing reagent $\left[\left(p-\mathrm{BrC}_{6} \mathrm{H}_{4}\right)_{3} \mathrm{~N}\right] \mathrm{SbCl}_{6}$ is toxic to environment. So, all the waste was collected in a separate waste container. Another 
crystallization effort was to replace the sodium cation by a bulky cation which can help crystallization. Tetrabutylammonium (TBA) cation, $\left(\mathrm{NCH}_{2} \mathrm{CH}_{2} \mathrm{CH}_{2} \mathrm{CH}_{3}\right)^{+}$, was employed to synthesize tetrabutylammonium salt, $\mathrm{TBA}\left(\mathrm{Cp} \mathrm{P}^{\mathrm{OBu}} \mathrm{Co}\right)$. However, this synthesis failed.

Scheme 9. Synthesis Scheme of Co(III)-supersandwich Salt, $\left[\left(\mathrm{CpP}^{\mathrm{OBu}} \mathrm{Co}\right)_{2} \mathrm{Co}\right] \mathrm{SbCl}_{6}$ (7).



(2)
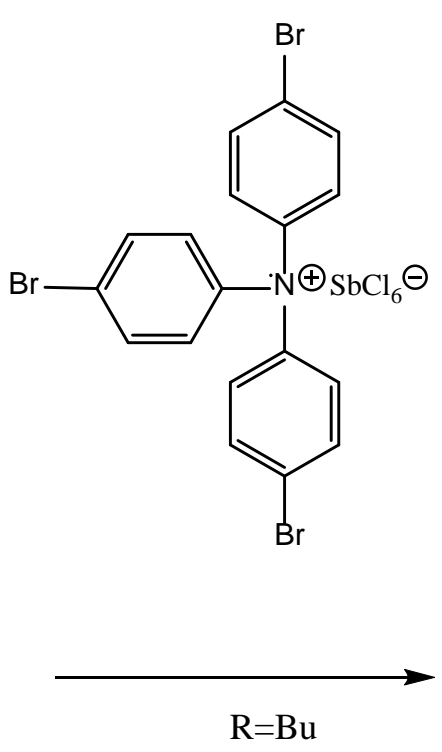

For the synthesis of the Kläui ligand, as the size of R group became larger, the reaction time was longer. $\left(\mathrm{CpP}^{\mathrm{OMe}} \mathrm{Co}\right)^{-}$is commercially available. The synthesis time for $\left(\mathrm{CpP}^{\mathrm{OEt}} \mathrm{Co}\right)^{-}$was $2 \mathrm{~h}$ and for $\left(\mathrm{CpP}^{\mathrm{OBu}} \mathrm{Co}\right)^{-}$was $7 \mathrm{~h}$, indicating that the bukyl $\left(\mathrm{CpP}^{\mathrm{OBu}} \mathrm{Co}\right)^{-}$is less reactive.

Characterization. The frequencies in infrared (IR) spectroscopy of $\mathrm{P}=\mathrm{O}$ double bond in secondary phosphites $\mathrm{HP}(\mathrm{O}) \mathrm{R}_{2}$ are in the range $1256-1260 \mathrm{~cm}^{-1}$ (102). For the supersandwich complexes, the $\mathrm{P}=\mathrm{O}$ frequencies are in the range $1121-1150 \mathrm{~cm}^{-1}$ and the lower frequencies are due to binding to the center $\mathrm{M}(\mathrm{V}, \mathrm{Ni}, \mathrm{Co})$. 
The (CpP $\left.{ }^{\mathrm{OMe}} \mathrm{Co}\right)_{2} \mathrm{Co}$, $\left(\mathrm{CpP}^{\mathrm{OEt}} \mathrm{Co}\right)_{2} \mathrm{Co}(\mathbf{1})$ and $\left(\mathrm{CpP}^{\mathrm{OBu}} \mathrm{Co}\right)_{2} \mathrm{Co}$ (2) complexes were synthesized and characterized by Kläui $(78,102)$ and co-workers, Harder $(99)$ and co-workers and our group (88-89) previously. The $\mathrm{P}=\mathrm{O}$ bonds stretching for these three supersandwich complexes are all in the range 1128-1130 $\mathrm{cm}^{-1}$ in the IR spectra. The sizes of the substituents $\mathrm{R}$ do not affect the POCo interaction, as shown in Table 1.

The $\left(\mathrm{CpP}{ }^{\mathrm{OMe}} \mathrm{Co}\right)_{2} \mathrm{Ni},\left(\mathrm{CpP}^{\mathrm{OEt}} \mathrm{Co}\right)_{2} \mathrm{Ni}$ complexes were synthesized and characterized by Harder and co-workers (105). The $\mathrm{P}=\mathrm{O}$ stretch is at $1150 \mathrm{~cm}^{-1}$ for $\left(\mathrm{CpP}^{\mathrm{OMe}} \mathrm{Co}\right)_{2} \mathrm{Ni}$ and $1121 \mathrm{~cm}^{-1}$ for $\left(\mathrm{CpP}{ }^{\mathrm{OEt}} \mathrm{Co}\right)_{2} \mathrm{Ni}$. The synthesis of $\left(\mathrm{CpP} \mathrm{PBu}^{\mathrm{OB}} \mathrm{Co}\right)_{2} \mathrm{Ni}$ (5) was based on Kläui (102) and IR data showed the $\mathrm{P}=\mathrm{O}$ stretch is at $1129 \mathrm{~cm}^{-1}$. The $\left(\mathrm{Cp} \mathrm{P}^{\mathrm{OMe}} \mathrm{Co}\right)_{2} \mathrm{Ni}$ has high frequency in $\mathrm{P}=\mathrm{O}$ value compared to $\left(\mathrm{CpP}{ }^{\mathrm{OEt}} \mathrm{Co}\right)_{2} \mathrm{Ni}$ and $\left(\mathrm{CpP}^{\mathrm{OBu}} \mathrm{Co}\right)_{2} \mathrm{Ni}$ (5). The smaller substituent $\mathrm{R}$ results in weaker $\mathrm{PO}-\mathrm{Ni}$ interaction, shown in Table 1.

The $\left(\mathrm{CpP}^{\mathrm{OBu}} \mathrm{Co}\right)_{2}(\mathrm{~V}=\mathrm{O})(\mathbf{6})$ has the $\mathrm{P}=\mathrm{O}$ stretch frequency at $1129 \mathrm{~cm}^{-1}$. Compared to the $\left(\mathrm{CpP} \mathrm{PBu}^{\mathrm{O}} \mathrm{Co}\right)_{2} \mathrm{Co}$ (2) at $1129 \mathrm{~cm}^{-1}$ and $\left(\mathrm{CpP}^{\mathrm{OBu}} \mathrm{Co}\right)_{2} \mathrm{Ni}$ (5) at $1129 \mathrm{~cm}^{-1}$, varying the center metal do not affect the $\mathrm{PO}-\mathrm{M}$ interaction. However, the shapes of $\mathrm{P}=\mathrm{O}$ stretching are different between them, shown in Figure 18. The $\left(\mathrm{CpP}^{\mathrm{OBu}} \mathrm{Co}\right)_{2}(\mathrm{~V}=\mathrm{O})(\mathbf{6})$ has a weaker $\mathrm{P}=\mathrm{O}$ wavenumber in energy, which may result from the geometry change. The $\left(\mathrm{CpP}^{\mathrm{OBu}} \mathrm{Co}\right)_{2}(\mathrm{~V}=\mathrm{O})(\mathbf{6})$ has a $\mathrm{V}=\mathrm{O}$ double bond stretching shown around $971 \mathrm{~cm}^{-1}$ which can cause the $\mathrm{P}=\mathrm{O}$ stretch to be weaker. In addition, the $\mathrm{V}=\mathrm{O}$ frequency in $\left(\mathrm{CpP} \mathrm{PBu}^{\mathrm{OB}} \mathrm{Co}\right)_{2}(\mathrm{~V}=\mathrm{O})(\mathbf{6})$ was really close compared to $\left(\mathrm{CpP}{ }^{\mathrm{OEt}} \mathrm{Co}\right)_{2}(\mathrm{~V}=\mathrm{O})$, which is $965 \mathrm{~cm}^{-1}$, reported by Kläui and co-workers (103). The possible structure of vanadium supersandwich is shown in Figure 17. (6) shows that the oxovanadium metal center is bonded by two $\left(\mathrm{CpP}^{\mathrm{OBu}} \mathrm{Co}\right)^{-}$ligands equally via six $\mathrm{P}=\mathrm{O}$ arms which construct a seven-coordinate system. The seven-coordinate system for vanadium complexes exist in several cases $(8,103,106)$ 

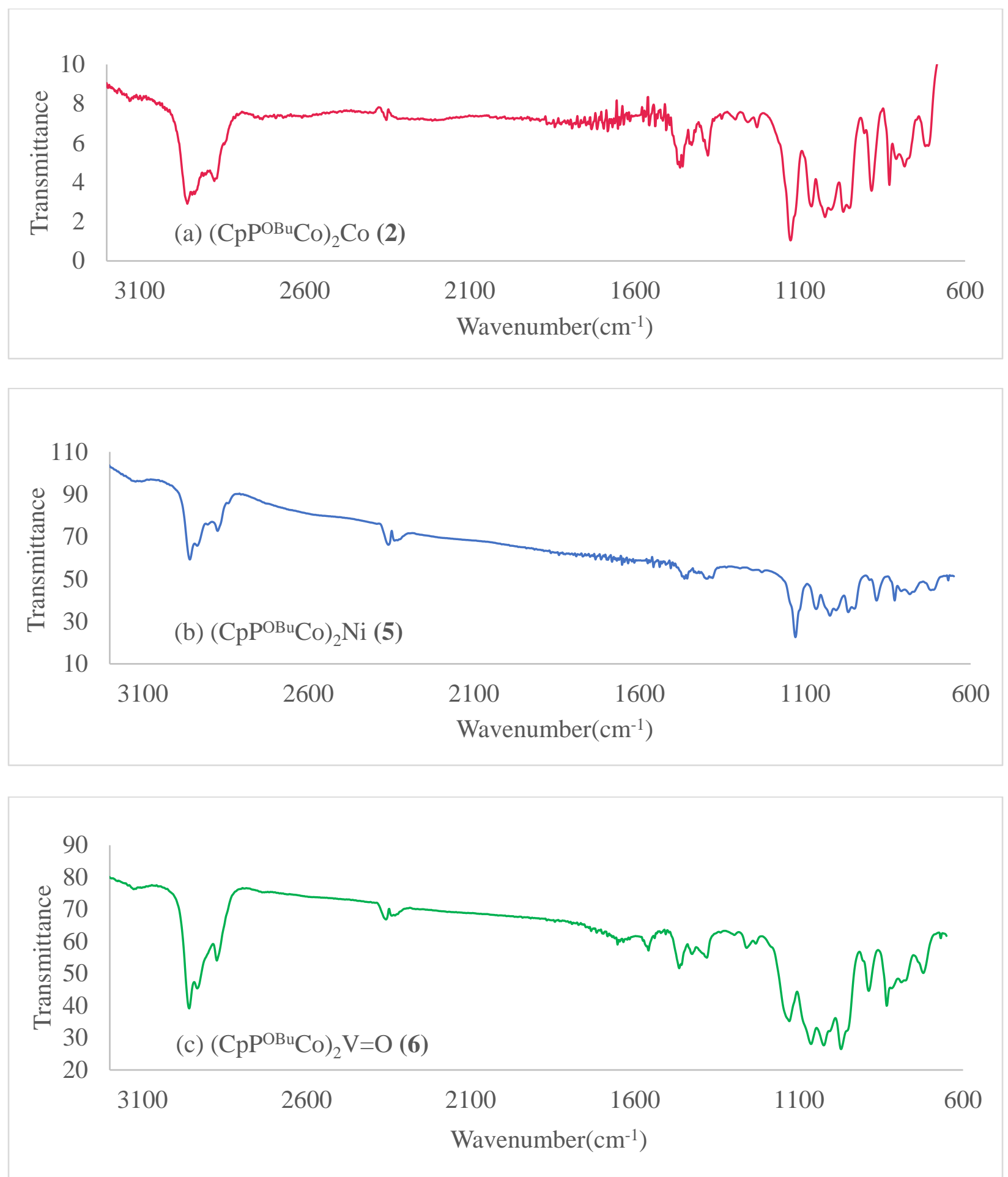

Figure 18. The Comparison among the IR Spectra of these Three Supersandwich Complexes. (a) (CpP $\left.{ }^{\mathrm{OBu}} \mathrm{Co}\right)_{2} \mathrm{Co}$ (2), (b) (CpP $\left.{ }^{\mathrm{OBu}} \mathrm{Co}\right)_{2} \mathrm{Ni}$ (5), (c) $\left(\mathrm{CpP}^{\mathrm{OBu}} \mathrm{Co}\right)_{2}(\mathrm{~V}=\mathrm{O})$ (6). 
Table 1. $\mathrm{P}=\mathrm{O}$ Stretching Frequencies of Supersandwich Complexes.

\begin{tabular}{|c|c|c|}
\hline Compounds & $\mathbf{P}=\mathbf{O}$ stretch $\left(\mathrm{cm}^{-1}\right)$ & Reference \\
\hline$\left(\mathrm{Cp} \mathrm{P}^{\mathrm{OMe}} \mathrm{Co}\right)_{2} \mathrm{Co}$ & 1130,1127 & (99), (102) \\
\hline$\left(\mathrm{CpP} \mathrm{PE}^{\mathrm{OEt}} \mathrm{Co}\right)_{2} \mathrm{Co}(\mathbf{1})$ & 1130, 1130, 1132 & (99), (102), a \\
\hline$\left(\mathrm{Cp} \mathrm{P}^{\mathrm{OBu}} \mathrm{Co}\right)_{2} \mathrm{Co}(2)$ & 1128,1129 & (102), a \\
\hline$\left(\mathrm{CpP} \mathrm{PMe}^{\mathrm{OM}} \mathrm{Co}\right)_{2} \mathrm{Ni}$ & 1150 & (105) \\
\hline$\left(\mathrm{CpP} \mathrm{P}^{\mathrm{OEt}} \mathrm{Co}\right)_{2} \mathrm{Ni}$ & 1121 & (105) \\
\hline$\left(\mathrm{Cp} \mathrm{P}^{\mathrm{OBu}} \mathrm{Co}\right)_{2} \mathrm{Ni}(\mathbf{5})$ & 1129 & A \\
\hline$\left(\mathrm{CpP}^{\mathrm{OBu}} \mathrm{Co}\right)_{2}(\mathrm{~V}=\mathrm{O})(\mathbf{6})$ & 1129 & A \\
\hline $\mathrm{HP}(\mathrm{O})\left(\mathrm{OCH}_{3}\right)_{2}$ & 1260 & (102) \\
\hline $\mathrm{HP}(\mathrm{O})\left(\mathrm{OCH}_{2} \mathrm{CH}_{3}\right)_{2}$ & 1258 & (102) \\
\hline $\mathrm{HP}(\mathrm{O})\left(\mathrm{OCH}_{2} \mathrm{CH}_{2} \mathrm{CH}_{2} \mathrm{CH}_{3}\right)_{2}$ & 1260 & (102) \\
\hline
\end{tabular}

a represent the work in this project.

The magnetic susceptibilities for $\left(\mathrm{CpP}^{\mathrm{OR}} \mathrm{Co}\right)_{2} \mathrm{Co}$ were characterized. The $\mu$ B for these $\left(\mathrm{Cp} \mathrm{P}^{\mathrm{OR}} \mathrm{Co}\right)_{2} \mathrm{Co}$ are in the region between 4.72-5.2, which agree with the magnetic moment of one high spin $\mathrm{d}^{7} \mathrm{Co}^{2+}$ and two low spin $\mathrm{d}^{6} \mathrm{Co}^{3+}$ species, in the region 4.3-5.2 (107), shown in Table 2. Table 2. Magnetic Susceptibilities of Supersandwich Complexes.

\begin{tabular}{ccc}
\hline Compounds & Magnetic Susceptibilities $\boldsymbol{\mu}_{\mathbf{B}}$ & Reference \\
\hline$\left(\mathrm{CpP}{ }^{\mathrm{OMe}} \mathrm{Co}\right)_{2} \mathrm{Co}$ & 5.2 & $(99)$ \\
$\left(\mathrm{CpP}{ }^{\mathrm{OEt}} \mathrm{Co}\right)_{2} \mathrm{Co}(\mathbf{1})$ & 4.72 & $\mathrm{~A}$ \\
$\left(\mathrm{CpP}{ }^{\mathrm{OBu}} \mathrm{Co}\right)_{2} \mathrm{Co}(\mathbf{2})$ & 4.76 & $\mathrm{~A}$ \\
\hline
\end{tabular}

a represent the work in this project. 
There are three types of Kläui ligands that were studied: $\mathrm{Na}\left(\mathrm{CpP}^{\mathrm{OMe}} \mathrm{Co}\right), \mathrm{Na}\left(\mathrm{CpP}{ }^{\mathrm{OEt}} \mathrm{Co}\right)$ (3) and $\mathrm{Na}\left(\mathrm{CpP}{ }^{\mathrm{OBu}} \mathrm{Co}\right)$ (4). As the $\mathrm{R}$ group varies from methyl to butyl, the carbon chain becomes longer and the compound become less water soluble and more favors organic solvent which means more non-polar. The $\mathrm{Na}\left(\mathrm{CpP}^{\mathrm{OMe}} \mathrm{Co}\right)$ and $\mathrm{Na}\left(\mathrm{CpP}^{\mathrm{OEt}} \mathrm{Co}\right)(3)$ are powders. However, the $\mathrm{Na}\left(\mathrm{CpP}^{\mathrm{OBu}} \mathrm{Co}\right)$ (4) is waxy solid. The appearance changes are well corresponding to the properties infected by variation of $\mathrm{R}$ group. Longer carbon chain makes the $\mathrm{Na}\left(\mathrm{CpP} \mathrm{PBu}^{\mathrm{OB}} \mathrm{Co}\right)$ ligand more disordered and crystallization was a challenge.

The IR spectroscopy is a powerful tool to characterize these Kläui ligands and the peaks correspond to the characteristics of varying R group. However, the $\mathrm{P}-\mathrm{O}-\mathrm{C}$ bonds have both $\mathrm{P}-\mathrm{O}$ and $\mathrm{C}-\mathrm{O}$ bonds and these two kinds of bonds have close frequencies. Thus, the interaction between $\mathrm{P}-\mathrm{O}$ and $\mathrm{C}-\mathrm{O}$ bond can overlap and is not very characteristic. Raman spectroscopy was employed to further characterize these Kläui ligands. The IR spectral data and Raman spectral data are compiled in Table 3. The $\mathrm{P}=\mathrm{O}$ stretch in IR spectra showed $1170 \mathrm{~cm}^{-1}$ in $\mathrm{Na}\left(\mathrm{CpP}^{\mathrm{OMe}} \mathrm{Co}\right), 1166 \mathrm{~cm}^{-}$ ${ }^{1}$ in $\mathrm{Na}\left(\mathrm{CpP} \mathrm{P}^{\mathrm{OEt}} \mathrm{Co}\right)$, and $1167 \mathrm{~cm}^{-1}$ in $\mathrm{Na}\left(\mathrm{CpP}^{\mathrm{OBu}} \mathrm{Co}\right)$ and they are close to each other. This means the interaction between $\mathrm{Co}-(\mathrm{P}=\mathrm{O})$ metal phosphorus bonds are similar. The similarities of the $\mathrm{Co}-$ $(\mathrm{P}=\mathrm{O})$ interactions also can confirmed by Raman spectroscopy, which showed around $1122 \mathrm{~cm}^{-1}$ in all three compounds. Theoretically, the $\mathrm{P}=\mathrm{O}$ stretching values in both IR and Raman spectroscopy should be identical. The differences may be due to the systemic errors. Another reason could due to the method of collecting the data. For the Raman spectroscopy measurement, the sample was put on the gold surface under the monochromatic laser light without further manipulation. However, for the IR spectroscopy measurement, the sample was mixed and mulled with $\mathrm{KBr}$ finely followed by the mechanical press to form a translucent pellet which the beam of the spectrometer can pass through. 
Table 3. IR and Raman Spectroscopy of the Three Kläui Ligands.

\begin{tabular}{ccc}
\hline Compounds & $\mathbf{P}=\mathbf{O}$ stretch $\left(\mathbf{c m}^{-\mathbf{1}}\right)$ in IR & $\mathbf{P}=\mathbf{O}$ stretch $\left(\mathbf{c m}^{-\mathbf{1}}\right)$ in Raman \\
\hline $\mathrm{Na}\left(\mathrm{Cp} \mathrm{P}^{\mathrm{OMe}} \mathrm{Co}\right)$ & 1170 & 1122 \\
$\mathrm{Na}\left(\mathrm{CpP}{ }^{\mathrm{OEt}} \mathrm{Co}\right)(\mathbf{3})$ & 1166 & 1122 \\
$\mathrm{Na}\left(\mathrm{Cp}^{\mathrm{OBu}} \mathrm{Co}\right)(\mathbf{4})$ & 1167 & 1122 \\
\hline
\end{tabular}

The ${ }^{1} \mathrm{H}$ NMR spectroscopy of $\mathrm{Na}\left(\mathrm{CpP}^{\mathrm{OBu}} \mathrm{Co}\right)(4)$ confirms the oxidation of $\mathrm{Co}$ is +2 by showing a diamagnetic NMR spectrum. The singlet at $4.92 \mathrm{ppm}$ corresponds to the protons belonging to the $\mathrm{Cp}$ rings. The multiplet at $3.83 \mathrm{ppm}$ is due to the protons belong to the $-\mathrm{OCH}_{2}-$ attached to phosphorus. The peaks at 1.48, 1.32 and $0.87 \mathrm{ppm}$ are corresponding to the remaining three types of protons attached to the carbon chain in the R group. The ${ }^{13} \mathrm{C}$ NMR spectrum confirms successful synthesis of $\mathrm{Na}\left(\mathrm{CpP}^{\mathrm{OBu}} \mathrm{Co}\right)$. The $\mathrm{Cp}$ rings appears at $89.39 \mathrm{ppm}$. The other four peaks at 62.80 , 33.32, 19.34 and 13.98 ppm correspond to the four carbons in butyl group. There is only one peak visible in the ${ }^{31} \mathrm{P}$ NMR spectrum, which can confirm the existence of the hanging dibutylphosphonate arms as well as symmetry and the tridentate properties of $\mathrm{Na}\left(\mathrm{CpP}{ }^{\mathrm{OBu}} \mathrm{Co}\right)$.

To further explore the similarities and difference between these Kläui ligands, multi-nuclear NMR spectroscopy was employed to study them. The stacked ${ }^{1} \mathrm{H}$ NMR spectra of the three Kläui ligands is shown in Figure 19. All the peaks of Cp rings attached to the Co metal center are showed in the region between 4.91-4.99 ppm, only 0.08 ppm difference. The peaks in $\mathrm{Na}\left(\mathrm{Cp} \mathrm{P}^{\mathrm{OEt}} \mathrm{Co}\right)$ (3) and in $\mathrm{Na}\left(\mathrm{CpP}{ }^{\mathrm{OBu}} \mathrm{Co}\right)(4)$ are closer in ${ }^{1} \mathrm{H}$ NMR spectra. These data also confirm the similarity between $\mathrm{Na}\left(\mathrm{CpP}{ }^{\mathrm{OEt}} \mathrm{Co}\right)$ and $\mathrm{Na}\left(\mathrm{CpP}^{\mathrm{OBu}} \mathrm{Co}\right)$. So even though the exact crystal structure of the $\mathrm{Na}\left(\mathrm{CpP} \mathrm{OBu}^{\mathrm{Ou}} \mathrm{C}\right)$ was not collected by $\mathrm{X}$-ray diffraction, these spectroscopic data can still be an evidence in the interpretation of the similarities between $\mathrm{Na}\left(\mathrm{CpP}^{\mathrm{OEt}} \mathrm{Co}\right)(3)$ and $\mathrm{Na}\left(\mathrm{Cp} \mathrm{P}^{\mathrm{OBu}} \mathrm{Co}\right)(\mathbf{4})$. 
$\mathrm{Na}\left(\mathrm{CpP}^{\mathrm{OMe}} \mathrm{Co}\right)$, as mentioned before, favors aqueous solvent due to the short carbon chain of the methyl group, and this could be the reason causing the different behaviors in ${ }^{1} \mathrm{H}$ NMR spectra.

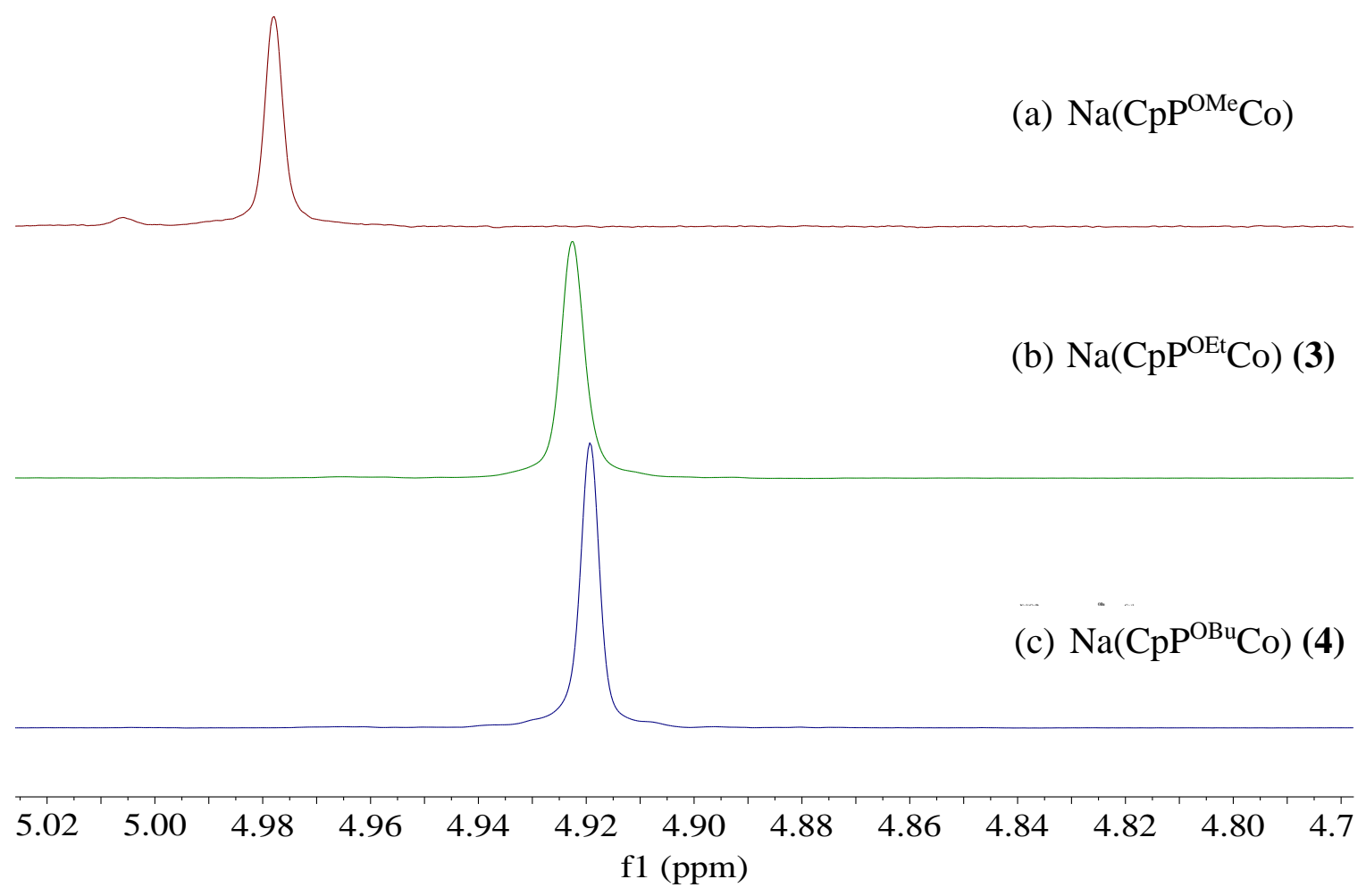

Figure 19. Stacked ${ }^{1} \mathrm{H}$ NMR $400.13 \mathrm{MHz}$ Spectra of Cp Rings of the Three Kläui Ligands. $\left.\mathrm{Na}\left(\mathrm{CpP}{ }^{\mathrm{OMe}} \mathrm{Co}\right)\right]$ is at $4.98 \mathrm{ppm}$; $\mathrm{Na}\left[\left(\mathrm{CpP}{ }^{\mathrm{OEt}} \mathrm{Co}\right)(3)\right.$ is at $4.92 \mathrm{ppm}$; $\mathrm{Na}\left(\mathrm{CpP}{ }^{\mathrm{OBu}} \mathrm{Co}\right)(4)$ is at 4.92 ppm. Solvent is $\mathrm{CDCl}_{3}$.

The ${ }^{31} \mathrm{P}$ NMR spectra were collected in $\mathrm{CDCl}_{3}$ for all three sodium salts $\mathrm{Na}\left(\mathrm{CpP}{ }^{\mathrm{OMe}} \mathrm{Co}\right)$, $\mathrm{Na}\left(\mathrm{CpP}{ }^{\mathrm{OEt}} \mathrm{Co}\right)$ (3) and $\mathrm{Na}\left(\mathrm{CpP}^{\mathrm{OBu}} \mathrm{Co}\right)$ (4). The ${ }^{31} \mathrm{P}$ NMR spectrum was silent for $\mathrm{Na}\left(\mathrm{Cp} \mathrm{P}^{\mathrm{OMe}} \mathrm{Co}\right)$ in $\mathrm{CDCl}_{3}$ and visible at $111.6 \mathrm{ppm}$ in $\mathrm{D}_{2} \mathrm{O}$. The ${ }^{31} \mathrm{P}$ NMR spectroscopy showed $97.6 \mathrm{ppm}$ for $\mathrm{Na}\left(\mathrm{CpP}^{\mathrm{OEt}} \mathrm{Co}\right)$ (3) and $106.8 \mathrm{ppm}$ for $\mathrm{Na}\left(\mathrm{CpP}^{\mathrm{OBu}} \mathrm{Co}\right)$ (4), indicating that the size can affect the chemical shift in ${ }^{31} \mathrm{P}$ NMR spectra. The $\mathrm{Na}\left(\mathrm{CpP}^{\mathrm{OBu}} \mathrm{Co}\right)(\mathbf{4})$ has a bigger substituent and the chemical shift in ${ }^{31} \mathrm{P}$ NMR spectrum is more downfield, illustrating that the phosphorus atoms are more electron rich compared to $\mathrm{Na}\left(\mathrm{Cp}^{\mathrm{OEt}} \mathrm{Co}\right)$. 
Table 4. ${ }^{31} \mathrm{P}$ NMR Chemical Shift Correlation of the Three Kläui Ligands.

\begin{tabular}{cc}
\hline Compounds & ${ }^{31} \mathbf{P}$ NMR chemical shift (ppm) \\
\hline $\mathrm{Na}\left(\mathrm{CpP}{ }^{\mathrm{OMe}} \mathrm{Co}\right)$ & $111.6\left(\mathrm{D}_{2} \mathrm{O}\right)$, silent in $\mathrm{CDCl}_{3}$ \\
$\mathrm{Na}\left(\mathrm{CpP}{ }^{\mathrm{OEt}} \mathrm{Co}\right) \mathbf{( 5 )}$ & $97.6\left(\mathrm{CDCl}_{3}\right)$ \\
$\mathrm{Na}\left(\mathrm{CpP}{ }^{\mathrm{OBu}} \mathrm{Co}\right)(\mathbf{6})$ & $106.8\left(\mathrm{CDCl}_{3}\right)$ \\
\hline
\end{tabular}




\title{
CHAPTER III: SYNTHESIS AND CHARACTERIZATION OF SERIES \\ VANADIUM PRECURSORS CONTAINING \\ THE KLÄUI LIGAND (CpP $\left.{ }^{\mathrm{OBu}} \mathrm{Co}\right)^{-}$
}

\begin{abstract}
Vanadium complexes with phosph(in/on) bridging are the target structures to synthesize the dimeric complexes used to model the $\mathrm{VO}_{6}$ octahedral linked $\mathrm{PO}_{4}$ core in $\mathrm{VOPO}_{4}$ catalyst. The vanadium monomer is the precursor to synthesize these dimeric bridging complexes. In this chapter, three types of vanadium precursors with different ligands $\left[\left(\mathrm{CpP}{ }^{\mathrm{OBu}} \mathrm{Co}\right) \mathrm{VOCl}\right]_{2}$, $\left(\mathrm{CpP}{ }^{\mathrm{OBu}} \mathrm{Co}\right) \mathrm{VCl}_{2}(\mathrm{DMF}),(\mathrm{CpPOBuCo}) \mathrm{VO}(\mathrm{acac})$ were synthesized and characterized.

\section{Introduction}

Vanadium complexes have shown tremendous use and could be potential catalysts for oxidation reactions (44,108-110). $\mathrm{VOPO}_{4}$ is a well-characterized extended solid structure without fully understood mechanism. To model these catalytic reactions, the proposed structural model should contain two vanadium(IV) centers with organophosphorus bridging moieties. To obtain the bridging complexes, it is necessary to synthesize the vanadium precursors containing Kläui ligands that fulfill the charge balance and construct a core with vanadium surrounded by oxygens.
\end{abstract}


$\left(\mathrm{Cp} \mathrm{P}^{\mathrm{OMe}} \mathrm{Co}\right)^{-}$and $\left(\mathrm{CpP}^{\mathrm{OEt}} \mathrm{Co}\right)^{-}$were successfully used to synthesize the vanadium precursors by our group (84-86), shown in Scheme 10. These vanadium precursors also have catalytic activities, which will be introduced in next chapter. In this chapter, several vanadium precursors were synthesized and characterized using $\left(\mathrm{CpP}^{\mathrm{OBu}} \mathrm{Co}\right)^{-}$.

Scheme 10. Synthesis Scheme of Vanadium Precursors Containing the Kläui Ligands.

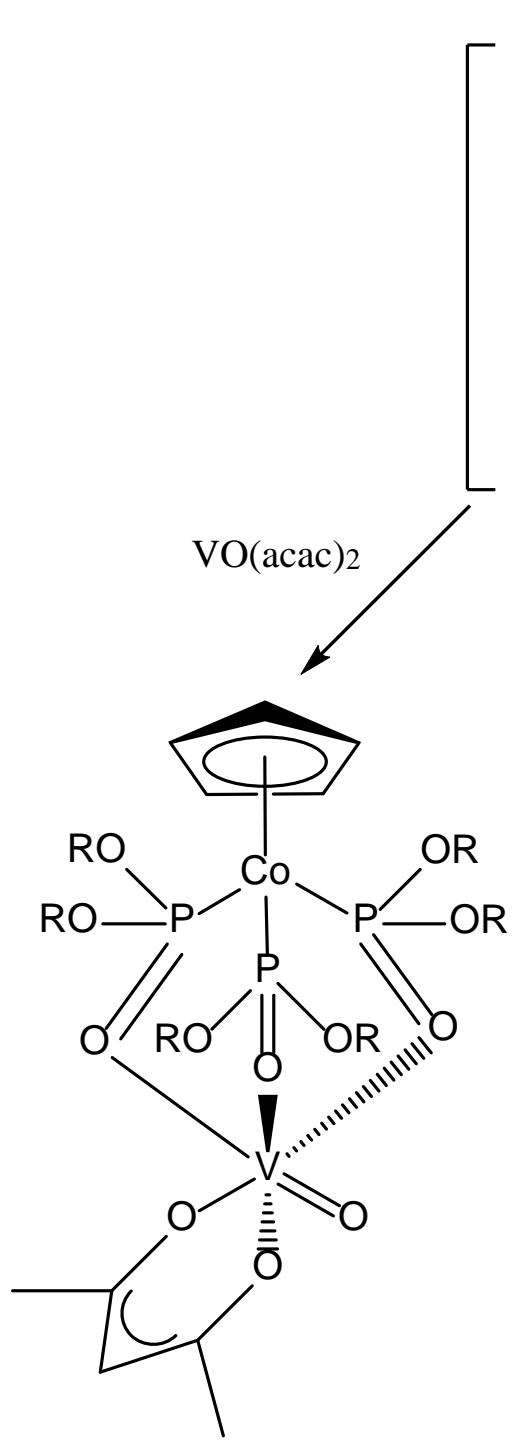

(a)

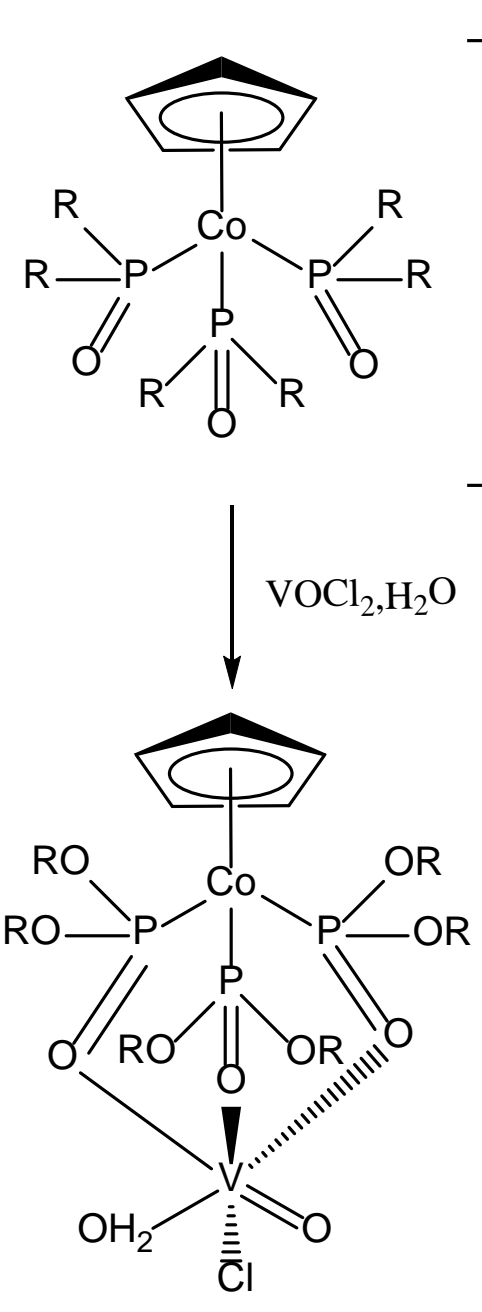

(b)



(c) 


\section{Experimental}

General considerations. All experimental procedures were performed under ambient conditions unless otherwise stated. Vanadium(IV) oxide sulfate hydrate $\left(\mathrm{VOSO}_{4} \cdot \mathrm{xH}_{2} \mathrm{O}, 97 \%\right)$ was purchased from Aldrich. Vanadium acetylacetonate (99\%) was purchased from Acros. Barium Chloride (99.9\%) was purchased from J.T.Baker. Analytical reagent methylene chloride (Fisher. 99.9\%), acetonitrile (Fisher, 99.9\%) were used without further purification. $N, N$ dimethylformamide (DMF) of BakerDRY quality was purchased from Aldrich. Vanadium (III) chloride (Arcos,97\%) was stored in the glovebox before use. Infrared spectra were collected on a Perkin-Elmer FT-IR spectrometer as KBr mulls. ${ }^{1} \mathrm{H}$ NMR spectra were collected on a $400.13 \mathrm{MHz}$ Bruker spectrometer and were referenced to residual chloroform. UV-Vis spectra were collected on an Agilent 8453 Ultraviolet/Visible spectrometer.

VOCl $_{2}$. $\mathrm{VOSO}_{4} \cdot \mathrm{xH}_{2} \mathrm{O}(1.563 \mathrm{~g})$ was dissolved in $16 \mathrm{~mL}$ water resulting blue solution. $\mathrm{BaCl}_{2} \cdot 2 \mathrm{H}_{2} \mathrm{O}(1.92 \mathrm{~g}, 7.86 \mathrm{mmol})$ in $16 \mathrm{~mL}$ water was added, resulting in a blue solution. The two solution above were mixed resulting in an oraque blue solution. The mixture was stirred for $1 \mathrm{~h}$. The solution was filtrated by gravity filtration and refiltrated by reduce pressure remained viscous blue liquid.

[(CpP $\left.{ }^{\mathrm{OBu}} \mathrm{Co}\right) \mathrm{VOCl}_{2}$ (8). Complex (5), $\mathrm{Na}\left(\mathrm{CpP}{ }^{\mathrm{OBu}} \mathrm{Co}\right),(0.266 \mathrm{~g}, 0.476 \mathrm{mmol})$ was added to 10 $\mathrm{mL}$ water. $\mathrm{VOCl}_{2}(0.247 \mathrm{mM}, 2.00 \mathrm{~mL})$ was added into the solution. The reaction was stirred for 24 h remained green with a green solid. $\mathrm{CH}_{2} \mathrm{Cl}_{2}$ was added to the solution resulting two layers: an opaque green white water layer and a clearly green $\mathrm{CH}_{2} \mathrm{Cl}_{2}$ layer. The $\mathrm{CH}_{2} \mathrm{Cl}_{2}$ layer was collected and solvent was removed by reduced pressure. The green oil was further dried under high vacuum for few days yield $0.620 \mathrm{~g}(0.333 \mathrm{mmol}, 70 \%)$ olive green oil. IR( $\left.\mathrm{cm}^{-1}, \mathrm{KBr}\right): 3380 \mathrm{~s}, 2976 \mathrm{vs}$, 
2927 s, 2880 s, 1637 s, 1477 w, 1441 w, 1410 w, 1387 s, 1296 w, 1260 w, 1154 s, 1100 vs, 1050 vs, 1038 vs, 935 vs, 834 vs, 772 s, 731 s.

(CpP $\left.{ }^{\mathrm{OBu}} \mathrm{Co}\right) \mathrm{VCl}_{2}$ (DMF) (9). Complex (4), $\mathrm{Na}\left(\mathrm{CpP}^{\mathrm{OBu}} \mathrm{Co}\right)$ (0.756 g, $1.00 \mathrm{mmol}$ ) was added to $25 \mathrm{~mL} \mathrm{DMF} . \mathrm{VCl}_{3}(0.164 \mathrm{~g}, 1.04 \mathrm{mmol})$ was weighed in glovebox and added into $15 \mathrm{~mL}$ DMF. The $\mathrm{VCl}_{3}$ suspension was added to the $\mathrm{Na}\left(\mathrm{CpP}^{\mathrm{OBu}} \mathrm{Co}\right)$ suspension via canula. The solution became brown. The reaction was stirred for $24 \mathrm{~h}$. The resulting green solution was filtered via cannula filtration. The clear green solution was collected and the solvent was distilled yield $0.643 \mathrm{~g} \mathrm{(0.620}$ mmol, 62\%) product. IR(cm $\left.{ }^{-1}, \mathrm{KBr}\right): 2960$ vs, 2922 s, 2874 s, 1729 m, 1648 s, 1465 w, 1380 w, 1252 w, 1062 s, 1038 vs, 973 vs, 890 vs, 839 s, 789 s.

(CpP ${ }^{\mathrm{OBu}} \mathrm{Co}$ )VO(acac) (10). Complex (4), Na(CpP $\left.{ }^{\mathrm{OBu}} \mathrm{Co}\right)$ (0.196 g, $0.271 \mathrm{mmol}$ ) was dissolved in $\mathrm{CH}_{2} \mathrm{Cl}_{2}(20.0 \mathrm{~mL})$. The color is yellow. Vanadyl acetylacetonate, $\mathrm{VO}(\mathrm{acac}) 2,(0.081 \mathrm{~g}, 0.305$ mmol) was added to the mixture. The color became green immediately, with some solid remaining. The reaction was stirred for overnight resulting a green solution. The solvent was removed by rotary evaporation. The resulting solid was dissolved in acetonitrile and gravity filtered, yield 0.198 g (0.228 mmol, 84\%) compounds. IR(cm-1 $\left.{ }^{-1} \mathrm{KBr}\right): 2958$ vs, 2874 s, 1712 w, 1598 vs, 1521 vs, 1460 m, 1398 vs, 1274 w, 1144 vs, 1064 vs, 1024 vs, 969 vs, 887 s, 833 s, 789 s.

\section{Results and Discussion}

Syntheses. The synthetic strategy for $\left[\left(\mathrm{CpP}^{\mathrm{OBu}} \mathrm{Co}\right) \mathrm{VOCl}\right]_{2}(\mathbf{8}),\left(\mathrm{Cp} \mathrm{P}^{\mathrm{OBu}} \mathrm{Co}\right) \mathrm{VCl}_{2}(\mathrm{DMF})(\mathbf{9})$ and $\left(\mathrm{CpP}{ }^{\mathrm{OBu}} \mathrm{Co}\right) \mathrm{VO}(\mathrm{acac})(\mathbf{1 0})$ employed is based on McLauchlan $(85-87,89)$ and Carrano $(63-64,70)$ with their co-workers.

For $\left[\left(\mathrm{CpP}{ }^{\mathrm{OBu}} \mathrm{Co}\right) \mathrm{VOCl}\right]_{2}(\mathbf{8}), \mathrm{VOCl}_{2}(\mathrm{aq})$ generated via the Smith method (111) was used in situ and combined with $\left(\mathrm{CpP} \mathrm{PBu}^{\mathrm{O}} \mathrm{Co}\right)^{-}$to synthesize the target compound. Owing to the hydrophobic property of ligand $\left(\mathrm{CpP}^{\mathrm{OBu}} \mathrm{Co}\right)^{-}$, water is not a good solvent for the reaction, thus aqueous methanol 
(50:50) was employed as the solvent, based on McLauchlan (84-86) and co-workers. During the reaction period, the solution turned green, with some brown oil remaining in the flask. This color change confirmed the synthesis of vanadium(IV) precursors.

For $\left(\mathrm{CpP}^{\mathrm{OBu}} \mathrm{Co}\right) \mathrm{Cl}_{2}(\mathrm{DMF})$ (9), a vanadium(III) complex containing the $\left(\mathrm{CpP}^{\mathrm{OBu}} \mathrm{Co}\right)^{-}$ligand along with two chloride ligands as well as a solvent molecule DMF via metathesis method. Airfree conditions for synthesis of $\left(\mathrm{CpP}^{\mathrm{OBu}} \mathrm{Co}\right) \mathrm{Cl}_{2}(\mathrm{DMF})$ were carried out in Schlenk line under nitrogen gas and stored in an inert atmosphere glovebox (112). The dichloromethane $\left(\mathrm{CH}_{2} \mathrm{Cl}_{2}\right)$ and $N, N$-dimethylformamide (DMF) were of BakerDRY ${ }^{\mathrm{TM}}$ quality and deoxygenated before use. The oxidation of ( $\left.\mathrm{CpP}^{\mathrm{OBu}} \mathrm{Co}\right) \mathrm{Cl}_{2}(\mathrm{DMF})$ under $\mathrm{O}_{2}$ can yield a $\mathrm{V}(\mathrm{IV})$ species.

For $\left(\mathrm{CpP}^{\mathrm{OBu}} \mathrm{Co}\right) \mathrm{VO}(\mathrm{acac})(\mathbf{1 0})$, an $\mathrm{VO}(\mathrm{acac})_{2}$ was used to combine with $\left(\mathrm{CpP}^{\mathrm{OBu}} \mathrm{Co}\right)^{-}$to generate target molecule. These monomeric species are fertile for further synthesis of dimeric vanadium complexes containing Kläui ligand via double displacement method owing to the labile nature of the solvent and chloride ligand.

Characterization. It is important to point out the physical properties of these vanadium precursors. [(CpP $\left.\left.{ }^{\mathrm{OBu}} \mathrm{Co}\right) \mathrm{VOCl}\right]_{2}$ (8), $\left(\mathrm{CpP}^{\mathrm{OBu}} \mathrm{Co}\right) \mathrm{Cl}_{2}(\mathrm{DMF})$ (9) and $\left(\mathrm{CpP}^{\mathrm{OBu}} \mathrm{Co}\right) \mathrm{VO}(\mathrm{acac})$ (10) are all oils. The appearance of $\left[\left(\mathrm{CpP}^{\mathrm{OBu}} \mathrm{Co}\right) \mathrm{VOCl}\right]_{2}(\mathbf{8})$ is brownish green; $\left(\mathrm{CpP}{ }^{\mathrm{OBu}} \mathrm{Co}\right) \mathrm{Cl}_{2}(\mathrm{DMF}) \mathbf{( 9 )}$ is dark green; $\left(\mathrm{CpP}^{\mathrm{OBu}} \mathrm{Co}\right) \mathrm{VO}(\mathrm{acac})(\mathbf{1 0})$ is light green. These compounds were heated at $200{ }^{\circ} \mathrm{C}$ for $3 \mathrm{~h}$ and remained oils. So, Energy-dispersive X-ray spectroscopy (EDS), which can help determining elements ratio, is not possible to characterize the elemental composition.

NMR Spectroscopy is also not applicable in these three complexes, because a V(IV) metal is involved in formation of these paramagnetic complexes. V(IV) has a $[\mathrm{Ar}] 3 \mathrm{~d}^{1}$ electron configuration with an unpaired electron, thus consequently resulting in paramagnetic properties. The ${ }^{1} \mathrm{H}$ NMR of $\left[\left(\mathrm{CpP}^{\mathrm{OBu}} \mathrm{Co}\right) \mathrm{VOCl}\right]_{2}(\mathbf{8})$ were shown in Figure $\mathrm{C}$, which yield wide chemical 
shift range and broadened signals. The swipe width was extended to $-50-50 \mathrm{ppm}$ and no other signals appear except the peaks corresponding to the butyl group.

IR spectroscopy is a powerful tool to analyze these precursors. Both $\left[\left(\mathrm{CpP}{ }^{\mathrm{OBu}} \mathrm{Co}\right) \mathrm{VOCl}\right]_{2}(\mathbf{8})$ and $\left(\mathrm{Cp} \mathrm{P}^{\mathrm{OBu}} \mathrm{Co}\right) \mathrm{VO}(\mathrm{acac})(\mathbf{1 0})$ have $\mathrm{V}(\mathrm{IV})$ centers. $\left[\left(\mathrm{CpP}^{\mathrm{OBu}} \mathrm{Co}\right) \mathrm{VOCl}_{2}\right.$ (8) has $\mathrm{P}=\mathrm{O}$ stretching at $1154 \mathrm{~cm}^{-1}$ and compound $\left(\mathrm{CpP}^{\mathrm{OBu}} \mathrm{Co}\right) \mathrm{VO}(\mathrm{acac})(\mathbf{1 0})$ at $1144 \mathrm{~cm}^{-1}$. As can be seen from Table 5, vanadium(IV) complexes contain methyl substituent have a highest $\mathrm{P}=\mathrm{O}$ stretching value, illustrating the weaker PO-V(IV) interaction. The complexes with butyl substitutional group with relative higher $\mathrm{P}=\mathrm{O}$ stretching value indicate the weaker $\mathrm{PO}-\mathrm{V}(\mathrm{IV})$ interaction than complexes with ethyl substitutional group. The $\mathrm{V}=\mathrm{O}$ stretching for complexes with butyl substitutional group and methyl substitutional group are similar. However, the complexes with ethyl substitutional groups showed significantly lower $\mathrm{V}=\mathrm{O}$ stretching value, which indicate the weaker $\mathrm{V}=\mathrm{O}$ bond strength. In those vanadium complexes with ethyl substitutional groups, ligands donate more electron density to the V(IV) metal center and pulled away by the oxygen. It increases electron density into antibonding orbitals and weakens the $\mathrm{V}-\mathrm{O}$ bond. That is to say, the vanadium complexes with ethyl substitutional group have stronger PO-V(IV) interaction, which is in agreement with the $\mathrm{P}=\mathrm{O}$ stretch results. 
Table 5. $\mathrm{P}=\mathrm{O}$ Stretching Frequencies of Selected Vanadium Monomer Complexes.

\begin{tabular}{cccc}
\hline Compounds & $\mathbf{P}=\mathbf{O}$ stretching $\left(\mathbf{c m}^{-\mathbf{1}}\right)$ & $\mathbf{V = O}$ stretching $\left(\mathbf{c m}^{-\mathbf{1}}\right)$ & References \\
\hline$\left[\left(\mathrm{Cp}{ }^{\mathrm{OBu}} \mathrm{Co}\right) \mathrm{VOCl}\right]_{2} \mathbf{( 8 )}$ & 1154 & 967 & $\mathrm{~A}$ \\
$\left(\mathrm{Cp}{ }^{\mathrm{OEt}} \mathrm{Co}\right) \mathrm{VOCl} \cdot \mathrm{H}_{2} \mathrm{O}$ & 1142 & 940 & $\mathrm{~A}$ \\
$\left(\mathrm{CpP}{ }^{\mathrm{OMe}} \mathrm{Co}\right) \mathrm{VOCl} \cdot \mathrm{H}_{2} \mathrm{O}$ & 1172 & 976 & $(85)$ \\
$\left(\mathrm{Cp} \mathrm{PBu}^{\mathrm{OBu}} \mathrm{Co}\right) \mathrm{VO}(\mathrm{acac})(\mathbf{1 0})$ & 1144 & 965 & $\mathrm{a}$ \\
$\left(\mathrm{Cp} \mathrm{OPEt}^{\mathrm{OE}} \mathrm{Co}\right) \mathrm{VO}(\mathrm{acac})$ & 1135 & 930 & $(97)$ \\
$\left(\mathrm{Cp} \mathrm{P}^{\mathrm{OMe}} \mathrm{Co}\right) \mathrm{VO}(\mathrm{acac})$ & 1172 & 962 & $(85)$ \\
\hline
\end{tabular}

a represent the work in this project.

The lack of $\mathrm{O}-\mathrm{H}$ stretching in IR spectrum of $\left[\left(\mathrm{CpP}{ }^{\mathrm{OBu}} \mathrm{Co}\right) \mathrm{VOCl}\right]_{2}(\mathbf{8})$ disobeys the common structure for $\left(\mathrm{CpP}^{\mathrm{OR}} \mathrm{Co}\right) \mathrm{VOCl} \cdot \mathrm{H}_{2} \mathrm{O}$, which has a water ligand to help support the structure. As discussed in Chapter II, the Kläui ligand with butyl substitutional group favors organic solvent rather than water, which is in agreement with this result. Because the solvent is aqueous methanol and there is no other ligand to participate in the reaction except Cl-ligand, thus there are two possible structures, shown in Figure 20. In Figure 20 (a), a Cl- ligand replaces the $\mathrm{H}_{2} \mathrm{O}$ molecule, which will lead to a $V(V)$ metal center rather than V(IV). Figure 20 (b) is a more reasonable dimeric structure in which the two $\mathrm{V}(\mathrm{IV})$ center were linked by $\mathrm{Cl}$ bridging, constructing a $\mathrm{V}_{2} \mathrm{Cl}_{2}$ core. Similar vanadium complexes with a $\mathrm{V}_{2} \mathrm{Cl}_{2}$ core were published before (113). 


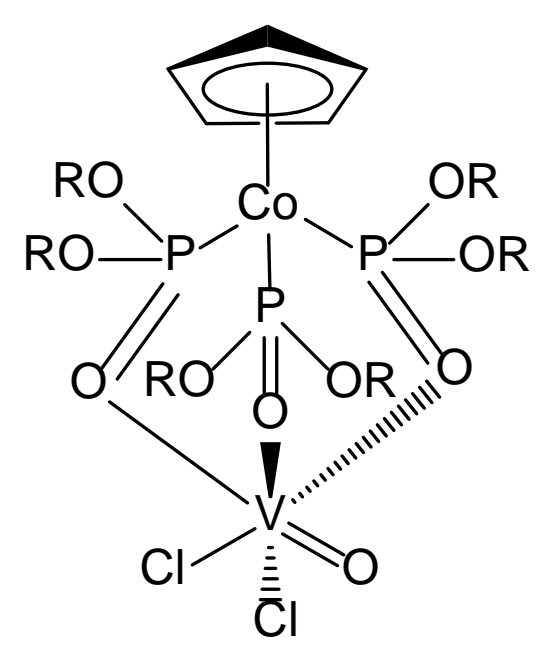

(a)

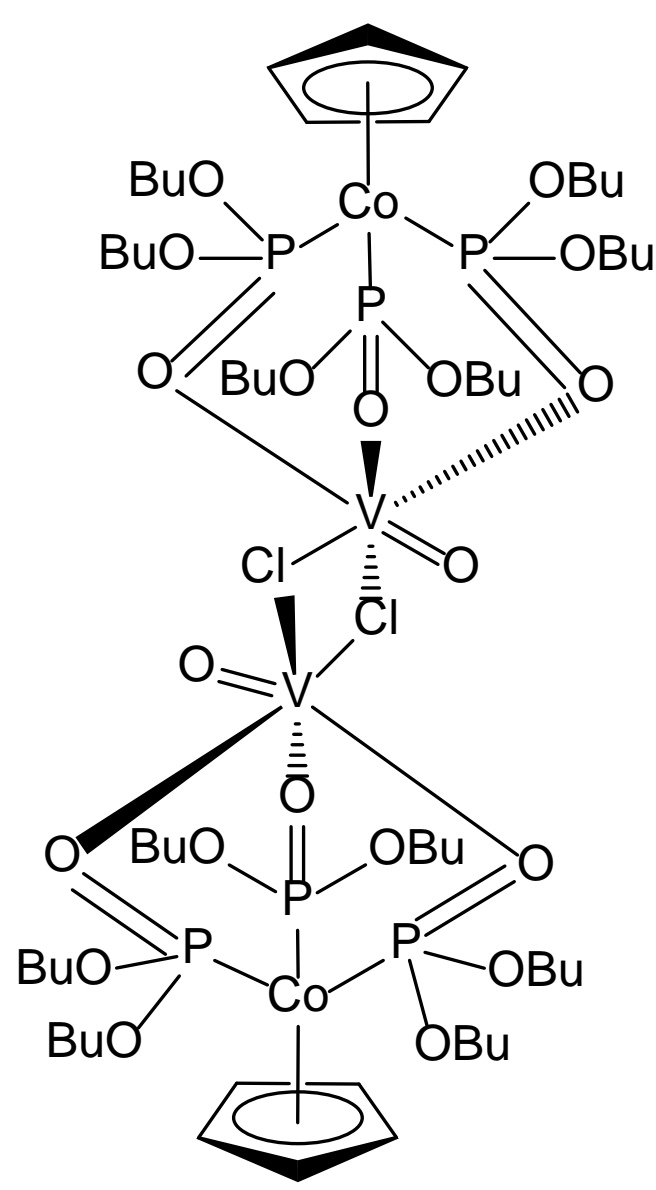

(b)

Figure 20. Possible Structures of Compound (8). (a) is vanadium(V) monomer. (b) is dimeric vanadium (IV) complex with Cl-bridge.

As for $\left(\mathrm{CpP}^{\mathrm{OBu}} \mathrm{Co}\right) \mathrm{Cl}_{2}(\mathrm{DMF})(\mathbf{9})$, it has a $\mathrm{V}(\mathrm{III})$ metal center as well as a DMF ligand binding to the metal center. The absence of $\mathrm{V}=\mathrm{O}$ stretch peaks on IR spectra prove the V(III) metal center. The $\mathrm{P}=\mathrm{O}$ stretch was barely seen in the IR spectra. Instead, a strong P-O stretch showed at 1062 $\mathrm{cm}^{-1}$. This may cause by $\mathrm{P}=\mathrm{O}-\mathrm{V}-\mathrm{O}=\mathrm{C}$ bond system which will reduce the $\mathrm{P}=\mathrm{O}$ double bond character. The similar trend also showed in $\left(\mathrm{CpP}^{\mathrm{OR}} \mathrm{Co}\right) \mathrm{Cl}_{2}(\mathrm{DMF})$ complexes with methyl and ethyl substitutional groups, as summarized in Table 6. 
Table 6. P-O Stretching Frequencies of Selected Vanadium Monomer Complexes.

\begin{tabular}{ccc}
\hline Compounds & P-O stretching $\left.\mathbf{( c m}^{-\mathbf{1}}\right)$ & References \\
\hline$\left(\mathrm{CpP}{ }^{\mathrm{OBu}} \mathrm{Co}\right) \mathrm{Cl}_{2}(\mathrm{DMF})(\mathbf{9})$ & 1062 & $\mathrm{a}$ \\
$\left(\mathrm{CpP}{ }^{\mathrm{OEt}} \mathrm{Co}\right) \mathrm{Cl}_{2}(\mathrm{DMF})$ & 1032 \\
$\left(\mathrm{Cp} \mathrm{P}^{\mathrm{OMe}} \mathrm{Co}\right) \mathrm{Cl}_{2}(\mathrm{DMF})$ & 1029
\end{tabular}

a represent the work in this project.

UV spectroscopy is another powerful tool to characterize these vanadium monomers. The electron configuration of vanadium showed that the two $2 \mathrm{p} \pi$ orbitals on oxygen can satisfy the $\pi$ bonding capacities of the two $3 \mathrm{~d}_{\pi}$ orbitals (114-116). The vanadium complexes remain as $\mathrm{V}=\mathrm{O}$, performing like $\left[\left(\mathrm{CpP}{ }^{\mathrm{OBu}} \mathrm{Co}\right) \mathrm{VOCl}\right]_{2}(\mathbf{8})$ and $\left(\mathrm{CpP}{ }^{\mathrm{OBu}} \mathrm{Co}\right) \mathrm{VO}(\mathrm{acac})(\mathbf{1 0})$. The transition metals also have the $d$ - $d$ transition property which means the electron in $d$ sub-shell is excited from one $d$ level to another. The excitation of electrons to various vibrationally excited states of the $d$-orbital electronic state results in very broad and weak signals shown around $800 \mathrm{~nm}$. This character can be detected at concentrated solution of these vanadium complexes. Figure 21 showed a representative spectrum of $d$ - $d$ transition of $\left[\left(\mathrm{CpP}{ }^{\mathrm{OBu}} \mathrm{Co}\right) \mathrm{VOCl}\right]_{2}(\mathbf{8})$. It showed a weak and broad signal at $830 \mathrm{~nm}$ in diluted solution which corresponding to $d$ - $d$ transition character of the vanadium metal center. 


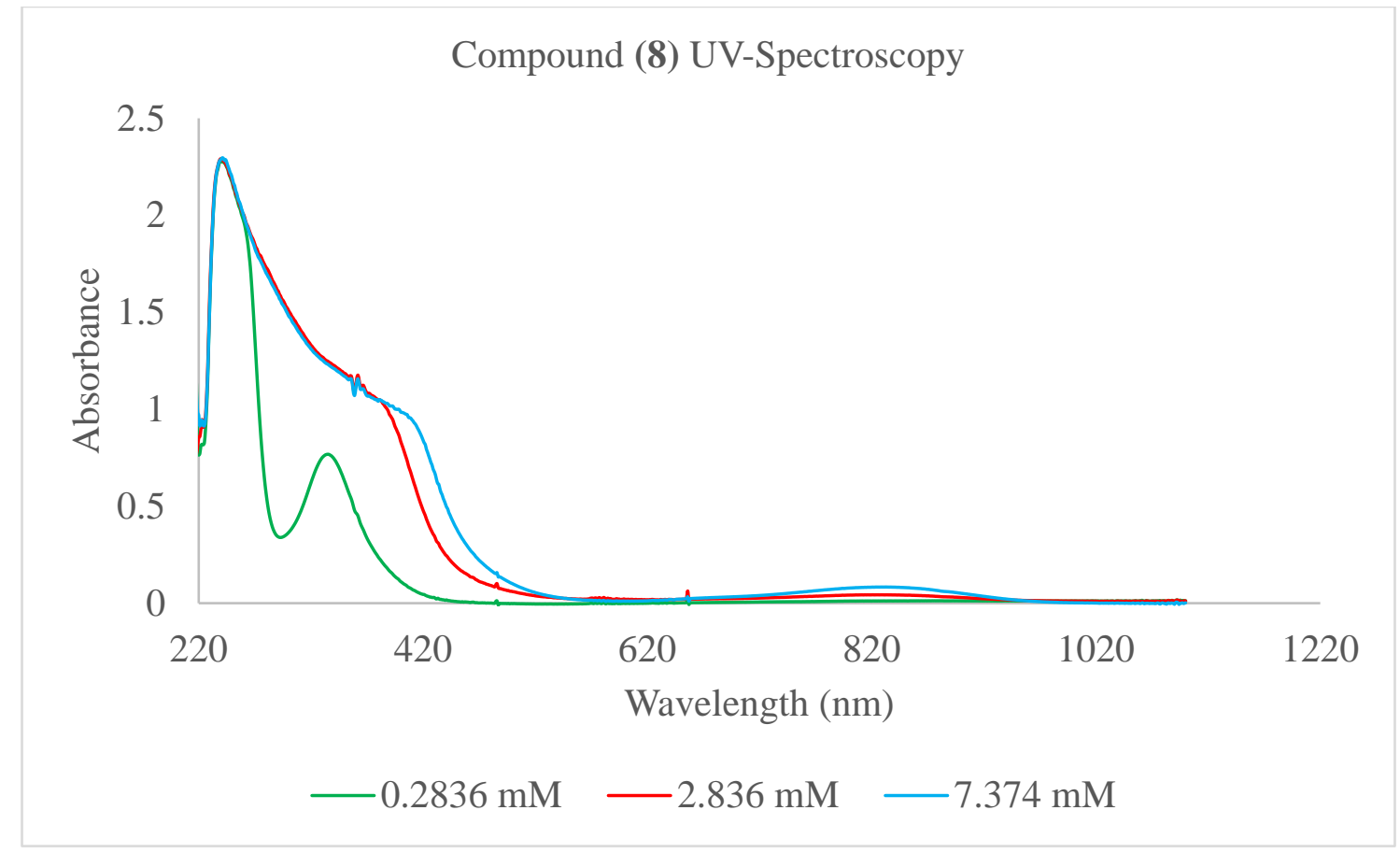

(a)

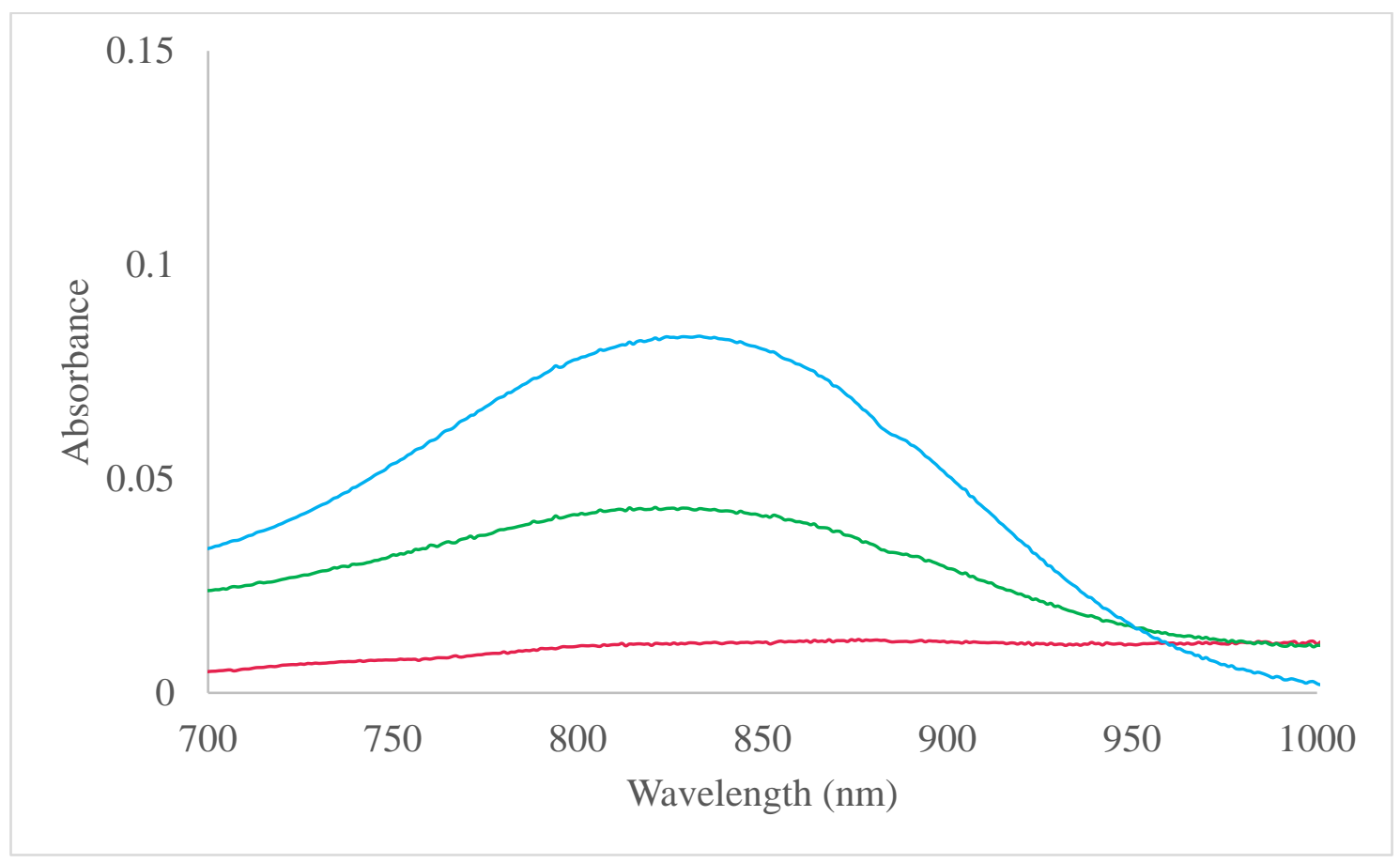

(b)

Figure 21. UV-Vis Spectra of $\left[\left(\mathrm{CpP}^{\mathrm{OBu}} \mathrm{Co}\right) \mathrm{VOCl}\right]_{2}$ (8). (a) are stack spectra with verified molarities. (b) is amplifying range between $700-1000 \mathrm{~nm}$. The solvents are $\mathrm{CHCl}_{3}$. 
The wavelength of vanadium precursors were summarized in Table 7. $\left[\left(\mathrm{CpP}{ }^{\mathrm{OBu}} \mathrm{Co}\right) \mathrm{VOCl}\right]_{2}(\mathbf{8})$ has $\lambda_{\max }$ at $244,330,833 \mathrm{~nm}$; ( $\left.\mathrm{CpP}^{\mathrm{OBu}} \mathrm{Co}\right) \mathrm{VCl}_{2}(\mathrm{DMF})(\mathbf{9})$ has $\lambda_{\max }$ at $247,332,604 \mathrm{~nm}$; (CpP $\left.{ }^{\mathrm{OBu}} \mathrm{Co}\right) \mathrm{VO}(\mathrm{acac})(\mathbf{1 0})$ has $\lambda_{\max }$ at $246,320,807 \mathrm{~nm}$. The lower $\lambda_{\max }$ value at in the range $244-$ $247 \mathrm{~nm}$ is corresponding to the $\pi-\pi^{*}$. The $\lambda_{\max }$ values of these three complexes in that range are closed, indicating that they have similar $d$-orbital splitting energy. It is noticeable that $\left[\left(\mathrm{CpP} \mathrm{PBu}^{\mathrm{Ou}} \mathrm{Co}\right) \mathrm{VOCl}\right]_{2}(\mathbf{8})$ and $\left(\mathrm{CpP} \mathrm{PBu}^{\mathrm{Ou}} \mathrm{Co}\right) \mathrm{VO}(\mathrm{acac})(\mathbf{1 0})$ have $d-d$ transition signal in $833 \mathrm{~nm}$ and $807 \mathrm{~nm}$ where as $\left(\mathrm{CpP}^{\mathrm{OBu}} \mathrm{Co}\right) \mathrm{VCl}_{2}(\mathrm{DMF})(9)$ has a broad peak at $604 \mathrm{~nm}$. This is in consistent of the different environments of vanadium in these complexes: $\left[\left(\mathrm{Cp} \mathrm{P}^{\mathrm{OBu}} \mathrm{Co}\right) \mathrm{VOCl}\right]_{2}(\mathbf{8})$ and $\left(\mathrm{CpP} \mathrm{PBu}^{\mathrm{O}} \mathrm{Co}\right) \mathrm{VO}(\mathrm{acac})$ have oxovanadium, $\mathrm{V}(\mathrm{IV})$ species, and $\left(\mathrm{CpP} \mathrm{PBu}^{\mathrm{Ou}} \mathrm{Co}\right) \mathrm{VCl}_{2}(\mathrm{DMF})$ (9) has V(III) species. In addition, the wavelength for these complexes are closed to these vanadium precursors containing methyl and ethyl substitutional groups. as shown in Table 7. 
Table 7. UV-Vis Spectra Data of Vanadium Precursors Containing the Kläui Ligand.

\begin{tabular}{|c|c|c|}
\hline Compounds & Wavelength $\lambda_{\max }(\mathbf{n m})$ & References \\
\hline$\left[\left(\mathrm{CpP}{ }^{\mathrm{OBu}} \mathrm{Co}\right) \mathrm{VOCl}_{2}(\mathbf{8})\right.$ & $244,330,833$ & $\mathrm{a}$ \\
\hline$\left(\mathrm{CpP}{ }^{\mathrm{OEt}} \mathrm{Co}\right) \mathrm{VOCl} \cdot \mathrm{H}_{2} \mathrm{O}$ & 245,333 & a \\
\hline$\left(\mathrm{CpP} \mathrm{OMe}^{\mathrm{OM}}\right) \mathrm{VOCl} \cdot \mathrm{H}_{2} \mathrm{O}$ & 331,814 & $(85)$ \\
\hline$\left(\mathrm{CpP} \mathrm{PBu}^{\mathrm{O}} \mathrm{Co}\right) \mathrm{VCl}_{2}(\mathrm{DMF})$ (9) & 247, 332, 604 & a \\
\hline$\left(\mathrm{CpP}{ }^{\mathrm{OEt}} \mathrm{Co}\right) \mathrm{VCl}_{2}(\mathrm{DMF})$ & 329 & (87) \\
\hline$\left(\mathrm{CpP} \mathrm{OMe}^{\mathrm{O}} \mathrm{Co}\right) \mathrm{VCl}_{2}(\mathrm{DMF})$ & 329 & $(85)$ \\
\hline$\left(\mathrm{CpP}{ }^{\mathrm{OBu}} \mathrm{Co}\right) \mathrm{VO}(\mathrm{acac})(\mathbf{1 0})$ & 246, 320, 807 & a \\
\hline$\left(\mathrm{CpP} \mathrm{PEt}^{\mathrm{Ot}}\right) \mathrm{VO}(\mathrm{acac})$ & 810 & (97) \\
\hline$\left(\mathrm{Cp} \mathrm{P}^{\mathrm{OMe}} \mathrm{Co}\right) \mathrm{VO}(\mathrm{acac})$ & 333,876 & (85) \\
\hline
\end{tabular}

a represent the work in this project. 


\title{
CHAPTER IV: SYNTHESIS AND CHARACTERIZATION OF SERIES \\ VANADIUM DIMERS CONTAINING THE \\ KLÄUI LIGAND (CpP $\left.{ }^{\mathrm{OBu}} \mathrm{Co}\right)^{-}$
}

\begin{abstract}
Several dinuclear vanadium complexes containing butyl substitutional Kläui ligand have been synthesized as a structural model for the industrially-used vanadium phosphate oxidation catalyst. These dimeric species contain two vanadium centers in a $\mathrm{VO}_{6}$ environment bridged by phosphate or oxalate unit. Structures were characterized through UV-Vis and IR spectrometry and discussed in this section.

\section{Introduction}

Understanding the related structure/function model is important to help characterize $\mathrm{VOPO}_{4}$ catalyst in which the mechanism how it works remains a challenge. The crystal structure of $\mathrm{VOPO}_{4}$ has a $\mathrm{VO}_{6}-\mathrm{PO}_{4}$ core, which may play the key role in catalytic activities. To get a better understanding of the $\mathrm{VOPO}_{4}$ catalyst and to create superior materials, several vanadium precursors were synthesized and introduced in Chapter III. These precursors had octahedral vanadium-ligand geometry with 6 or less oxygen binding. In this chapter, several dinuclear vanadium complexes containing butyl substitutional Kläui ligand have been synthesized. These complexes either have $\mathrm{VO}_{6}$ core or $\mathrm{VO}_{6}-\mathrm{PO}_{4}$ core.
\end{abstract}




\section{Experimental}

General considerations. All experiments were performed under ambient temperature. Reagent grade $\mathrm{CH}_{2} \mathrm{Cl}_{2}$ (Fisher, 99.9\%), methanol (Fisher, 99.9\%) was used as received without further purification. $\mathrm{Na}_{2} \mathrm{C}_{2} \mathrm{O}_{4}$ (Acros, 98.5\%) , $\mathrm{K}_{2} \mathrm{CO}_{3}$ (Fisher, 99\%) and Diphenyl phosphate (Aldrich, 99\%) were used as received.

(CpP $\left.{ }^{\mathrm{OBu}} \mathrm{Co}\right)_{2}[\boldsymbol{\mu}-\mathbf{o x}] \mathrm{V}_{2} \mathrm{O}_{2}$ (11). Compound (8) (0.409 g, $\left.0.64 \mathrm{mmol}\right)$ was weighed and dissolved in $15 \mathrm{~mL}$ aqueous methanol (50:50). $\mathrm{Na}_{2} \mathrm{C}_{2} \mathrm{O}_{4}(0.543 \mathrm{~g}, 0.41 \mathrm{mml})$ was dissolved in $10 \mathrm{~mL}$ water. The two solutions were mixed together and stirred for $24 \mathrm{~h}$. The solution become white/yellow cloudy and then clear with some green oil on the bottom. The mixture was extracted by $\mathrm{CH}_{2} \mathrm{Cl}_{2}$. The $\mathrm{CH}_{2} \mathrm{Cl}_{2}$ layer was collected and reduced to dryness. The product was dried under vacuum for several days and yielded olive green oil (0.670 g, 81\%). IR( $\left.\mathrm{cm}^{-1}, \mathrm{KBr}\right): 2958$ s, 2874 m, 1656 m, 1465 m, 1427 w, 1379 m, 1297 w, 1231 w, 1157 s, 1066 vs, 1025 vs, 970 vs, 885 s, 833 s, 784 m, $720 \mathrm{~m}$.

$\left[\left(\mathbf{C p P}{ }^{\mathrm{OBu}} \mathbf{C o}\right) \mathbf{V}(\mathbf{O})\left(\boldsymbol{\mu}-\mathbf{O}_{2} \mathbf{P P h}_{2}\right)\right]_{2}$ (12). Compound (9) (0.047 g, $\left.0.065 \mathrm{mmol}\right)$ was weighed and dissolved in $10 \mathrm{~mL} \mathrm{CH} \mathrm{Cl}_{2}$. Diphenyl phosphate (0. $023 \mathrm{~g}, 0.092 \mathrm{mmol}$ ) was dissolve in $2 \mathrm{ml}$ water and added to the solution. The mixture was heated and stirred for $24 \mathrm{~h}$. The resulting solution was gravity filtered and the reduced solvent. The product was dried under vacuum for several days and yield olive green oil (0.082 g, 77\%). IR(cm-1, KBr): 2959 s, 2873 m, 1592 m, 1490 m, 1397 m, 1270 w, 1205 m, 1087 s, 1027 s, 948 vs, 777 m, 720 w.

\section{Results and Discussion}

Syntheses. There are several ways to synthesize the dinuclear vanadium complexes containing Kläui ligand with phosph(in/on)ate bridging. One way is using V(III) precursors as starting material according to Anderson (84), shown in Scheme 6. Another way is using V(IV) precursors 
as starting material, according to Riart-Ferrer (85). During the synthesis of dimeric vanadium complexes, both ways were tried. The dinuclear vanadium complex with an oxalate bridging was synthesized by employing V(IV) species complex (8), shown in Scheme 11 (right). The dinuclear vanadium complexes with various phosphate bridging were tried few times employing V(IV) species as starting material. The reaction conditions were varied during the attempts. The first attempt was using aqueous methanol as the solvent to synthesize Scheme 11 (a, b), by employing diphenylphosphinic salt or phenylphosphinic salt. Neither reactions succeed. The dissolution process was slow, indicating that the solvent may not be the best choice leading to the failure of the synthesis. The second attempt used acetonitrile as the solvent by employing phenylphosphonic salt, which was reported before by Carrano and his co-workers (64). However, the reaction pathway failed. During these attempts, the initial strategy was to make the phenylphosphinic or phenylphosphonic salt by adding $\mathrm{K}_{2} \mathrm{CO}_{3}$, which can react with complex (8) and result in the formation of dimer. The failure could result from the use of Kläui ligand with butyl substitutional group, which was less reactive. The use of acetonitrile as solvent was not helpful for the reaction. Another possibility could be that the dimeric structure of compound (8), as shown in Figure 20, is bulky and makes the compound (8) less reactive. However, the reaction using complex (8) as starting material and oxalate ligand as bridge was achieved. The oxalate ligand is a small bidentate ligand which has two lone pairs can donate to the metal center and form a planer geometry. Thus, it has the ability to transmit efficiently magnetic interactions through its bridging mode, which is more suitable for the dimerization, according to Dridi (117), Modec (118), Sehimi (119). 
Scheme 11. Synthesis Scheme of $\left(\mathrm{CpP} \mathrm{OBu}^{\mathrm{O}} \mathrm{Co}\right)_{2}[\mu-\mathrm{ox}] \mathrm{V}_{2} \mathrm{O}_{2}$ (11).

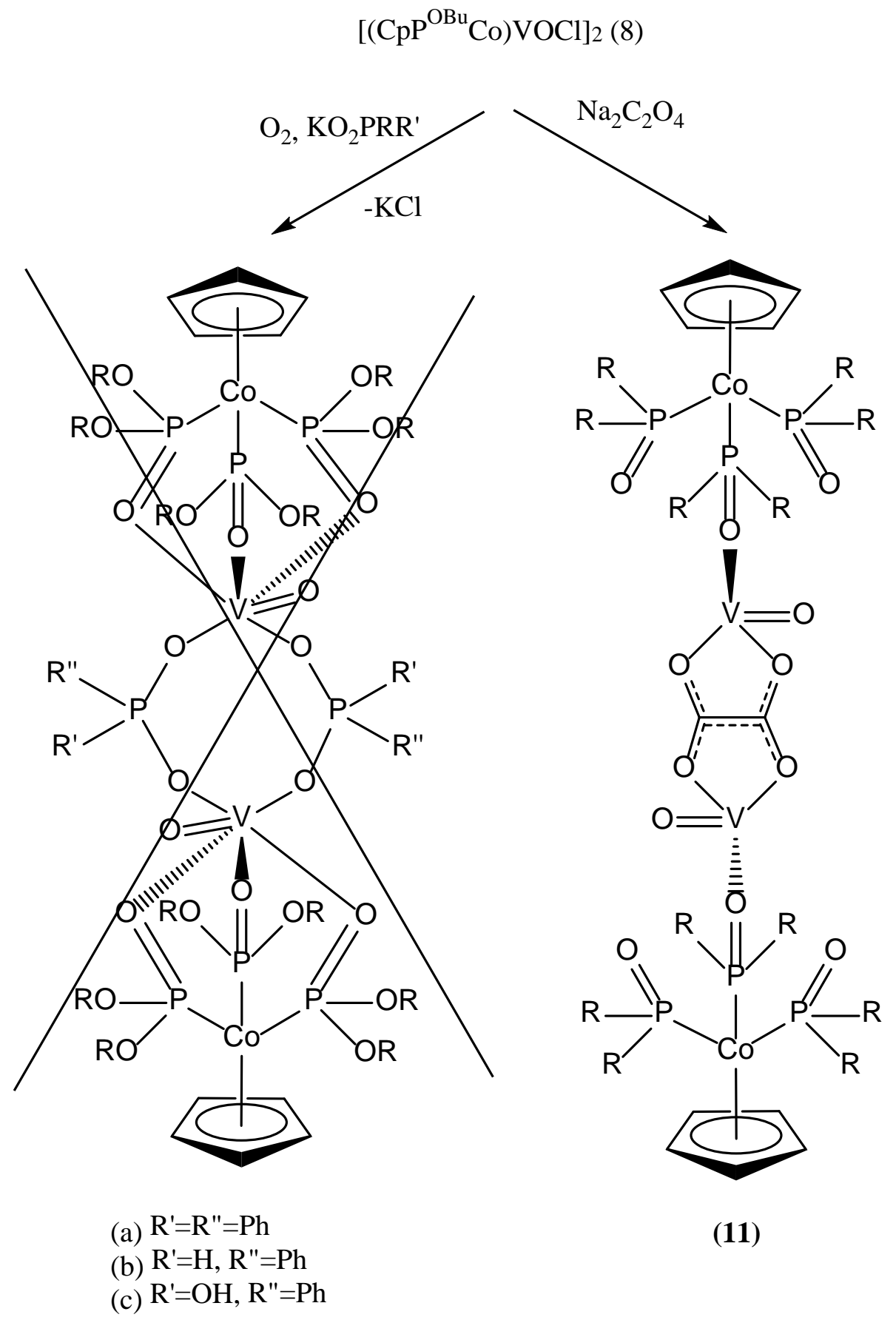

Except those attempts mentioned above, another attempt was using compound (9) as the starting material, acetonitrile as solvent and adding diphenyl phosphate directly with heating. This strategy worked and produced compound (12), shown in Scheme 12. Compound (9), with a V(III) metal 
center, which is more active than V(IV) species and showed significant difference properties in UV-Vis and IR spectroscopy in which showed more $\mathrm{P}-\mathrm{O}$ single bond stretching property rather than $\mathrm{P}=\mathrm{O}$ stretching.

Scheme 12. Synthesis Scheme of $\left[\left(\mathrm{CpP}^{\mathrm{OBu}} \mathrm{Co}\right) \mathrm{V}(\mathrm{O})\left(\mu-\mathrm{O}_{2} \mathrm{PPh}_{2}\right)\right]_{2}$ (12).

$\left(\mathrm{CpP}^{\mathrm{OBu}} \mathrm{Co}\right) \mathrm{VCl}_{2} \mathrm{DMF}$ (8)

Diphenyl phosphate

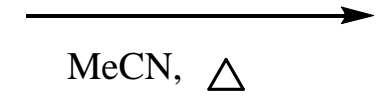

$\mathrm{R}=\mathrm{Bu}$



(12)

Characterization. IR is the most powerful tool to characterize dimeric vanadium complexes containing Kläui ligand. The signal at around $1654 \mathrm{~cm}^{-1}$ proves the synthesis of oxalate bridging dimer. Compared to the IR spectra of $\mathrm{Na}_{2} \mathrm{C}_{2} \mathrm{O}_{4}$, which has a much broader peak at this region, the narrower peak for $\left(\mathrm{CpP}^{\mathrm{OBu}} \mathrm{Co}\right)_{2}\left[\mu-\mathrm{Ox}_{2}\right] \mathrm{V}_{2} \mathrm{O}_{2}$ (11) is due to the formation of oxalate bridge between 
two vanadium-Kläui ligand moieties. It reduced the rotational transition of oxalate ion, shown in Figure 22.

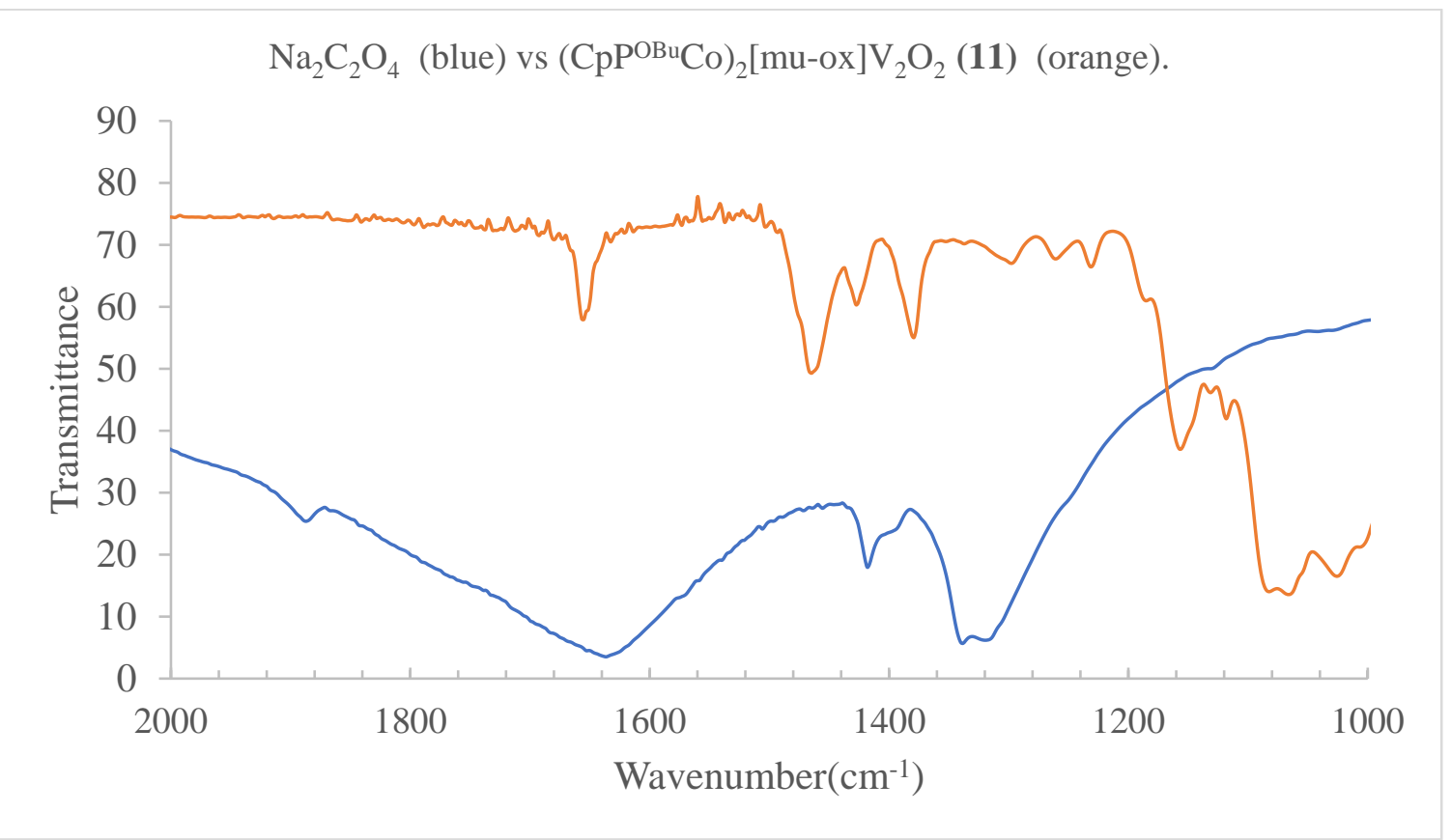

Figure 22. The Overlay IR Spectra of $\mathrm{Na}_{2} \mathrm{C}_{2} \mathrm{O}_{4}$ and $\left(\mathrm{CpP}{ }^{\mathrm{OBu}} \mathrm{Co}\right)_{2}[\mu-\mathrm{ox}] \mathrm{V}_{2} \mathrm{O}_{2}$ (11). The spectra are stack together for comparison. The Transmittance is not in real scale.

The IR data of vanadium dimeric complexes with oxalate bridge were summarized in Table 8. The $\mathrm{P}=\mathrm{O}$ stretching of $\left(\mathrm{CpP} \mathrm{PBu}^{\mathrm{O}} \mathrm{Co}\right)_{2}[\mu-\mathrm{ox}] \mathrm{V}_{2} \mathrm{O}_{2}$ (11) is at $1157 \mathrm{~cm}^{-1}$. It is higher than the $\mathrm{P}=\mathrm{O}$ stretching of $\left(\mathrm{CpP}{ }^{\mathrm{OEt}} \mathrm{Co}\right)_{2}[\mu-\mathrm{ox}] \mathrm{V}_{2} \mathrm{O}_{2}$ and lower than $\left(\mathrm{CpP}^{\mathrm{OMe}} \mathrm{Co}\right)_{2}[\mathrm{mu}-\mathrm{ox}] \mathrm{V}_{2} \mathrm{O}_{2}$. The $\mathrm{PO}-\mathrm{V}$ bond strength is in rank: $\left(\mathrm{CpP}{ }^{\mathrm{OMe}} \mathrm{Co}\right)_{2}[\mu-\mathrm{ox}] \mathrm{V}_{2} \mathrm{O}_{2}<\left(\mathrm{CpP}^{\mathrm{OBu}} \mathrm{Co}\right)_{2}[\mu-\mathrm{ox}] \mathrm{V}_{2} \mathrm{O}_{2}(\mathbf{1 1})<\left(\mathrm{CpP}{ }^{\mathrm{OEt}} \mathrm{Co}\right)_{2}[\mu-$ $\mathrm{ox}] \mathrm{V}_{2} \mathrm{O}_{2}$, which in consistent with the tendency of IR spectra in complex (8). The $\mathrm{V}=\mathrm{O}$ stretching with varying substitutional $\mathrm{R}$ groups show that $\left(\mathrm{CpP}{ }^{\mathrm{OMe}} \mathrm{Co}\right)_{2}[\mu-\mathrm{ox}] \mathrm{V}_{2} \mathrm{O}_{2}<\left(\mathrm{CpP}{ }^{\mathrm{OBu}} \mathrm{Co}\right)_{2}[\mu-$ $\mathrm{ox}] \mathrm{V}_{2} \mathrm{O}_{2}(\mathbf{1 1})<\left(\mathrm{CpP}{ }^{\mathrm{OEt}} \mathrm{Co}\right)_{2}[\mu-\mathrm{ox}] \mathrm{V}_{2} \mathrm{O}_{2}$, which in agreement with $\mathrm{P}=\mathrm{O}$ stretching consequence and in consistent with the tendency of IR spectroscopy performance in complex (8), too. 
Table 8. $\mathrm{P}=\mathrm{O}$ Stretching and $\mathrm{V}=\mathrm{O}$ Stretching Frequencies of Selected Vanadium Dimeric Complexes with Oxalate Bridge.

\begin{tabular}{cccc}
\hline Compounds & $\mathbf{P}=\mathbf{O}$ stretching $\left(\mathbf{c m}^{-\mathbf{1}}\right)$ & $\mathbf{V}=\mathbf{O}$ stretching $\left.\mathbf{( c m}^{\mathbf{- 1}}\right)$ & References \\
\hline Compound (11) & 1157 & 970 & $\mathrm{a}$ \\
$\left(\mathrm{CpP}{ }^{\mathrm{OEt}} \mathrm{Co}\right)_{2}[\mu-\mathrm{ox}] \mathrm{V}_{2} \mathrm{O}_{2}$ & 1129 & 977 & $(120)$ \\
$\left(\mathrm{CpP}{ }^{\mathrm{OMe}} \mathrm{Co}\right)_{2}[\mu-\mathrm{ox}] \mathrm{V}_{2} \mathrm{O}_{2}$ & 1174 & 968 & $(86)$ \\
\hline
\end{tabular}

a represent the work in this project.

As for $\left[\left(\mathrm{CpP}^{\mathrm{OBu}} \mathrm{Co}\right) \mathrm{V}(\mathrm{O})\left(\mu-\mathrm{O}_{2} \mathrm{PPh}_{2}\right)\right]_{2}(\mathbf{1 2})$, it lacks a strong $\mathrm{P}=\mathrm{O}$ stretch peaks showed at 1270 $\mathrm{cm}^{-1}$ in diphenyl phosphate ligand, which confirmed the formation of phosphate- bridge between the two vanadium-Kläui moieties, shown in Figure 23.

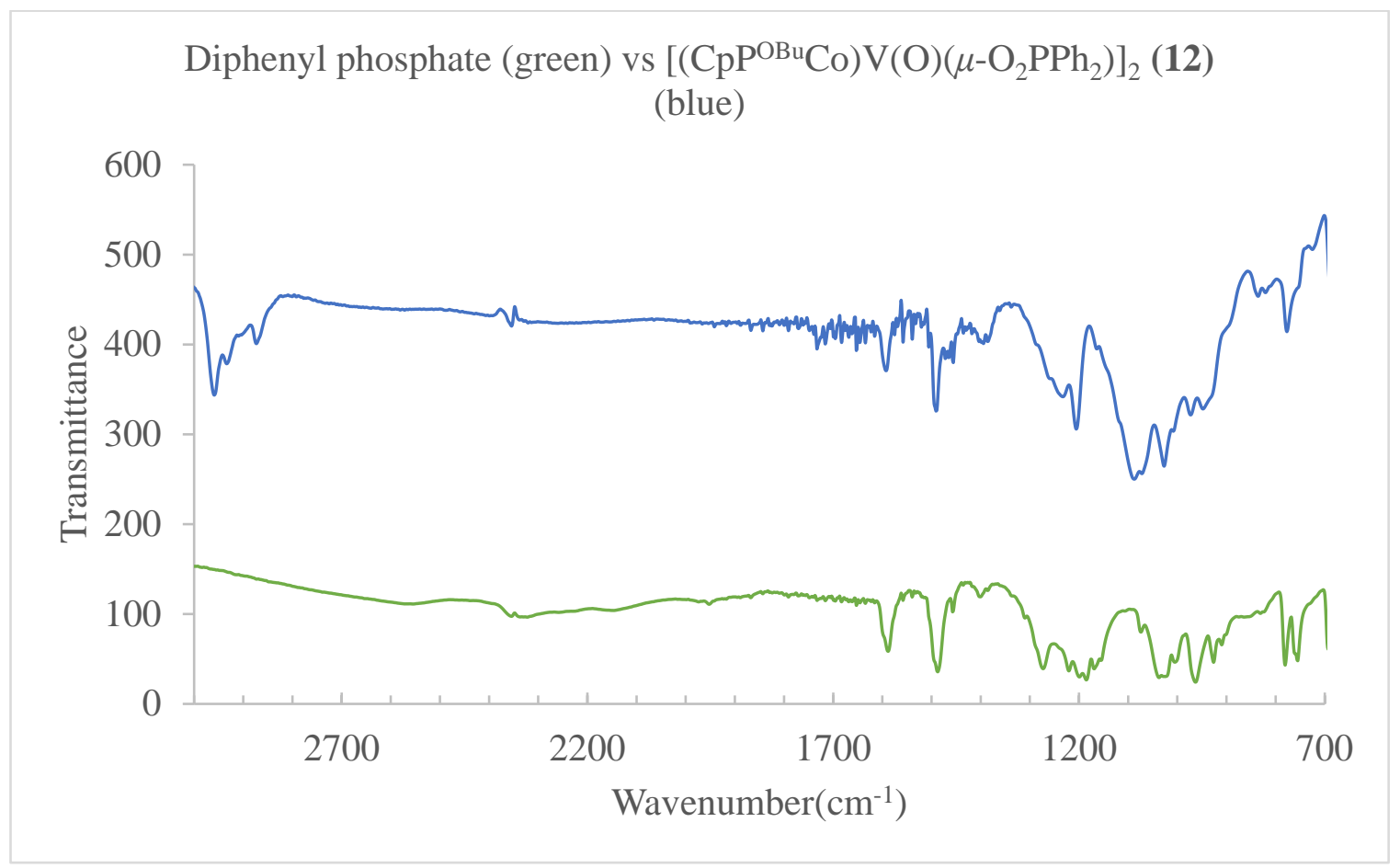

Figure 23. The Overlay IR Spectra of Diphenyl Phosphate (green) and $\left[\left(\mathrm{CpP}^{\mathrm{OBu}} \mathrm{Co}\right) \mathrm{V}(\mathrm{O})(\mu\right.$ $\left.\mathrm{O}_{2} \mathrm{PPh}_{2}\right)_{2}$ (12) (blue) Showed at $700-3000 \mathrm{~cm}^{-1}$ Range. The spectra are stack together for comparison. The transmittance is not in real scale. 


\title{
CHAPTER V: OXIDATIVE CATALYTIC ACTIVITY OF SERIES
}

\author{
VANADIUM COMPLEXES CONTAINING \\ THE KLÄUI LIGAND (CpP $\left.{ }^{\mathrm{OBu}} \mathrm{CO}\right)^{-}$
}

\begin{abstract}
The oxidative catalytic activity of series of vanadium complexes bearing Kläui ligand $\left(\mathrm{CpP} \mathrm{OBu}^{\mathrm{OB}}\right)^{-}$were examined via the oxidation of 3,5-di-tert-butylcatechol(3,5-DTBC) to 3,5-ditert-butyl-o-benzoquinone(3,5-DTBQ) with $\mathrm{H}_{2} \mathrm{O}_{2}$ in acetonitrile. Overall, these vanadium complexes showed the greatactivities.

\section{Introduction}

Vanadium oxidation catalysis is the driving force behind the mass production of many compounds vital to industry, including sulfuric acid and several industrial useful anhydrides (121). Well-characterized oxovanadium(IV) and peroxovanadium(V) complexes have been proven to be effective in the epoxidation of olefins and aromatic hydrocarbons (122). These complexes have well-understood crystal structures, but the catalytic mechanisms are difficult to characterize, so need better understanding of their properties and reactivities for the purpose of designing more active and longer lasting catalysts. One way to explore the catalytic properties of these complexes is to synthesize similar molecular analogs by dimensional reduction (54-56). If the model synthesized has similar geometry and electronic environments around those of the original catalyst, thus potentially increase catalytic activity by using several series of different ligands.
\end{abstract}


$\mathrm{VOPO}_{4}$ is a well-known catalyst that exhibits an octahedral $\mathrm{VO}_{6}$ lattice crystal structure with a periodic mixture of $\mathrm{V}(\mathrm{IV}) / \mathrm{V}(\mathrm{V})$ redox centers. To model the local environments around the V(IV) centers in $\mathrm{VOPO}_{4}$, a series of vanadium complexes were synthesized with a capping tridentate $\left(\mathrm{CpP}{ }^{\mathrm{OBu}} \mathrm{Co}\right)^{-}$ligand and bridged by several different sets of phosphonate ligands. To model the catalytic activities, a reaction model was used to test their activity in the catalytic oxidation of 3,5DTBC to 3,5-DTBQ, shown in Scheme 7.

\section{Experimental}

General considerations. Reagent grade acetonitrile (Fisher, $99.9 \%$ ) was used as received. 3,5di-tert-butylcatechol(3,5-DTBC) (Acros, 99\%) and 3,5-di-tert-butyl-o-benzoquinone(3,5-DTBQ) (Acros, 98\%) were used without purification. All experiments were performed using an Agilent 8453 Ultraviolet/Visible spectrometer, in acetonitrile at room temperature in sealed glass cuvettes.

Calibration. The calibration experiment was performed by making diluted solutions of 3,5DTBQ (0.09 mM-0.9 mM). 3,5-DTBQ has a strong absorbance at $398 \mathrm{~nm}$, so absorbance at this wavelength was used for quantification. The calibration curve was plotted in Excel and autofitted, shown in Figure 24. 


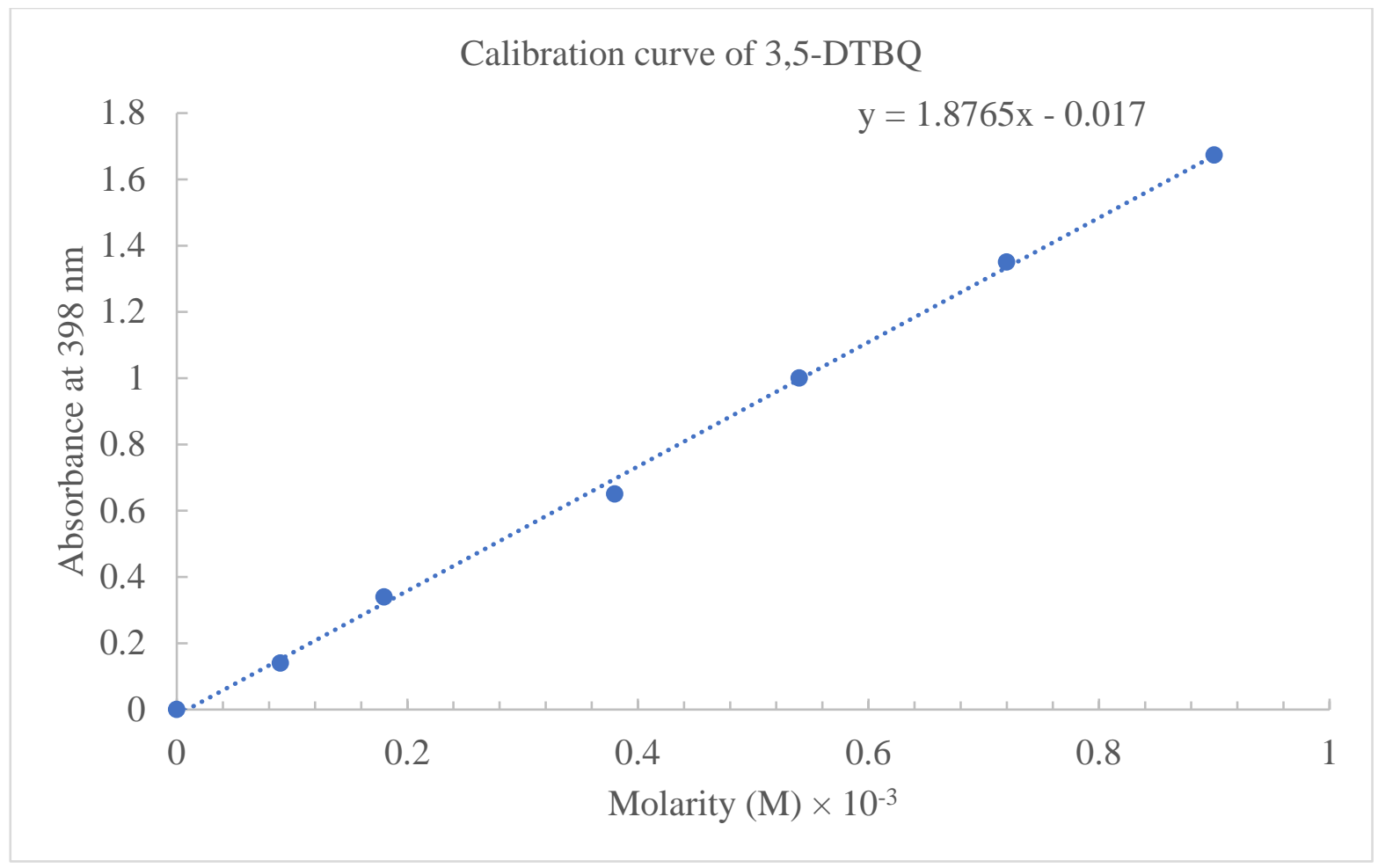

Figure 24. Calibration Curve of 3,5-DTBQ.

Catalytic activity. Each reaction was monitored for $30 \mathrm{~min}$ for parallel measurements. In each case, $1 \mathrm{~mol} \%$ catalyst was added to a light brown solution of 3,5-DTBC (4.98 mM), along with 1 equivalent of $\mathrm{H}_{2} \mathrm{O}_{2}$ in acetonitrile and quickly transferred to a sealed glass cuvette then seated in the spectrometer. Typically, the solution of the mixture began as a very light brown color and gradually turned to a dark yellow color as the 3,5-DTBQ concentration increase.

\section{Result and Discussion}

These vanadium complexes performed as good catalysts for the reaction showed in Scheme 7. A representative comparison of the catalytic activity is shown in Figure 25, by employing compound (10) as catalyst. The reaction was set at $30 \mathrm{~min}$ as the monitoring time. Without the catalyst, the oxidation reaction still works, but much more slowly. By adding catalyst, the reaction rate went 9.5 times faster, which showed significant improvement of the reaction rate. 


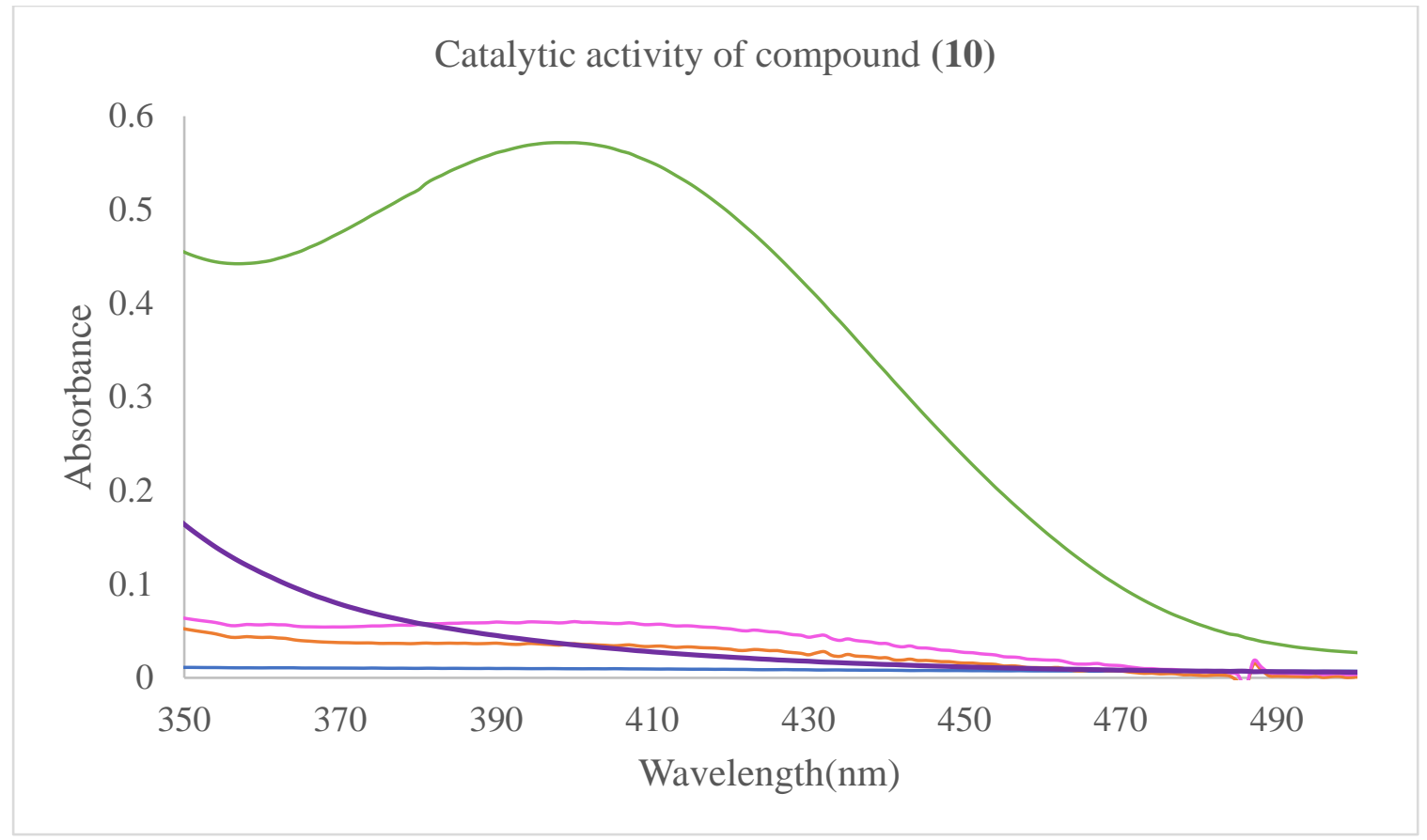

Figure 25. The Absorbance of the Product 3,5-DTBQ Formation Shown at Different Conditions. The catalyst employed is compound (10). Blue is only $5.0 \mathrm{mM} 3,5-\mathrm{DTBC}$ at $2 \mathrm{~min}$; orange is 5.0 $\mathrm{mM} \mathrm{3,5-DTBC}+5.0 \mathrm{mM} \mathrm{H}_{2} \mathrm{O}_{2}$ at 2 min; magenta is $5.0 \mathrm{mM} \mathrm{3,5-DTBC}+5.0 \mathrm{mM} \mathrm{H}_{2} \mathrm{O}_{2}$ at 30 min; purple is 3,5-DTBC $+5.0 \mathrm{mM} \mathrm{H} \mathrm{H}_{2}+$ compound (10) at $2 \mathrm{~min}$; green is 3,5-DTBC +5.0 $\mathrm{mM} \mathrm{H}_{2} \mathrm{O}_{2}+$ compound (10) at 30 min. The catalysis reaction model is shown in Scheme 7.

The catalytic activities of all three vanadium precursors (8), (9) and (10) were performed, shown in Table 9. The ( $\left.\mathrm{CpP}^{\mathrm{OBu}} \mathrm{Co}\right) \mathrm{VCl}_{2}(\mathrm{DMF})$ (9) showed significantly high $\mathrm{TOF}$, that is due to the oxidation of the compound (9) which yields a V(IV) species. The oxidation of compound (9) is confirmed by IR spectroscopy in which the $\mathrm{V}=\mathrm{O}$ double bond stretch showed on $970 \mathrm{~cm}^{-1}$. The $\left(\mathrm{CpP}{ }^{\mathrm{OBu}} \mathrm{Co}\right) \mathrm{VO}(\mathrm{acac})$ (10) and $\left(\mathrm{CpP}^{\mathrm{OBu}} \mathrm{Co}\right)_{2}[\mu-\mathrm{ox}] \mathrm{V}_{2} \mathrm{O}_{2}$ (11) did not show good catalytic activities. The reason may be the conjugated acetylacetonate ligand or oxalate ligand, which stabilize the metal-ligand coordination but make the complexes less reactive. $\left[\left(\mathrm{CpP}^{\mathrm{OBu}} \mathrm{Co}\right) \mathrm{V}(\mathrm{O})(\mu-\right.$ $\left.\left.\mathrm{O}_{2} \mathrm{PPh}_{2}\right)\right]_{2}$ (12) showed extremely high catalytic ability compared to other compounds. One possible reason is due to the $\mathrm{VO}_{6}-\mathrm{PO}_{4}$ core in the bridge dimer and it is in agreement with the 
structure of $\mathrm{VO}_{6}-\mathrm{PO}_{4}$ shown in $\mathrm{VOPO}_{4}$ catalyst. Another reason is that there may exist two reaction cores in the dimer because of the two V(IV) centers. However, the mechanism is still poorly understood.

Furthermore, the catalytic activity of dimeric complexes $\left[\left(\mathrm{CpP}{ }^{\mathrm{OBu}} \mathrm{Co}\right) \mathrm{V}(\mathrm{O})\left(\mu-\mathrm{O}_{2} \mathrm{PPh}_{2}\right)\right]_{2}$ (12) was compared to other two complex used methyl and ethyl Kläui ligand $\left[\left(\mathrm{CpP}^{\mathrm{OMe}} \mathrm{Co}\right) \mathrm{V}(\mathrm{O})(\mu\right.$ $\left.\left.\mathrm{O}_{2} \mathrm{PPh}_{2}\right)\right]_{2}$ and $\left[\left(\mathrm{CpP}^{\mathrm{OEt}} \mathrm{Co}\right) \mathrm{V}(\mathrm{O})\left(\mu-\mathrm{O}_{2} \mathrm{PPh}\right)\right]_{2}$. The $\left[\left(\mathrm{CpP}{ }^{\mathrm{OBu}} \mathrm{Co}\right) \mathrm{V}(\mathrm{O})\left(\mu-\mathrm{O}_{2} \mathrm{PPh}_{2}\right)\right]_{2}$ (12) showed significant improvement of the catalytic ability. It illustrates that vanadium complexes with butyl Kläui ligand are superior than vanadium complexes with methyl and ethyl Kläui ligand.

Briefly, our vanadium complexes are all both structural models and functional models. The $\left[\left(\mathrm{CpP}{ }^{\mathrm{OBu}} \mathrm{Co}\right) \mathrm{V}(\mathrm{O})\left(\mu-\mathrm{O}_{2} \mathrm{PPh}_{2}\right)\right]_{2}$ (12) showed superior catalytic ability compare to oxalate bridging dimer and vanadium monomers. However, it does not mean other monomer catalysts are not good. The preparation method for dimeric vanadium complexes are much harder than monomers. 
Table 9. Turnover Frequencies (TOF) of Product by Employing Vanadium Precursors and Vanadium Dimers Containing the Kläui Ligand as Catalysts.

\begin{tabular}{ccc}
\hline Compounds & $\mathbf{T O F}\left(\mathbf{h}^{-\mathbf{1}}\right)$ & References \\
\hline$\left[\left(\mathrm{CpP}{ }^{\mathrm{OBu}} \mathrm{Co}\right) \mathrm{VOCl}\right]_{2}(\mathbf{8})$ & 70.0 & $\mathrm{a}$ \\
$\left(\mathrm{CpP}{ }^{\mathrm{OBu}} \mathrm{Co}\right) \mathrm{VCl}_{2}(\mathrm{DMF})(\mathbf{9})$ & 196.7 & $\mathrm{a}$ \\
$\left(\mathrm{CpP}{ }^{\mathrm{OBu}} \mathrm{Co}\right) \mathrm{VO}(\mathrm{acac})(\mathbf{1 0})$ & 62.6 & $\mathrm{a}$ \\
$\left(\mathrm{CpP}{ }^{\mathrm{OBu}} \mathrm{Co}\right){ }_{2}[\mu-\mathrm{Ox}] \mathrm{V}_{2} \mathrm{O}_{2}(\mathbf{1 1})$ & 66.3 & $(123)$ \\
{$\left[\left(\mathrm{CpP}{ }^{\mathrm{OMe}} \mathrm{Co}\right) \mathrm{V}(\mathrm{O})\left(\mu-\mathrm{O}_{2} \mathrm{PPh}_{2}\right)\right]_{2}$} & 34.5 & $(123)$ \\
{$\left[\left(\mathrm{CpP}{ }^{\mathrm{OEt}} \mathrm{Co}\right) \mathrm{V}(\mathrm{O})\left(\mu-\mathrm{O}_{2} \mathrm{PPh}_{2}\right)\right]_{2}$} & 66.1 & $\mathrm{a}$ \\
{$\left[\left(\mathrm{CpP}{ }^{\mathrm{OBu}} \mathrm{Co}\right) \mathrm{V}(\mathrm{O})\left(\mu-\mathrm{O}_{2} \mathrm{PPh}_{2}\right)\right]_{2}(\mathbf{1 2})$} & 263.7 &
\end{tabular}

a represent the work in this project.

\section{Conclusion}

The butyl Kläui ligand is a new type ligand to us which showed similarities but also significant differences comparing to the methyl and the ethyl Kläui ligand. Several supersandwich complexes were synthesized and characterized to study the properties of metal-ligand coordination with the butyl Kläui ligand. In addition, three vanadium monomers as precursors and another two dimeric bridging complexes were synthesized and characterized. The catalytic activities of those complexes were studied and all showed great catalytic activities of the oxidation reaction of catechol.

\section{Future Works}

The crystallization work is challenge and remains further study. Synthesis of the series of vanadium dimers employing other phosph(on/in)ate bridging should be continued. The catalytic activities of the vanadium(IV) dimers should be further studied to confirm the functional model of 
$\mathrm{VOPO}_{4}$. The mechanism of catalytic activities of these vanadium monomers and dimers will be explored. 


\section{REFERENCES}

(1) Michibata, H.; Yamaguchi, N.; Uyama, T.; Ueki, T. Coord. Chem. Rev. 2003, 237(1), 41-51.

(2) Thompson, K. H.; McNeill, J. H.; Orvig, C. Chem. Rev. 1999, 99(9), 2561-2572.

(3) Crans, D. C.; Tarlton, M. L.; McLauchlan, C. C. Eur. J. Inorg. Chem. 2014, 2014(27), 44504468.

(4) McLauchlan, C. C.; Peters, B. J.; Willsky, G. R.; Crans, D. C. Coord. Chem. Rev. 2015, 301, 163-199.

(5) Crans, D. C.; Peters, B. J.; Wu, X.; McLauchlan, C. C. Coord. Chem. Rev. 2017, 344, 115130.

(6) Crans, D. C.; Smee, J. J.; Gaidamauskas, E.; Yang, L. Chem. Rev. 2004, 104(2), 849-902.

(7) Peters, K. G.; Davis, M. G.; Howard, B. W.; Pokross, M.; Rastogi, V.; Diven, C.; Greis, K. D.; Eby-Wilkens, E.; Maier, M.; Evdokimov, A. J. Inorg. Biochem. 2003, 96(2-3), 321-330.

(8) Wu, X.; Peters, B. J.; Rithner, C. D.; Crans, D. C. Polyhedron 2016, 114, 325-332.

(9) Khodakov, A.; Olthof, B.; Bell, A. T.; Iglesia, E. J. Catal. 1999, 181(2), 205-216.

(10) Mars, P.; Van Krevelen, D. W. Chem. Eng. Sci. 1954, 3, 41-59.

(11) Willsky, G. R.; Chi, L.-H.; Godzala III, M.; Kostyniak, P. J.; Smee, J. J.; Trujillo, A. M.; Alfano, J. A.; Ding, W.; Hu, Z.; Crans, D. C. Coord. Chem. Rev. 2011, 255(19-20), 2258-2269.

(12) Blasco, T.; Nieto, J. L. Appl. Catal., A 1997, 157(1-2), 117-142.

(13) Zhang, Q.; Wang, Y.; Ohishi, Y.; Shishido, T.; Takehira, K. J. Catal. 2001, 202(2), 308-318.

(14) Mizuno, N.; Kamata, K. Coord. Chem. Rev. 2011, 255(19-20), 2358-2370.

(15) Podgoršek, A.; Zupan, M.; Iskra, J. Angew. Chem. Int. Ed. 2009, 48(45), 8424-8450.

(16) Reis, P. M.; Armando, J.; Silva, L.; Fraústo da Silva, J. J.; Pombeiro, A. J. Chem. Commun. 2000, 20, 1845-1846. 
(17) Xia, J.-B.; Ma, Y.; Chen, C. Org. Chem. Front. 2014, 1(5), 468-472.

(18) Silva, T. F.; Luzyanin, K. V.; Kirillova, M. V.; Da Silva, M. F. G.; Martins, L. M.; Pombeiro, A. J. Adv. Synth. Catal. 2010, 352(1), 171-187.

(19) Reis, P. M.; Silva, J. A.; Palavra, A. F.; Fraústo da Silva, J. J.; Kitamura, T.; Fujiwara, Y.; Pombeiro, A. J. Angew. Chem. 2003, 115(7), 845-847.

(20) Kirillova, M. V.; da Silva, J. A.; Fraústo da Silva, J. J.; Palavra, A. F.; Pombeiro, A. J. Adv. Synth. Catal. 2007, 349(10), 1765-1774.

(21) Bonchio, M.; Conte, V.; Di Furia, F.; Modena, G. J. Org. Chem. 1989, 54(18), 4368-4371.

(22) Conte, V.; Di Furia, F.; Licini, G. Appl. Catal., A 1997, 157(1-2), 335-361.

(23) Sohn, J. R.; Cho, S. G.; Pae, Y. I.; Hayashi, S. J. Catal. 1996, 159(1), 170-177.

(24) Bolm, C. Coord. Chem. Rev. 2003, 237(1-2), 245-256.

(25) Ligtenbarg, A. G.; Hage, R.; Feringa, B. L. Coord. Chem. Rev. 2003, 237(1-2), 89-101.

(26) Shul'pin, G. B. Mini-Rev. Org. Chem. 2009, 6(2), 95-104.

(27) Conte, V.; Floris, B. Inorg. Chim. Acta 2010, 363(9), 1935-1946.

(28) Wojaczynska, E.; Wojaczynski, J. Chem. Rev. 2010, 110(7), 4303-4356.

(29) Bolm, C.; Bienewald, F. Angew. Chem. Int. Ed. Engl. 1996, 34(23-24), 2640-2642.

(30) Anisimov, A. V.; Fedorova, E. V.; Lesnugin, A. Z.; Senyavin, V. M.; Aslanov, L. A.; Rybakov, V. B.; Tarakanova, A. V. Catal. Today 2003, 78(1-4), 319-325.

(31) Clague, M. J.; Keder, N. L.; Butler, A. Inorg. Chem. 1993, 32(22), 4754-4761.

(32) Kodama, S.; Yoshida, J.; Nomoto, A.; Ueta, Y.; Yano, S.; Ueshima, M.; Ogawa, A. Tetrahedron Lett. 2010, 51(18), 2450-2452.

(33) Chakrabarti, A.; Hermann, K.; Druzinic, R.; Witko, M.; Wagner, F.; Petersen, M. Phys. Rev. B 1999, 59(16), 10583. 
(34) Lozano, L.; Juan, D. Miner. Eng. 2001, 14(5), 543-546.

(35) Chimentao, R. J.; Herrera, J. E.; Kwak, J. H.; Medina, F.; Wang, Y.; Peden, C. H. Applied Catalysis A: General 2007, 332(2), 263-272.

(36) Seargeant, L. E.; Stinson, R. A. Nature 1979, 281(5727), 152.

(37) Butler, A. Vanadium in biological systems Springer: Dordrecht, 1990; pp 25-49.

(38) Papoutsakis, D.; Jackson, J. E.; Nocera, D. G. Inorg. Chem. 1996, 35(4), 800-801.

(39) Da Silva, J. A.; Fraústo da Silva, J. J.; Pombeiro, A. J. Coord. Chem. Rev. 2011, 255(19), 2232-2248.

(40) Contractor, R.; Bergna, H.; Horowitz, H.; Blackstone, C.; Malone, B.; Torardi, C.; Griffiths, B.; Chowdhry, U.; Sleight, A. Catal. Today 1987, 1(1-2), 49-58.

(41) Ugo, R. Aspects of homogeneous catalysis: a series of advances Springer Science \& Business Media: Dordrecht, 2012; Vol. 5, pp.

(42) Lohbeck, K.; Haferkorn, H.; Fuhrmann, W.; Fedtke, N. Maleic and fumaric acids WileyVCH: Weinheim, 2000; pp 145-156.

(43) Culbertson, T.; Trivedi, B. Maleic Anhydride Plenum Press, New York: 1982; pp 17-40.

(44) Bordes, E.; Courtine, P. J. Catal. 1979, 57(2), 236-252.

(45) Bordes, E.; Courtine, P.; Pannetier, G. Ann. Chim.(Paris) 1973, 8, 105-113.

(46) Ballutaud, D.; Bordes, E.; Courtine, P. Mater. Res. Bull. 1982, 17(4), 519-526.

(47) Centi, G.; Trifiro, F.; Ebner, J. R.; Franchetti, V. M. Chem. Rev. 1988, 88(1), 55-80.

(48) Hutchings, G. J.; Kiely, C. J.; Sananes-Schulz, M. T.; Burrows, A.; Volta, J. C. Catal. Today 1998, 40(2-3), 273-286.

(49) Nakamura, M.; Kawai, K.; Fujiwara, Y. J. Catal. 1974, 34(3), 345-355.

(50) Tietze, H. R. Aust. J. Chem. 1981, 34(10), 2035-2038. 
(51) Tachez, M.; Theobald, F.; Bernard, J.; Hewat, A. Chemischer Informationsdienst 1983, 14(9), no-no.

(52) Goubitz, K.; Čapková, P.; Melánová, K.; Molleman, W.; Schenk, H. Acta Crystallogr., Sect. B: Struct. Sci. 2001, 57(2), 178-183.

(53) Girgsdies, F.; Schneider, M.; Brückner, A.; Ressler, T.; Schlögl, R. Solid State Sci 2009, 11(7), 1258-1264.

(54) Long, J. R.; Williamson, A. S.; Holm, R. H. Angew. Chem. Int. Ed. Engl. 1995, 34(2), 226229.

(55) Tulsky, E. G.; Long, J. R. Chem. Mater. 2001, 13(4), 1149-1166.

(56) Kolb, E. W.; Slansky, R. Phys. Lett. B 1984, 135(5-6), 378-382.

(57) Tenne, R.; Margulis, L.; Genut, M.; Hodes, G. Nature 1992, 360(6403), 444.

(58) Thorn, D.; Harlow, R.; Herron, N. Inorg. Chem. 1995, 34(10), 2629-2638.

(59) Herron, N.; Thorn, D. L.; Harlow, R. L.; Coulston, G. W. J. Am. Chem. Soc. 1997, 119(30), 7149-7150.

(60) Petit, S.; Borshch, S. A.; Robert, V. J. Am. Chem. Soc. 2002, 124(8), 1744-1749.

(61) Gorbunova, Y. E.; Linde, S. Soviet Physics Doklady, 1979; p 138.

(62) Nguyen, P.; Hoffman, R.; Sleight, A. Mater. Res. Bull. 1995, 30(9), 1055-1063.

(63) Kime-Hunt, E.; Spartalian, K.; DeRusha, M.; Nunn, C. M.; Carrano, C. J. Inorg. Chem. 1989, 28(24), 4392-4399.

(64) Otieno, T.; Mokry, L. M.; Bond, M. R.; Carrano, C. J.; Dean, N. S. Inorg. Chem. 1996, 35(4), 850-856.

(65) Dean, N. S.; Bond, M. R.; O'Connor, C.; Carrano, C. J. Inorg. Chem. 1996, 35(26), 76437648. 
(66) Trofimenko, S. The coordination chemistry of polypyrazolylborate ligands Imperial College Press: London, 1999; pp 1-23.

(67) Tellers, D. M.; Skoog, S. J.; Bergman, R. G.; Gunnoe, T. B.; Harman, W. D. Organometallics 2000, 19(13), 2428-2432.

(68) Etienne, M. Coord. Chem. Rev. 1996, 156, 201-236.

(69) Mokry, L. M.; Thompson, J.; Bond, M. R.; Otieno, T.; Mohan, M.; Carrano, C. J. Inorg. Chem. 1994, 33(13), 2705-2706.

(70) Bond, M. R.; Mokry, L. M.; Otieno, T.; Thompson, J.; Carrano, C. J. Inorg. Chem. 1995, 34(7), 1894-1905.

(71) Werner, H. Angew. Chem. Int. Ed. 1983, 22(12), 927-949.

(72) Neukomm, H.; Werner, H. J. Organomet. Chem. 1976, 108(3), C26-C28.

(73) Debreczeni, J. É.; Bullock, A. N.; Atilla, G. E.; Williams, D. S.; Bregman, H.; Knapp, S.; Meggers, E. Angew. Chem. Int. Ed. 2006, 45(10), 1580-1585.

(74) Cadierno, V.; Gamasa, M. P.; Gimeno, J. Coord. Chem. Rev. 2004, 248(15-16), 1627-1657.

(75) Leung, W.-H.; Zhang, Q.-F.; Yi, X.-Y. Coord. Chem. Rev. 2007, 251(17), 2266-2279.

(76) Yi, X.-Y.; Zhang, Q.-F.; Lam, T. C.; Chan, E. Y.; Williams, I. D.; Leung, W.-H. Inorg. Chem. 2006, 45(1), 328-335.

(77) Kelson, E. P.; Henling, L. M.; Schaefer, W. P.; Labinger, J. A.; Bercaw, J. E. Inorg. Chem. 1993, 32(13), 2863-2873.

(78) Domhöver, B.; Kläui, W. J. Organomet. Chem. 1996, 522(2), 207-212.

(79) Kläui, W.; Schramm, D.; Schramm, G. Inorg. Chim. Acta 2004, 357(6), 1642-1648.

(80) Kläui, W.; Hardt, T. J. Organomet. Chem. 1998, 553(1), 241-251.

(81) Sutra, P.; Igau, A. Coord. Chem. Rev. 2016, 308, 97-116. 
(82) Osborn, J. A.; Jardine, F.; Young, J. F.; Wilkinson, G. J. Chem. Soc. A 1966, 1711-1732.

(83) Taqui Kahn, M.; Martell, A. Homogeneous Catalysis by Transition Metal Complexes Academic Press: New York, 1974; pp 215-390.

(84) Anderson, A. E.; Weberski Jr, M. P.; McLauchlan, C. C. Inorg. Chem. 2012, 51(16), 87198728.

(85) Riart-Ferrer, X.; Anderson, A. E.; Nelson, B. M.; Hao, F.; McLauchlan, C. C. Eur. J. Inorg. Chem. 2012, 2012(29), 4585-4592.

(86) Tarlton, M. L.; Anderson, A. E.; Weberski Jr, M. P.; Riart-Ferrer, X.; Nelson, B. M.; McLauchlan, C. C. Inorg. Chim. Acta 2014, 420, 159-165.

(87) Weberski Jr, M. P.; McLauchlan, C. C. Inorg. Chem. Commun. 2007, 10(8), 906-909.

(88) McLauchlan, C. C.; Anderson, A. E. Acta Crystallogr. Sect. Sect. E: Struct. Rep. Online 2008, 64(9), m1129-m1130.

(89) Weberski Jr, M. P.; McLauchlan, C. C. Acta Crystallogr. Sect. Sect. E: Struct. Rep. Online 2007, 63(4), m1171-m1172.

(90) Salta, J.; Chen, Q.; Chang, Y. D.; Zubieta, J. Angew. Chem. Int. Ed. Engl. 1994, 33(7), 757760.

(91) Knopp, P.; Wieghardt, K.; Nuber, B.; Weiss, J.; Sheldrick, W. S. Inorg. Chem. 1990, 29(3), 363-371.

(92) Khan, M. I.; Chang, Y.; Chen, Q.; Hope, H.; Parking, S.; Goshorn, D.; Zubieta, J. Angew. Chem. Int. Ed. Engl. 1992, 31(9), 1197-1200.

(93) Barbaro, P.; Bianchini, C.; Frediani, P.; Meli, A.; Vizza, F. Inorg. Chem. 1992, 31(8), 15231529. 
(94) Triller, M. U.; Pursche, D.; Hsieh, W.-Y.; Pecoraro, V. L.; Rompel, A.; Krebs, B. Inorg. Chem. 2003, 42(20), 6274-6283.

(95) Manzur, J.; García, A. M.; Córdova, C.; Pizarro, O.; Acuña, V.; Spodine, E. Polyhedron 2002, 21(2), 181-185.

(96) Chin, D. H.; Sawyer, D. T. Inorg. Chem. 1982, 21(12), 4317-4318.

(97) Roman, E.; Tapia, F.; Barrera, M.; Garland, M.-T.; Le Marouille, J.-Y.; Giannotti, C. J. Organomet. Chem. 1985, 297(1), c8-c12.

(98) Casellato, U.; Tamburini, S.; Vigato, P.; Vidali, M.; Fenton, D. Inorg. Chim. Acta 1984, 84(1), 101-104.

(99) Harder, V.; Dubler, E. t.; Werner, H. J. Organomet. Chem. 1974, 71(3), 427-433.

(100) Kläui, W. Z. Naturforch. B 1979, 34(10), 1402-1407.

(101) Kläui, W. Angew. Chem. Int. Ed. 1990, 29(6), 627-637.

(102) Kläui, W.; Eberspach, W.; Guetlich, P. Inorg. Chem. 1987, 26(24), 3977-3982.

(103) Kläui, W.; Mueller, A.; Eberspach, W.; Boese, R.; Goldberg, I. J. Am. Chem. Soc. 1987, 109(1), 164-169.

(104) Fulmer, G. R.; Miller, A. J.; Sherden, N. H.; Gottlieb, H. E.; Nudelman, A.; Stoltz, B. M.; Bercaw, J. E.; Goldberg, K. I. Organometallics 2010, 29(9), 2176-2179.

(105) Harder, V.; Werner, H. Helv. Chim. Acta 1973, 56(5), 1620-1629.

(106) Towns, R. L.; Levenson, R. A. J. Am. Chem. Soc. 1972, 94(12), 4345-4346.

(107) Szafran, Z.; Pike, R. M.; Singh, M. M. Microscale inorganic chemistry J. Wiley: New York, 1991; pp 1-363.

(108) Li, J.; Lashier, M.; Schrader, G. L.; Gerstein, B. C. Appl. Catal. 1991, 73(1), 83-95.

(109) Ozkan, U. S.; Harris, T. A.; Schilf, B. T. Catal. Today 1997, 33(1-3), 57-71. 
(110) Sakurai, Y.; Suzaki, T.; Ikenaga, N.-o.; Suzuki, T. Appl. Catal., A 2000, 192(2), 281-288.

(111) Smith, T. S.; Root, C. A.; Kampf, J. W.; Rasmussen, P. G.; Pecoraro, V. L. J. Am. Chem. Soc. 2000, 122(5), 767-775.

(112) Shriver, D. F.; Drezdzon, M. A.; Drezdzon, M. A. The manipulation of air-sensitive compounds John Wiley \& Sons: New York, 1986; pp 1-151.

(113) Liu, G.; Lu, X.; Gagliardo, M.; Beetstra, D. J.; Meetsma, A.; Hessen, B. Organometallics 2008, 27(10), 2316-2320.

(114) Ballhausen, C. J.; Gray, H. B. Inorg. Chem. 1962, 1(1), 111-122.

(115) Paris, J.; Brandt, W. W. J. Am. Chem. Soc. 1959, 81(18), 5001-5002.

(116) Aksenov, I.; Kudo, Y.; Sato, K. Jpn. J. Appl. Phys. 1992, 31(2B), L145-L147.

(117) Dridi, R.; Cherni, S.; Zid, M. F. J. Chem. Sci. (Bangalore, India) 2015, 127(8), 1427-1433.

(118) Modec, B.; Brenčič, J. V.; Koller, J. Eur. J. Inorg. Chem. 2004, 2004(8), 1611-1620.

(119) Sehimi, H.; Chérif, I.; Zid, M. F. Acta Crystallogr. E 2016, 72(5), 724-729.

(120) Anderson, A. E. Phosph (on/in) ate-bridged Vanadium Clusters: Synthesis, Characterization and Reactivity. Master Thesis, Normal, IL, USA, Illinois State University, 2010.

(121) Swaddle, T. W. Inorganic chemistry: an industrial and environmental perspective Academic Press: San Diego, 1997; pp 191-204.

(122) Hamilton, G. A. Chemical models and mechanisms for oxygenases Elsevier: 1974; pp 405451.

(123) Tarlton, M. L. Penn., A. S.; Anderson, A. E.; McLauchlan, C. C. (unpublished) 2018. 


\section{APPENDIX A. IR SPECTRA}

Shown here are the infrared spectra of all the complexes. Sample were prepared as $\mathrm{KBr}$ mulls and then pressed in a mechanical press to form a translucent pellet which the beam can pass through, as illustrated. 


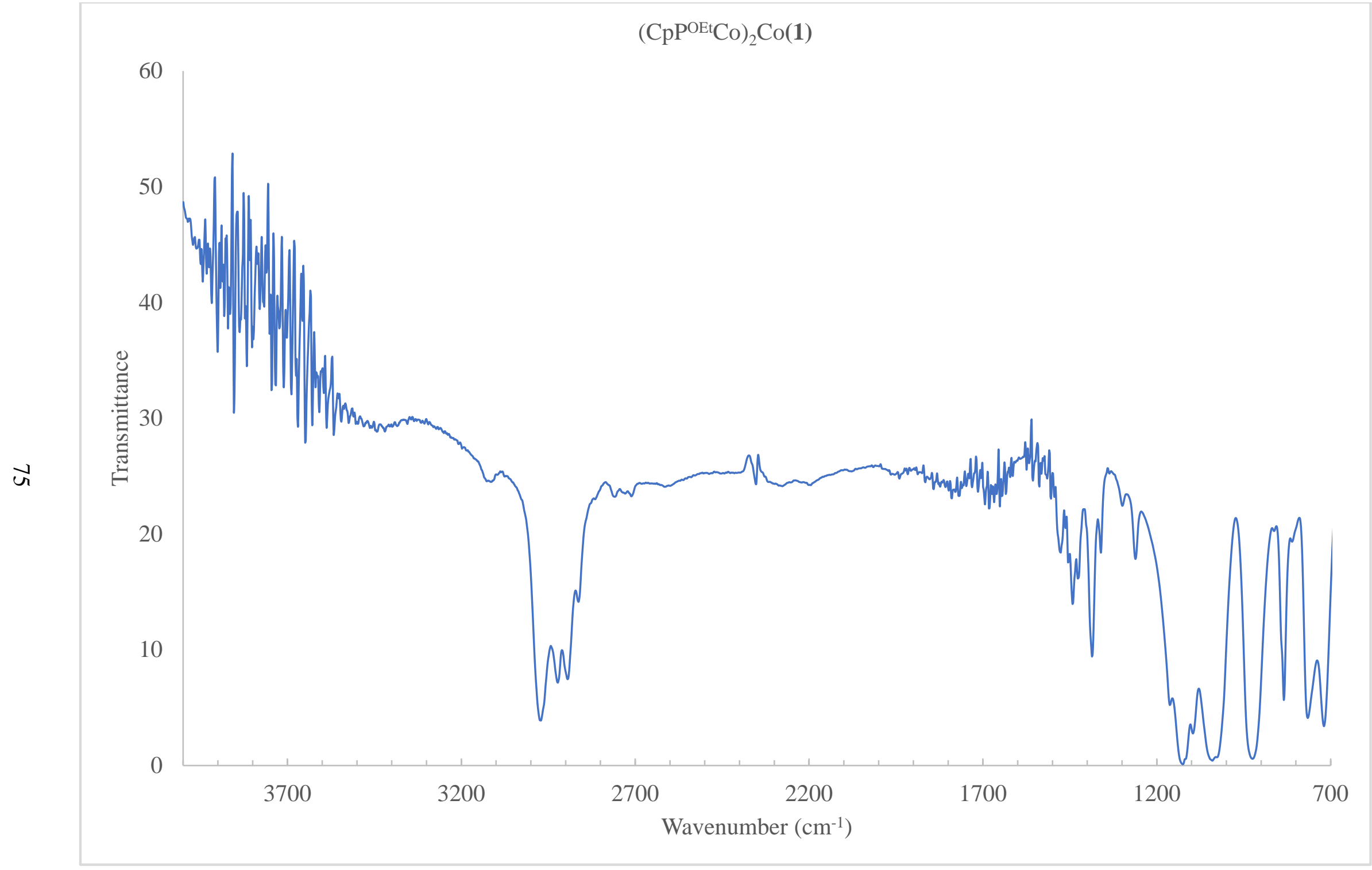

Figure A1. IR Spectrum of ( $\left.\mathrm{CpP} \mathrm{OEt}^{\mathrm{Ot}} \mathrm{O}\right)_{2} \mathrm{Co}(\mathbf{1})$ collected as $\mathrm{KBr}$ Mull. 


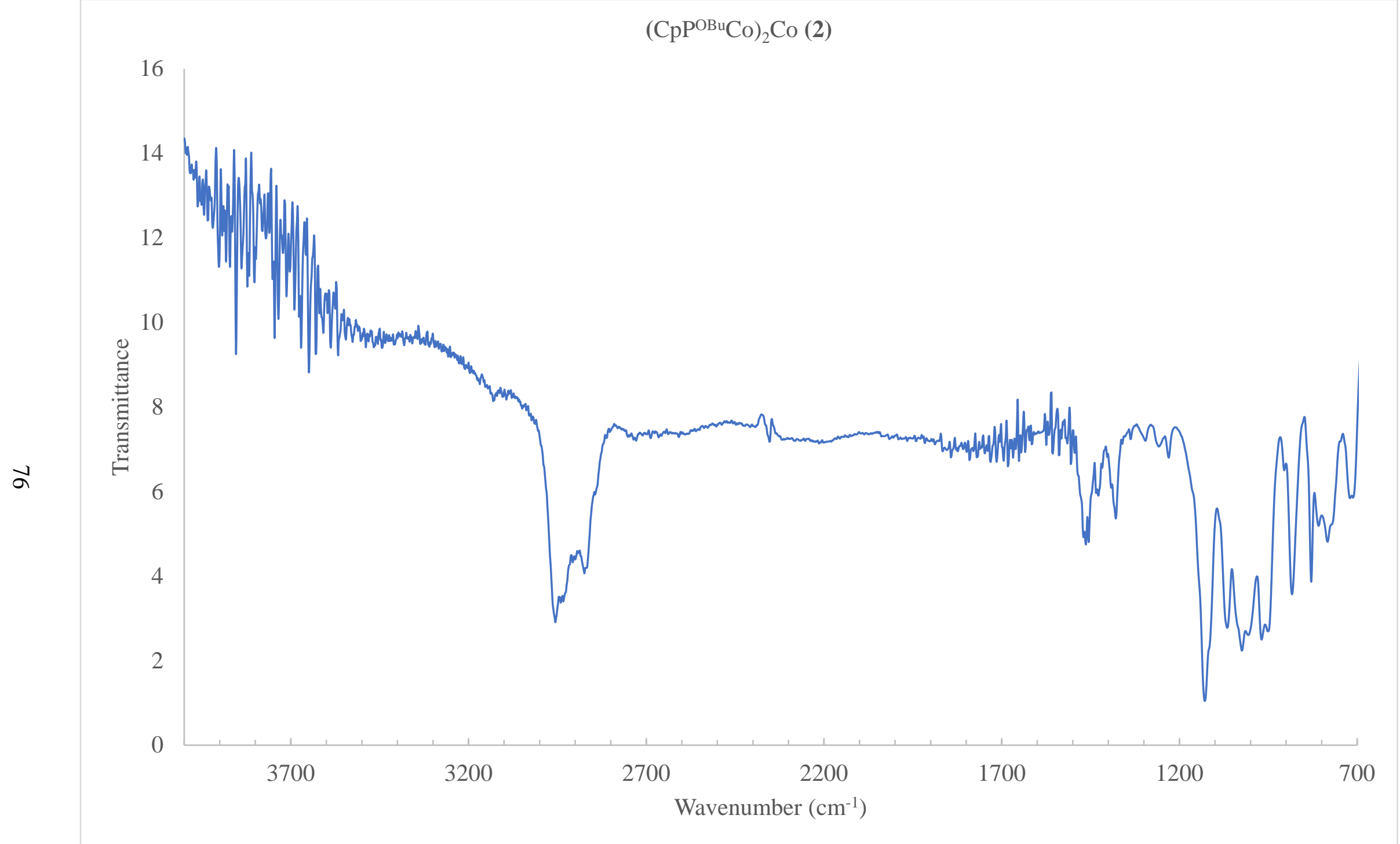

Figure A2. IR Spectrum of ( $\left.\mathrm{CpP}^{\mathrm{OBu}} \mathrm{Co}\right)_{2} \mathrm{Co}(2)$ collected as $\mathrm{KBr}$ Mull. 


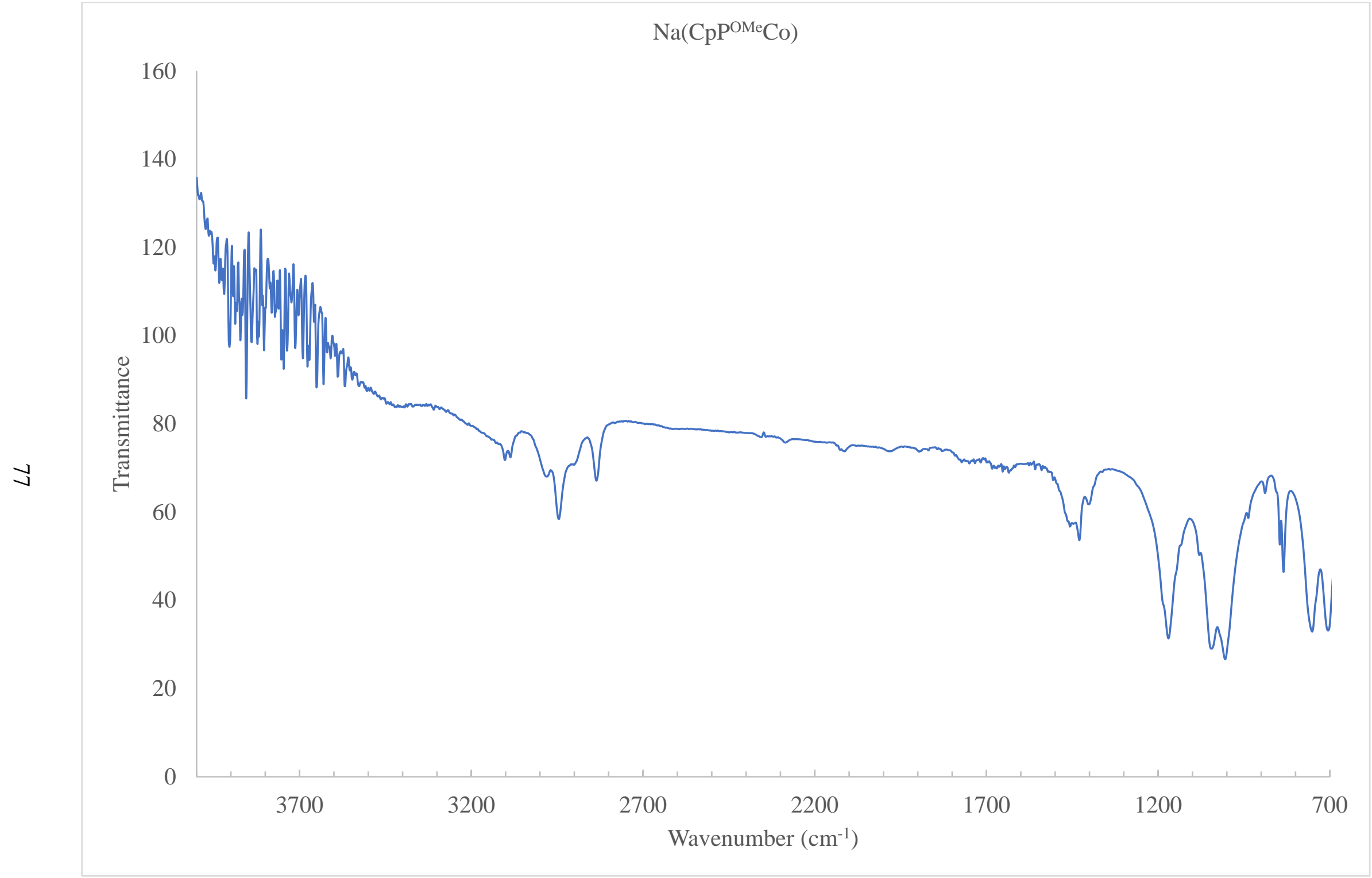

Figure A3. IR Spectrum of $\mathrm{Na}\left(\mathrm{CpP}^{\mathrm{OMe}} \mathrm{Co}\right)$ collected as $\mathrm{KBr}$ Mull. 




Figure A4. IR Spectrum of $\mathrm{Na}\left(\mathrm{CpP}^{\mathrm{OEt}} \mathrm{Co}\right)(3)$ collected as $\mathrm{KBr}$ Mull. 


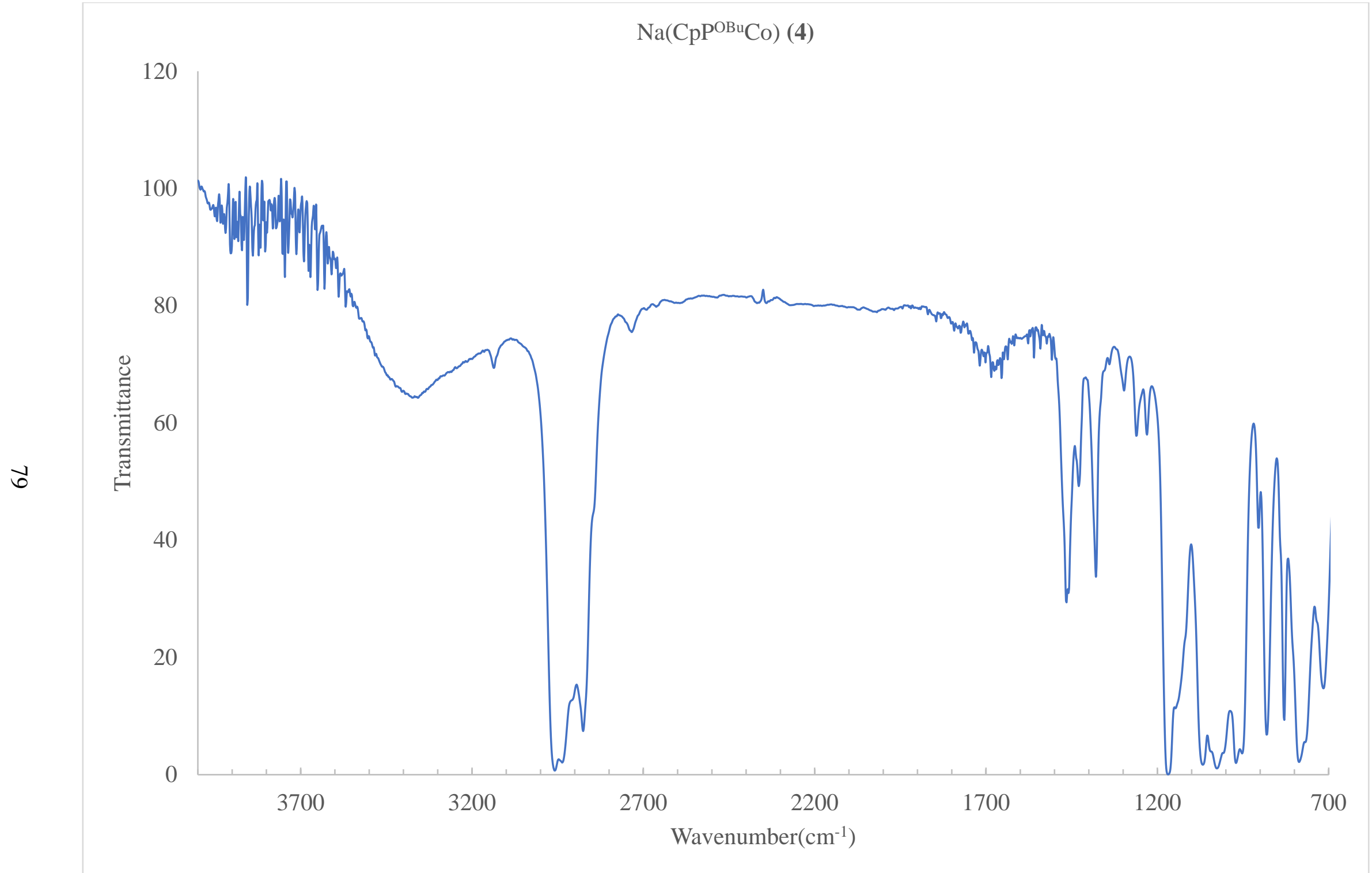

Figure A5. IR Spectrum of $\mathrm{Na}\left(\mathrm{CpP}^{\mathrm{OBu}} \mathrm{Co}\right)$ (4) collected as $\mathrm{KBr}$ Mull. 




Figure A6. IR Spectrum of (CpP $\left.{ }^{\mathrm{OBu}} \mathrm{Co}\right)_{2} \mathrm{Ni}(5)$ collected as $\mathrm{KBr}$ Mull. 


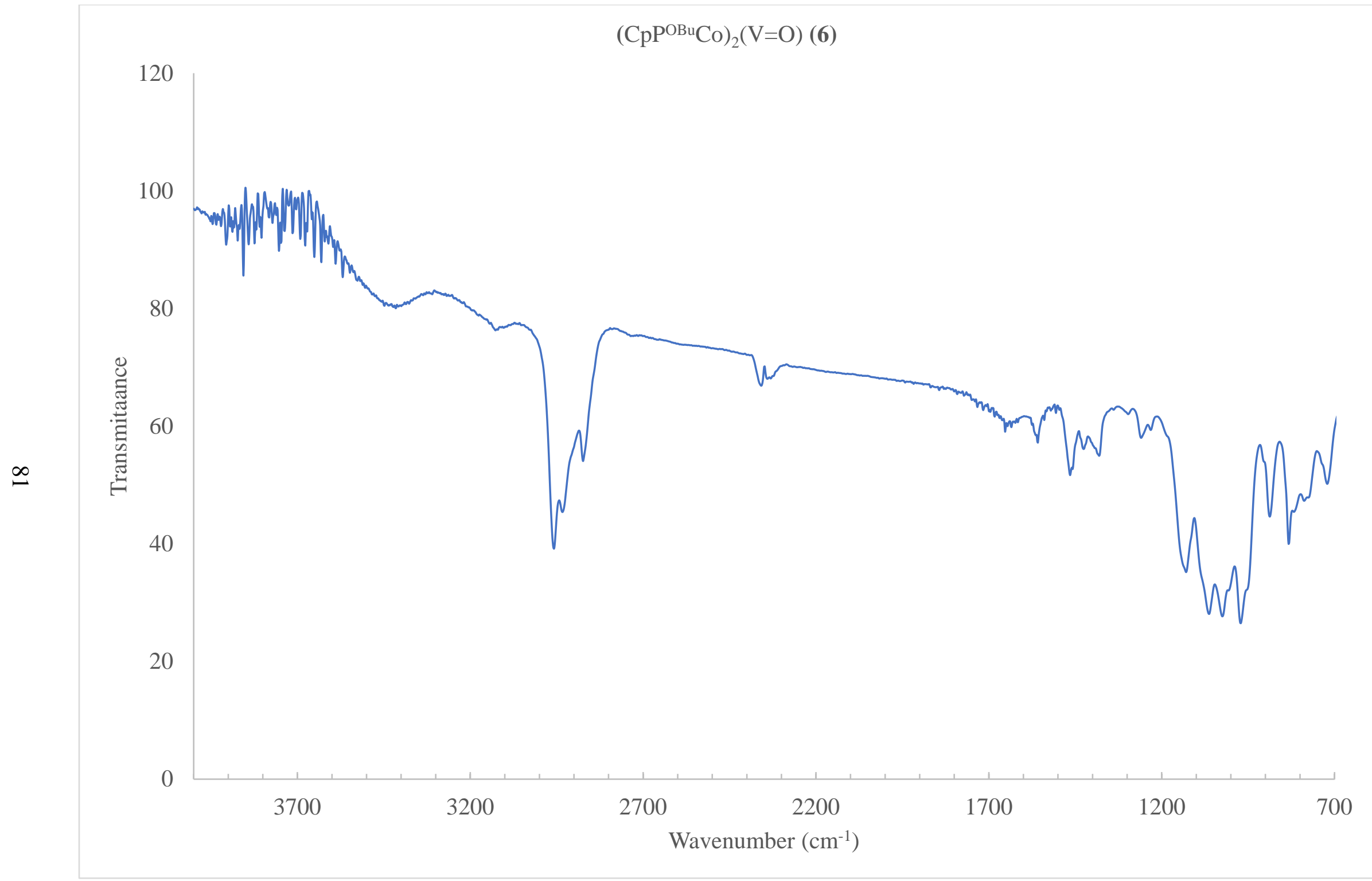

Figure A7. IR Spectrum of $\left(\mathrm{CpP} \mathrm{OBu}^{\mathrm{O}} \mathrm{Co}\right)_{2}(\mathrm{~V}=\mathrm{O})(\mathbf{6})$ collected as $\mathrm{KBr}$ Mull. 




Figure A8. IR Spectrum of $\left[\left(\mathrm{CpP}^{\mathrm{OBu}} \mathrm{Co}\right)_{2} \mathrm{Co}\right] \mathrm{SbCl}_{6}$ (7) collected as $\mathrm{KBr}$ Mull. 




Figure A9. IR Spectrum of $\left[\mathrm{CpP}{ }^{\mathrm{OBu}} \mathrm{CoVOCl}_{2}\right.$ (8) collected as $\mathrm{KBr}$ Mull. 


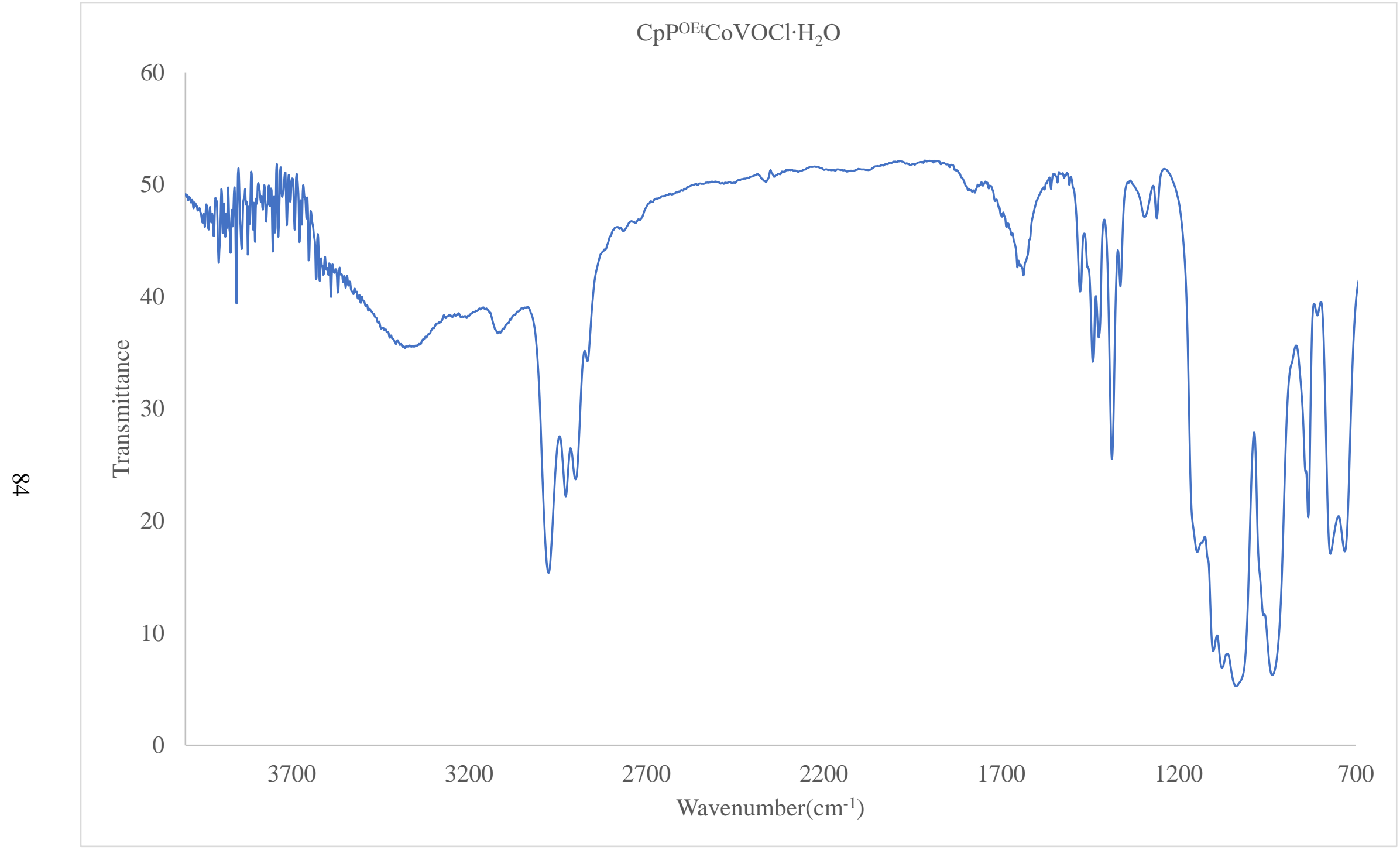

Figure A10. IR Spectrum of $\mathrm{CpP}^{\mathrm{OEt}} \mathrm{CoVOCl} \cdot \mathrm{H}_{2} \mathrm{O}$ collected as $\mathrm{KBr}$ Mull. 




Figure A11. IR Spectrum of ( $\left.\mathrm{CpP} \mathrm{PBu}^{\mathrm{OB}} \mathrm{Co}\right) \mathrm{VCl}_{2} \mathrm{DMF}$ (9) collected as $\mathrm{KBr}$ Mull. 


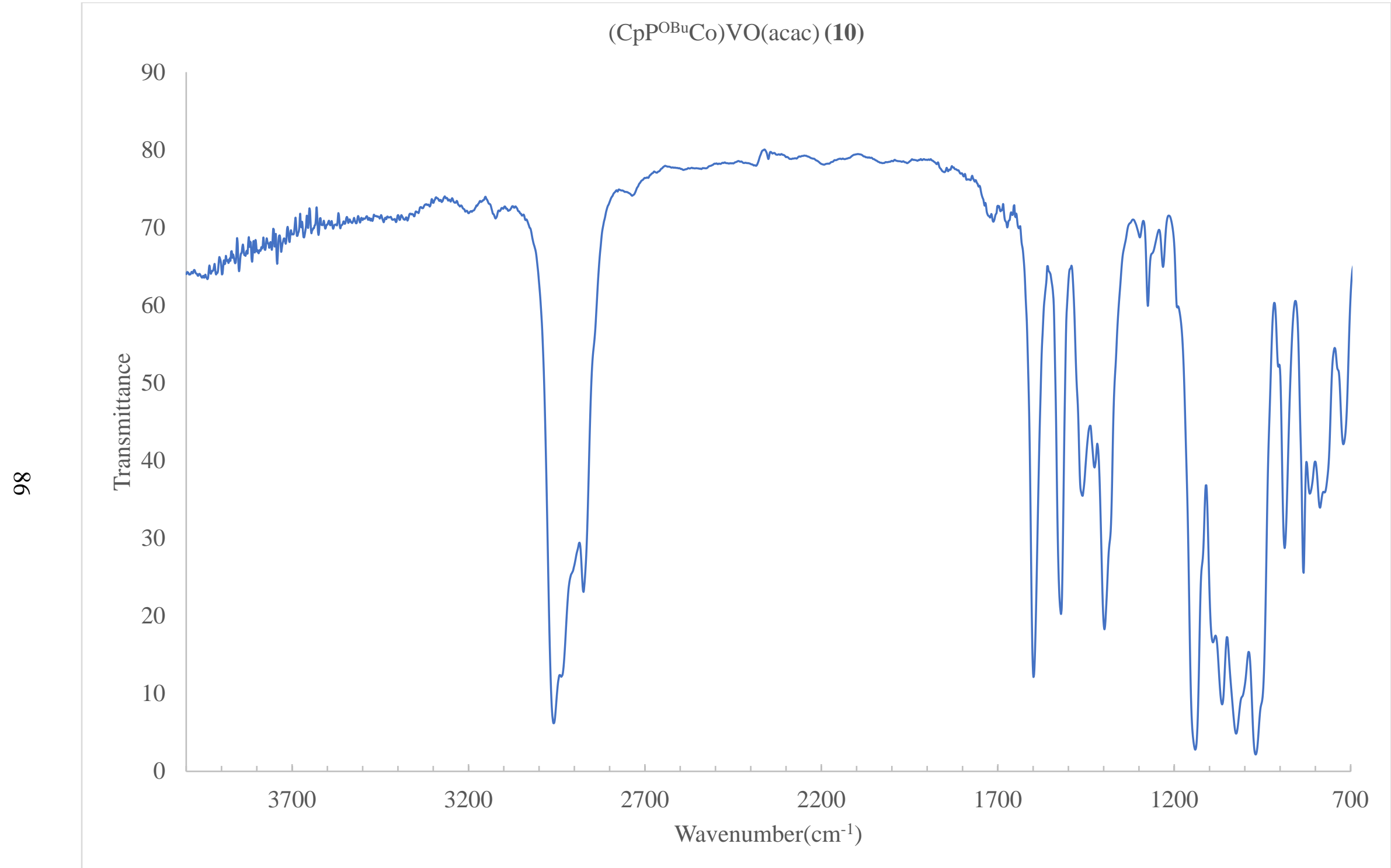

Figure A12. IR Spectrum of ( $\left.\mathrm{CpP}^{\mathrm{OBu}} \mathrm{Co}\right) \mathrm{VO}(\mathrm{acac})(\mathbf{1 0})$ collected as $\mathrm{KBr}$ Mull. 


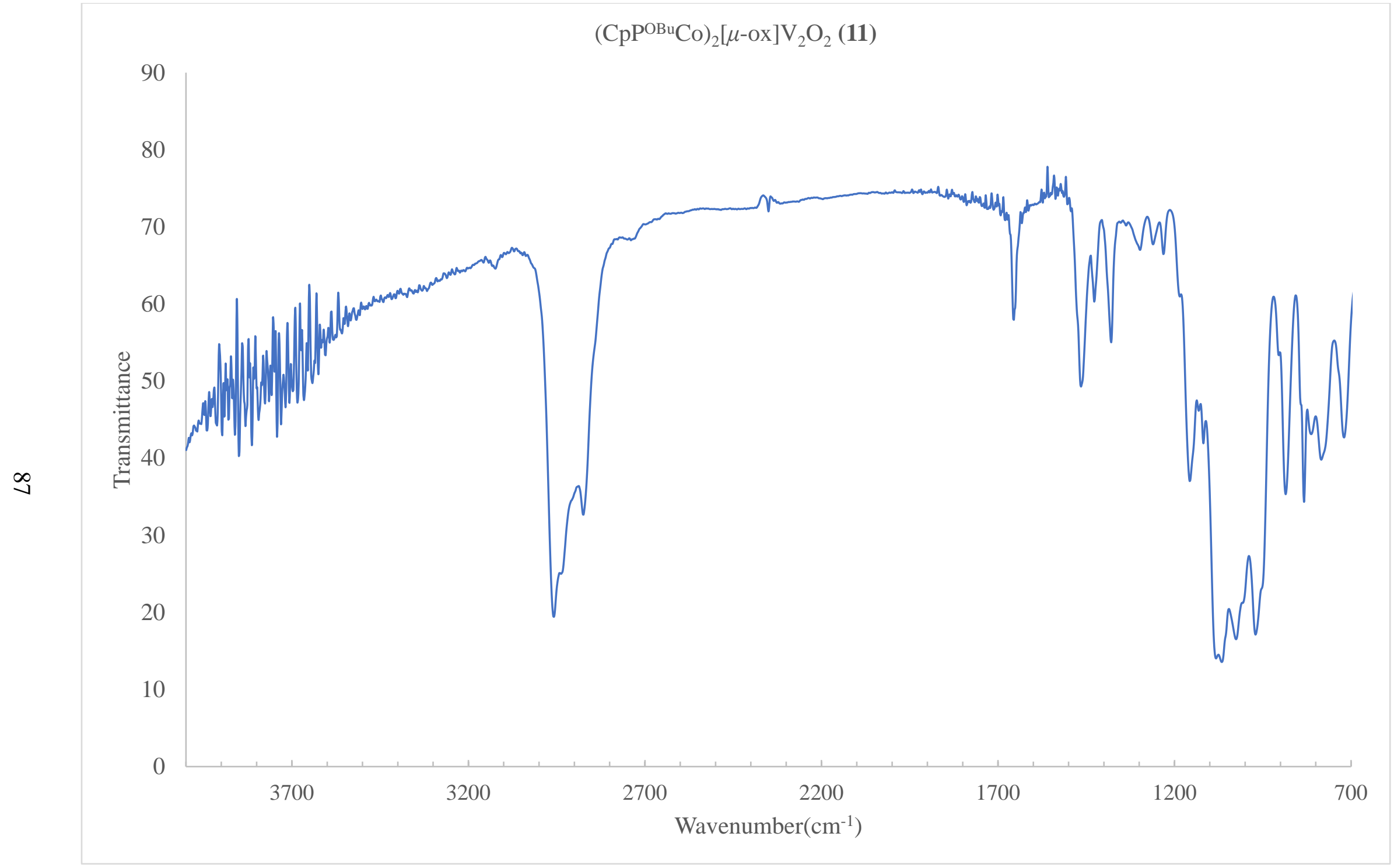

Figure A13. IR Spectrum of $\left(\mathrm{CpP} \mathrm{OBu}^{\mathrm{O}} \mathrm{Co}\right)_{2}[\mu-\mathrm{ox}] \mathrm{V}_{2} \mathrm{O}_{2}$ (11) collected as $\mathrm{KBr}$ Mull. 


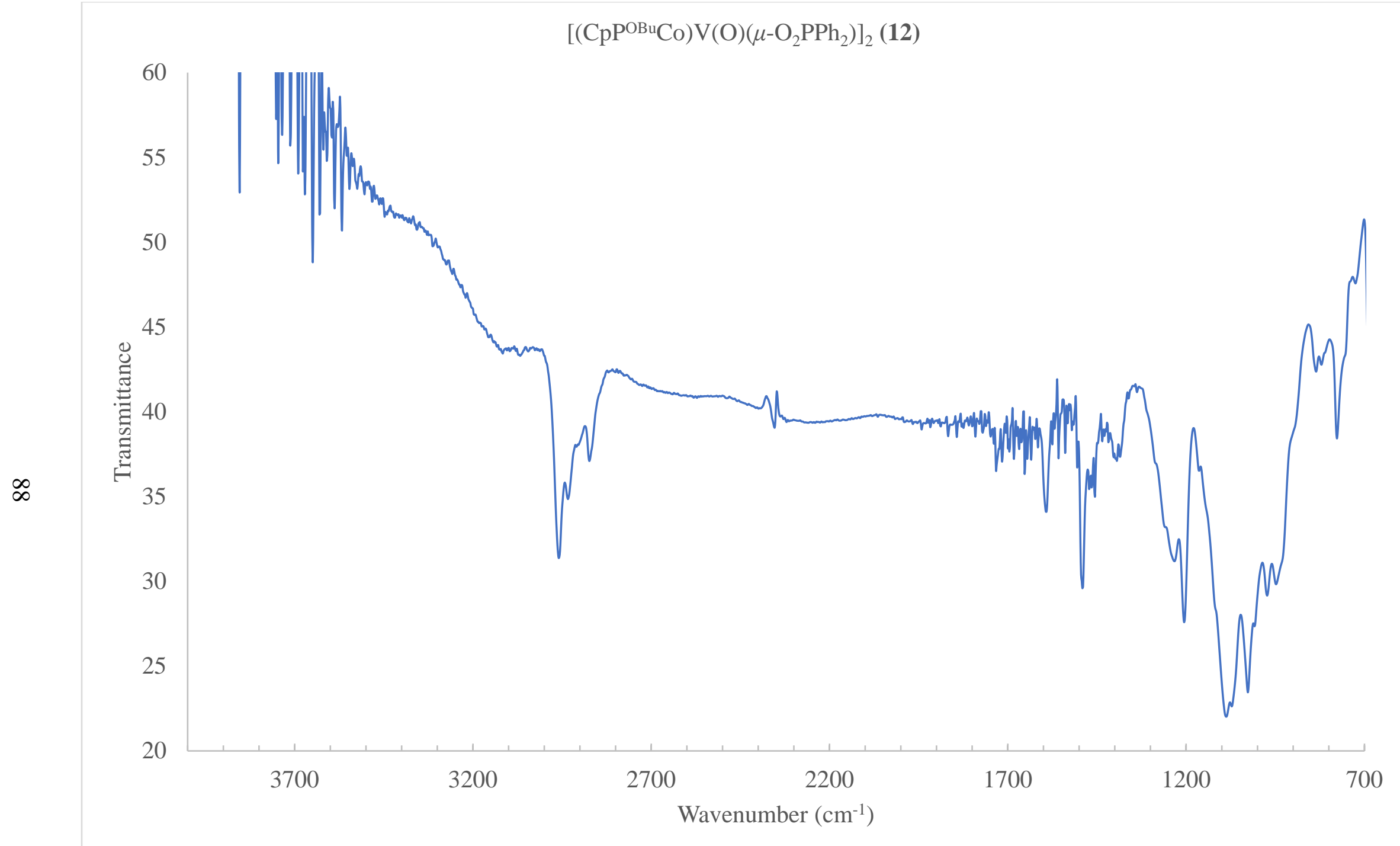

Figure A14. IR Spectrum of $\left[\left(\mathrm{CpP}{ }^{\mathrm{OBu}} \mathrm{Co}\right) \mathrm{V}(\mathrm{O})\left(\mu-\mathrm{O}_{2} \mathrm{PPh}_{2}\right)\right]_{2}$ (12) collected as $\mathrm{KBr}$ Mull. 


\section{APPENDIX B. RAMAN SPECTRA}

Shown here are the Raman spectra of all the complexes. Spectra were collected on a ProRaman L. Enwave Optronics Raman spectrometer. 


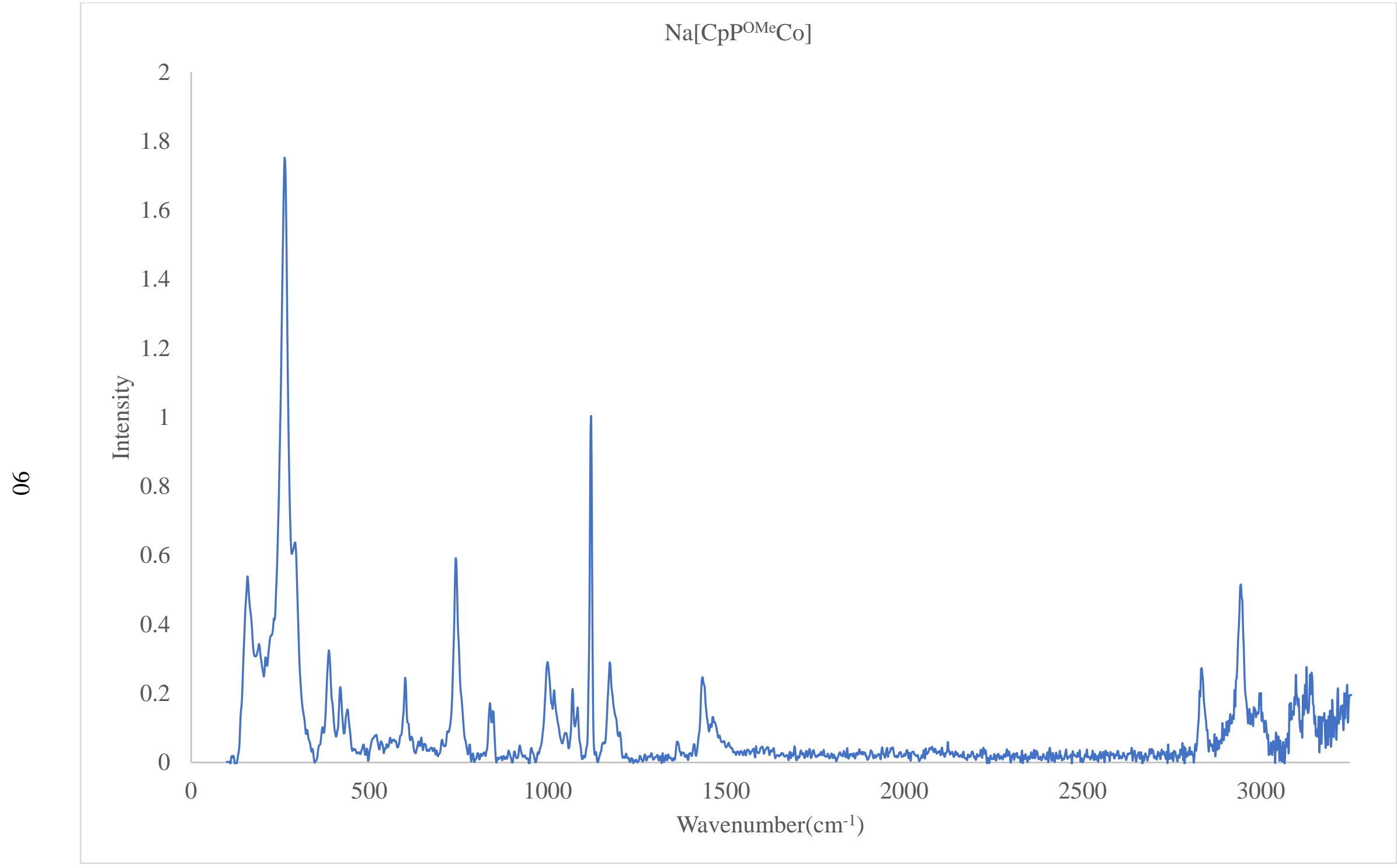

Figure B1. Raman Spectrum of $\mathrm{Na}\left[\left(\mathrm{CpP}^{\mathrm{OMe}} \mathrm{Co}\right)\right]$. 


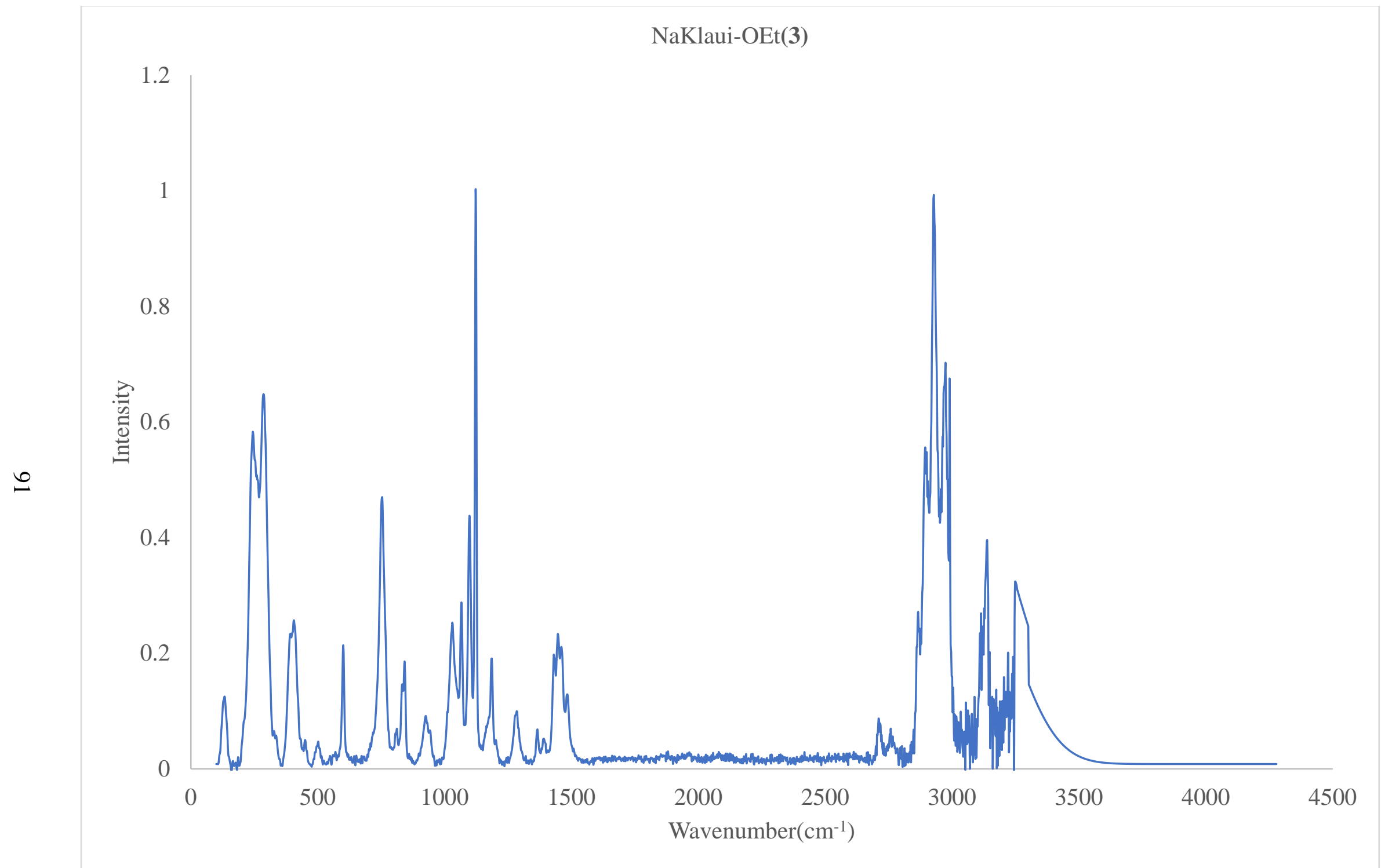

Figure B2. Raman Spectrum of $\mathrm{Na}\left[\left(\mathrm{CpP}{ }^{\mathrm{OEt}} \mathrm{Co}\right)\right]$ (3). 




Figure B3. Raman Spectrum of $\mathrm{Na}\left[\left(\mathrm{CpP} \mathrm{PBu}^{\mathrm{OB}} \mathrm{Co}\right)\right](4)$. 


\section{APPENDIX C. NMR SPECTRA}

Shown here are the NMR spectra of all the complexes. Spectra were collected on a Bruker spectrometer at 400.13 MHz for ${ }^{1} \mathrm{H}$ NMR, 100.62 MHz for ${ }^{13} \mathrm{C}$ NMR and $161.97 \mathrm{MHz}$ for ${ }^{31} \mathrm{P}$ NMR at room temperature. The solvents are $\mathrm{D}_{2} \mathrm{O}$ or $\mathrm{CDCl}_{3}$ as illustrated. 


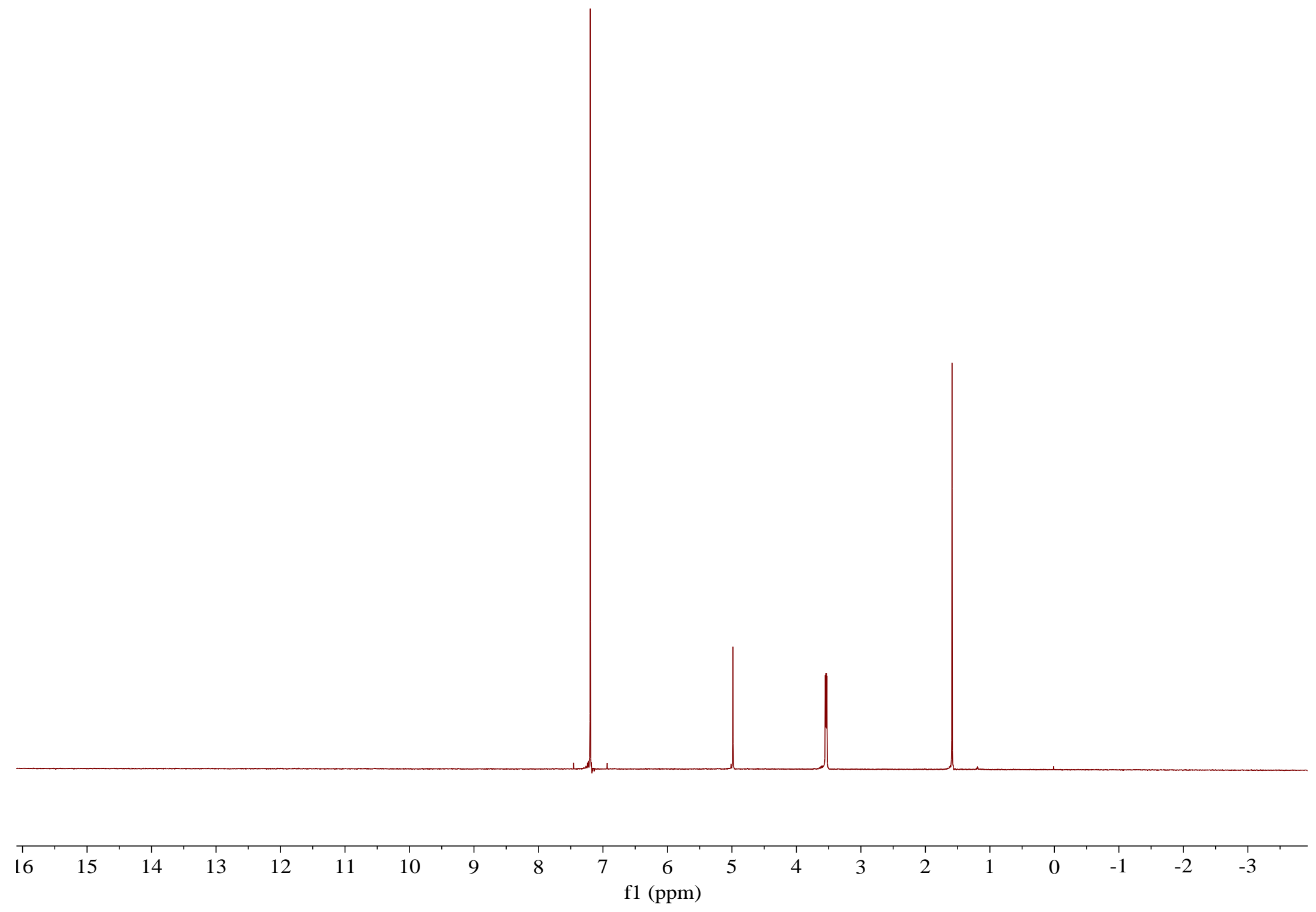

Figure C1. ${ }^{1} \mathrm{H}$ Spectrum of $\mathrm{Na}\left[\left(\mathrm{CpP}{ }^{\mathrm{OMe}} \mathrm{Co}\right)\right]$ in $\mathrm{CDCl}_{3}$. 


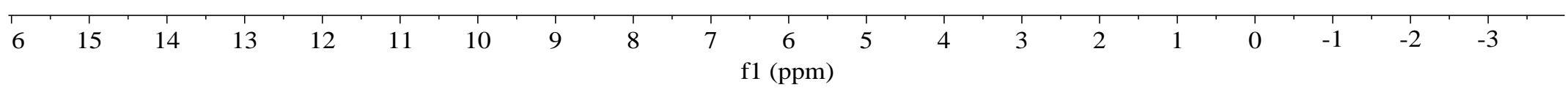

Figure C2. ${ }^{1} \mathrm{H}$ Spectrum of $\mathrm{Na}\left[\left(\mathrm{CpP}^{\mathrm{OEt}} \mathrm{Co}\right)\right]$ (3) in $\mathrm{CDCl}_{3}$. 


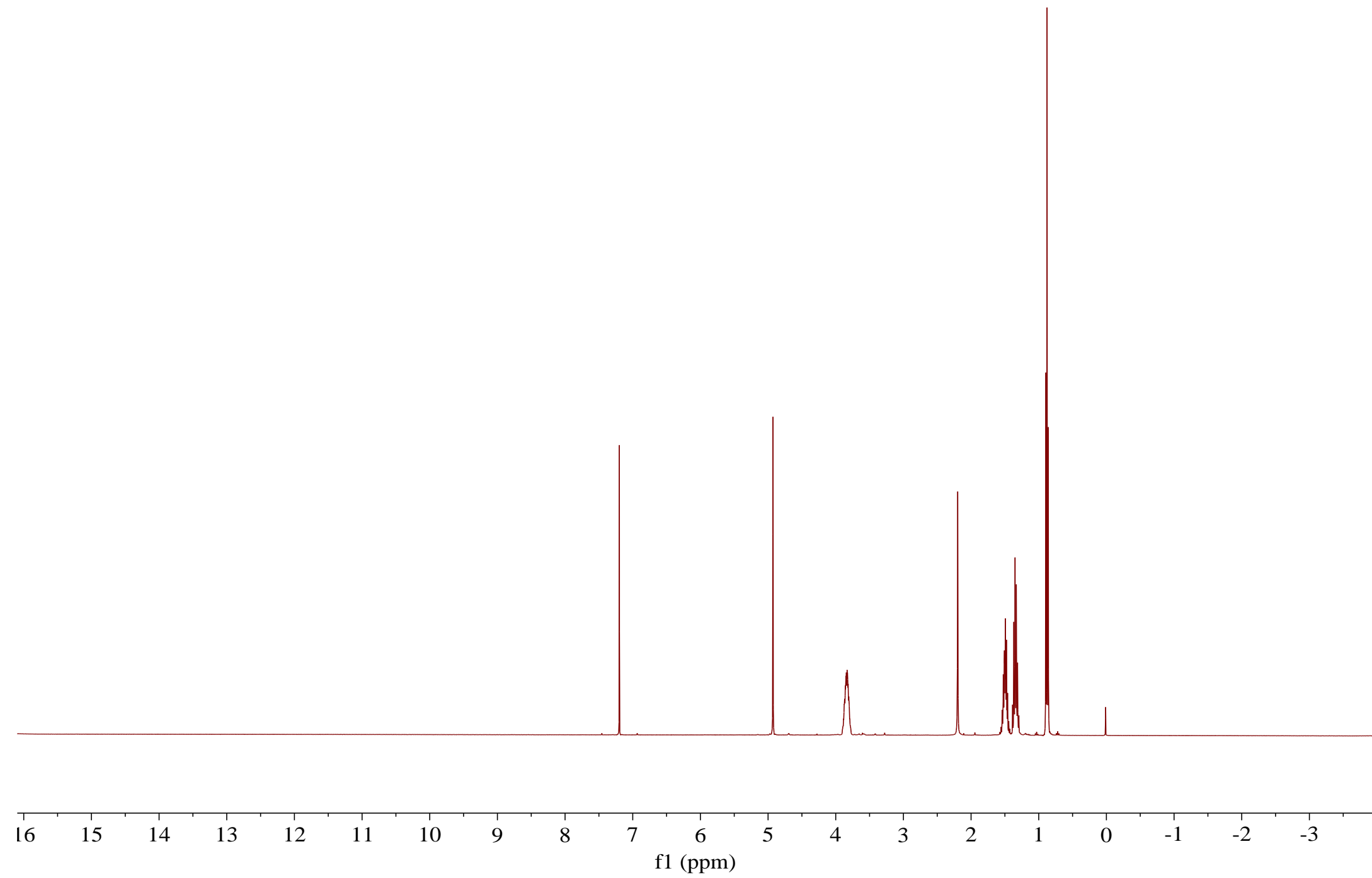

Figure C3. ${ }^{1} \mathrm{H}$ Spectrum of $\mathrm{Na}\left[\left(\mathrm{CpP}^{\mathrm{OBu}} \mathrm{Co}\right)\right]$ (4) in $\mathrm{CDCl}_{3}$. 


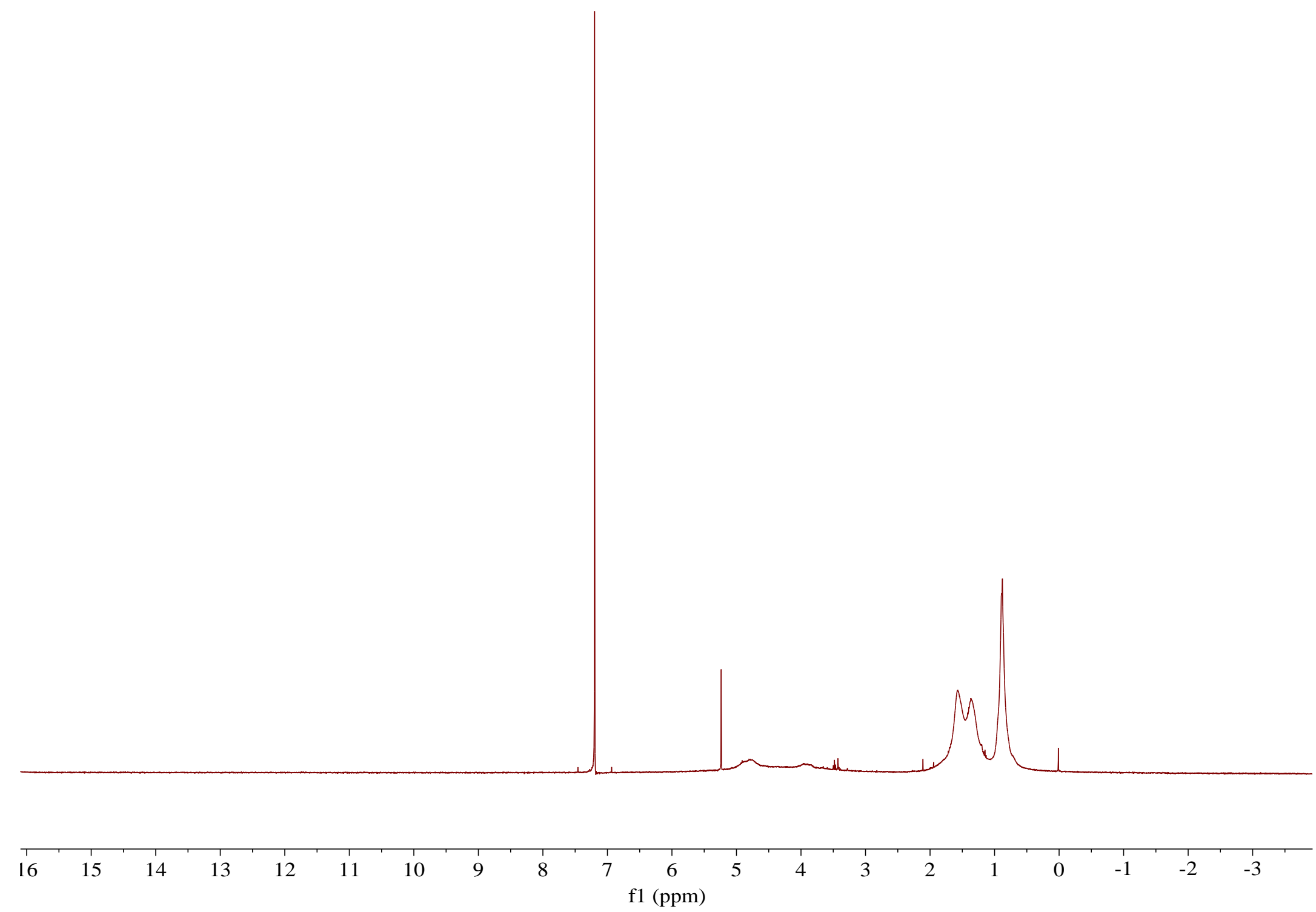

Figure C4. ${ }^{1} \mathrm{H}$ Spectrum of $\left[\left(\mathrm{CpP}{ }^{\mathrm{OBu}} \mathrm{Co}\right) \mathrm{VOCl}_{2}(\mathbf{8})\right.$ in $\mathrm{CDCl}_{3}$. 


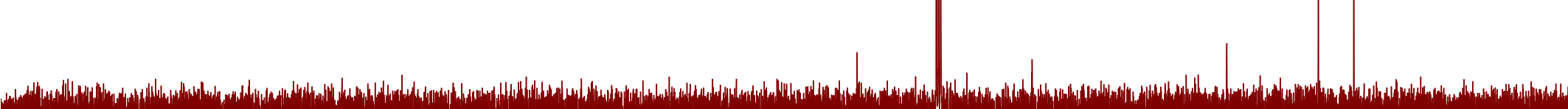
minn

210

$\begin{array}{lllll}000 & 190 & 180 & 170 & 160\end{array}$

150

$130 \quad 120$

11010090

$\mathrm{f} 1(\mathrm{ppm})$

Figure C5. ${ }^{13} \mathrm{C}$ Spectrum of $\mathrm{Na}\left(\mathrm{CpP}{ }^{\mathrm{OBu}} \mathrm{Co}\right)(\mathbf{4})$ in $\mathrm{CDCl}_{3}$. 


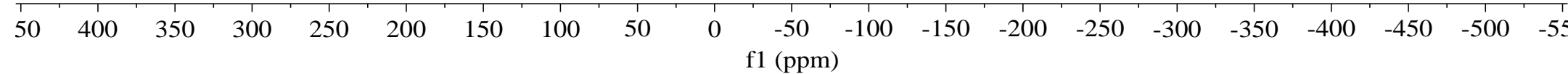

Figure C6. ${ }^{31} \mathrm{P}$ Spectrum of $\mathrm{Na}\left(\mathrm{CpP} \mathrm{PMe}^{\mathrm{Me}} \mathrm{Co}\right)$ in $\mathrm{D}_{2} \mathrm{O}$. 
$\overrightarrow{8}$

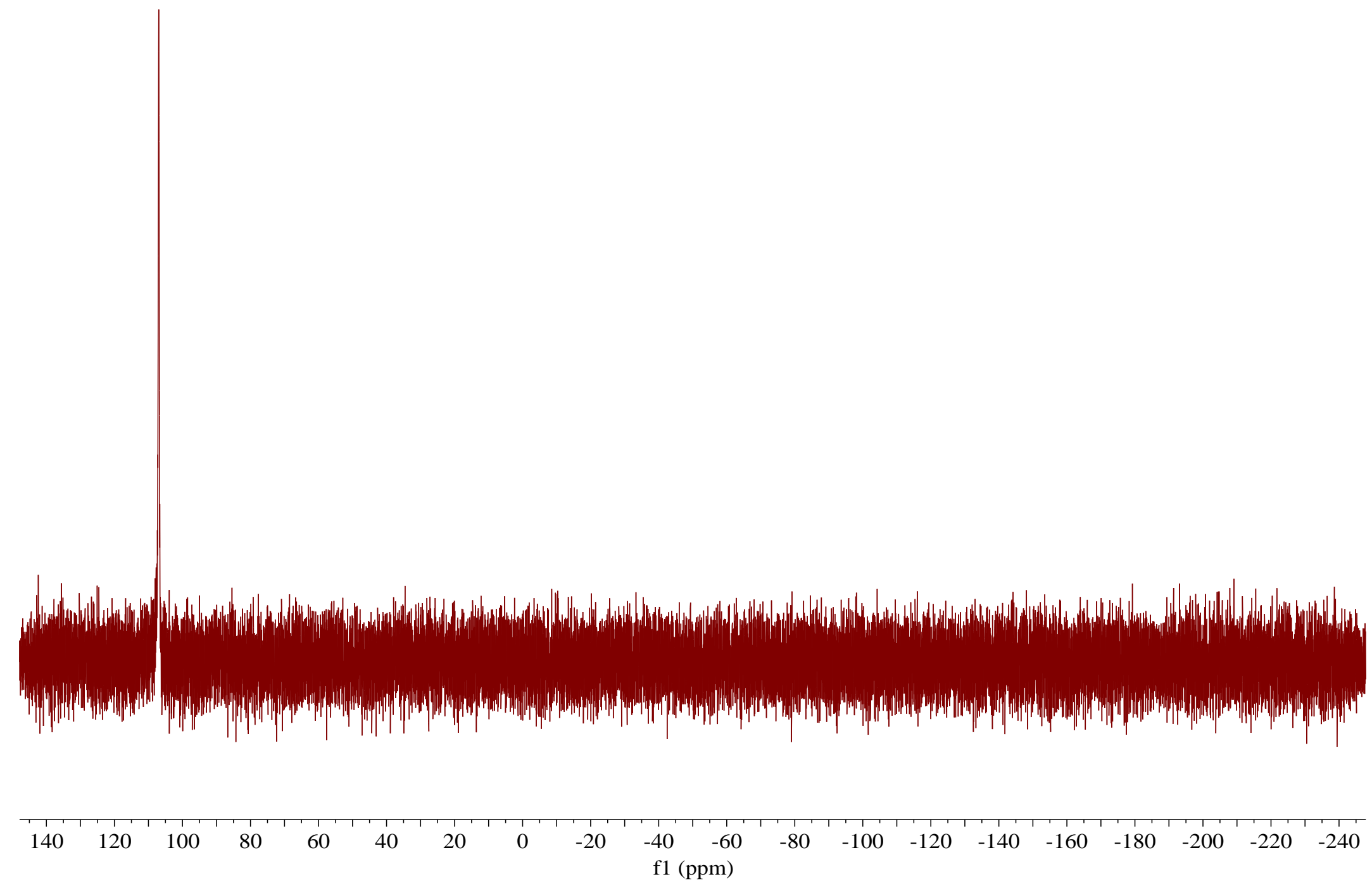

Figure C7. ${ }^{31} \mathrm{P}$ Spectrum of $\mathrm{Na}\left(\mathrm{CpP}^{\mathrm{OEt}} \mathrm{Co}\right)$ in $\mathrm{CDCl}_{3}$. 
。

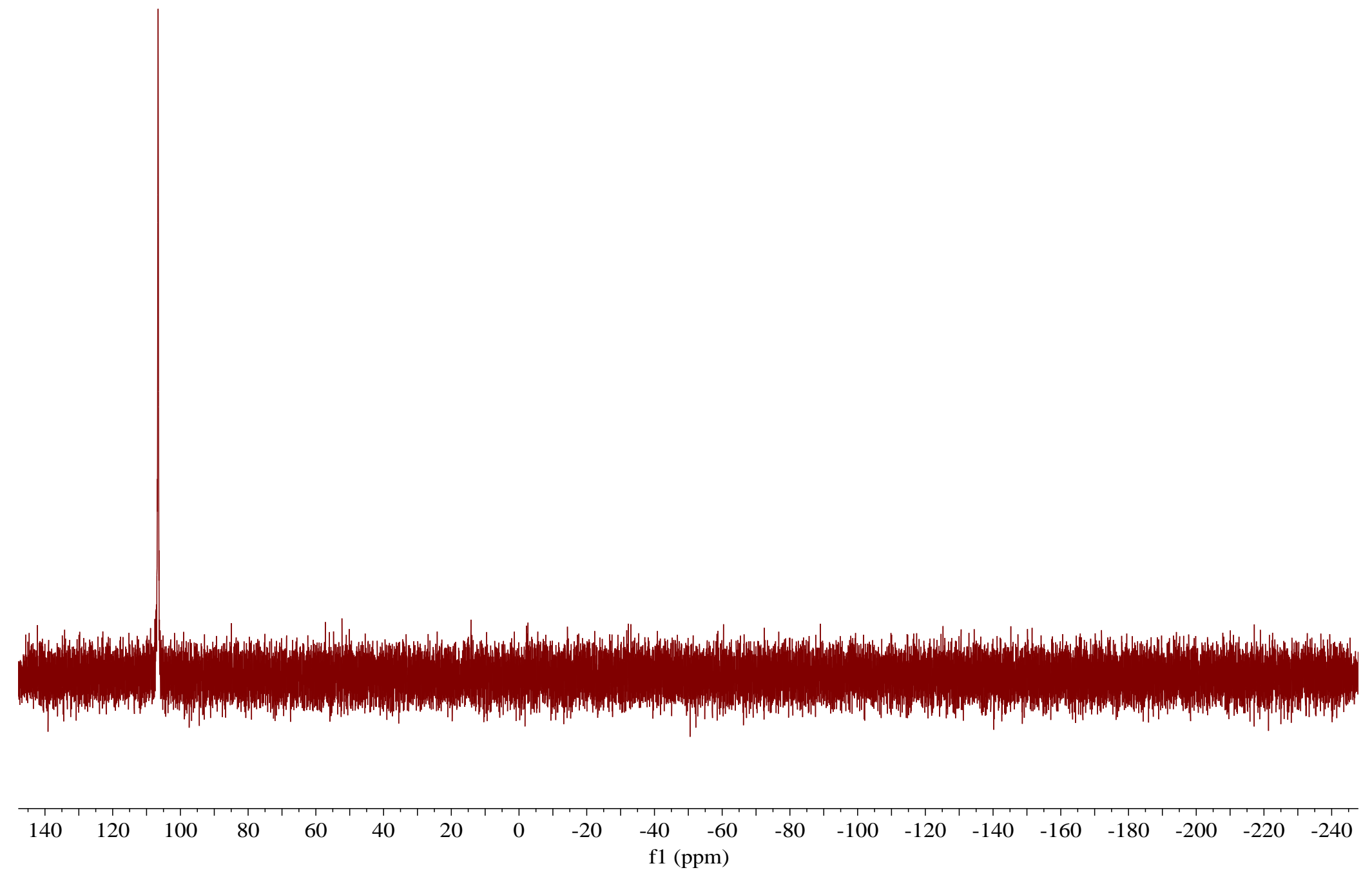

Figure C8. ${ }^{31} \mathrm{P}$ Spectrum of $\mathrm{Na}\left(\mathrm{CpP}^{\mathrm{OBu}} \mathrm{Co}\right)(\mathbf{4})$ in $\mathrm{CDCl}_{3}$. 


\section{APPENDIX D. UV-Vis SPECTRA}

Shown here are the UV-Vis spectra of all the complexes. Spectra were collected on Agilent 8453 Ultraviolet/Visible spectrometer at room temperature. The solvents are $\mathrm{CHCl}_{3}$ as illustrated. 
$(\mathrm{CpPOEt} \mathrm{Co})_{2} \mathrm{Co}(\mathbf{1})$

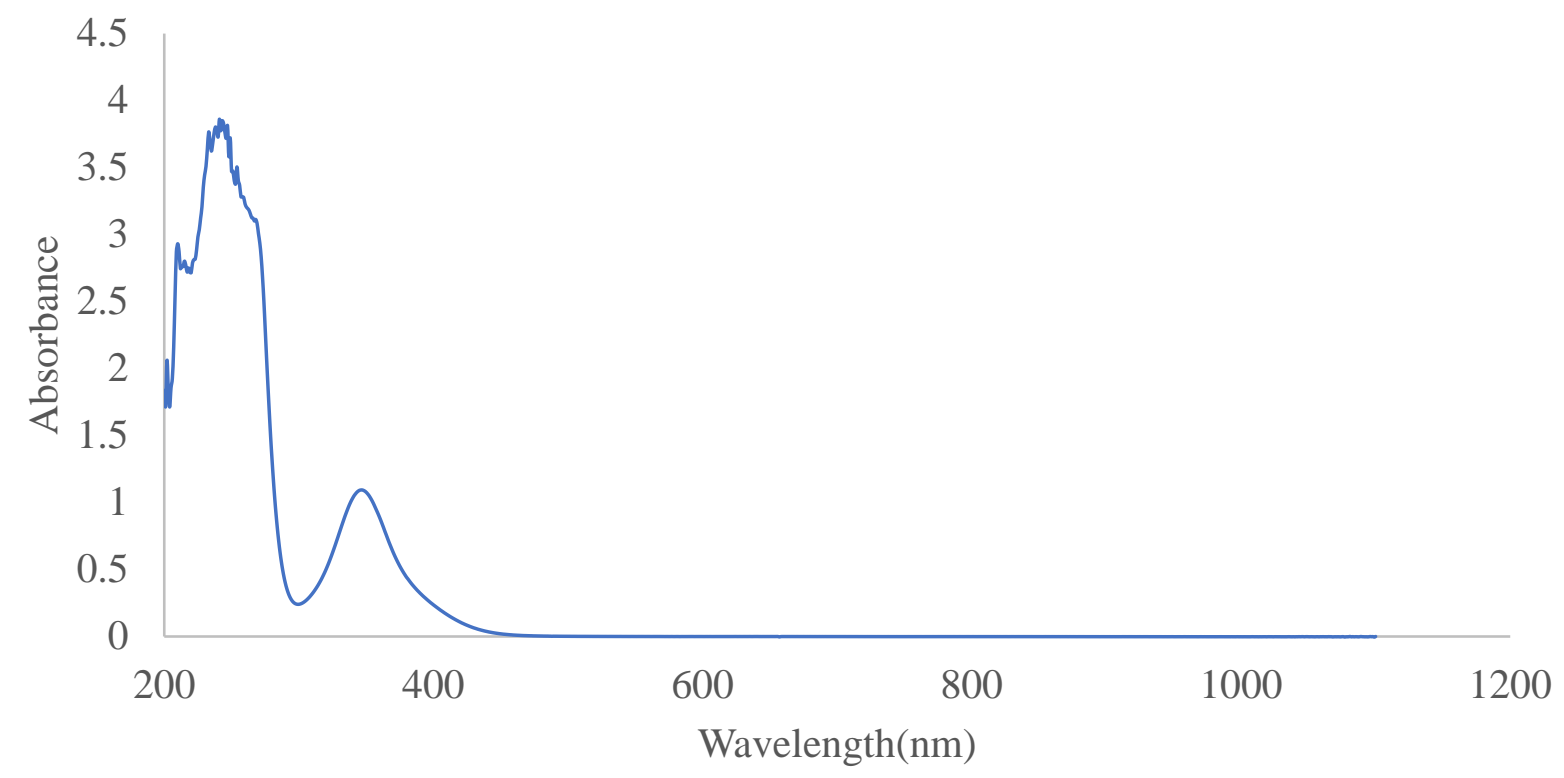

Figure D1. UV-Vis Spectrum of $\left(\mathrm{CpP}^{\mathrm{OEt}} \mathrm{Co}\right)_{2} \mathrm{Co}(\mathbf{1})$ in $\mathrm{CHCl}_{3}$.

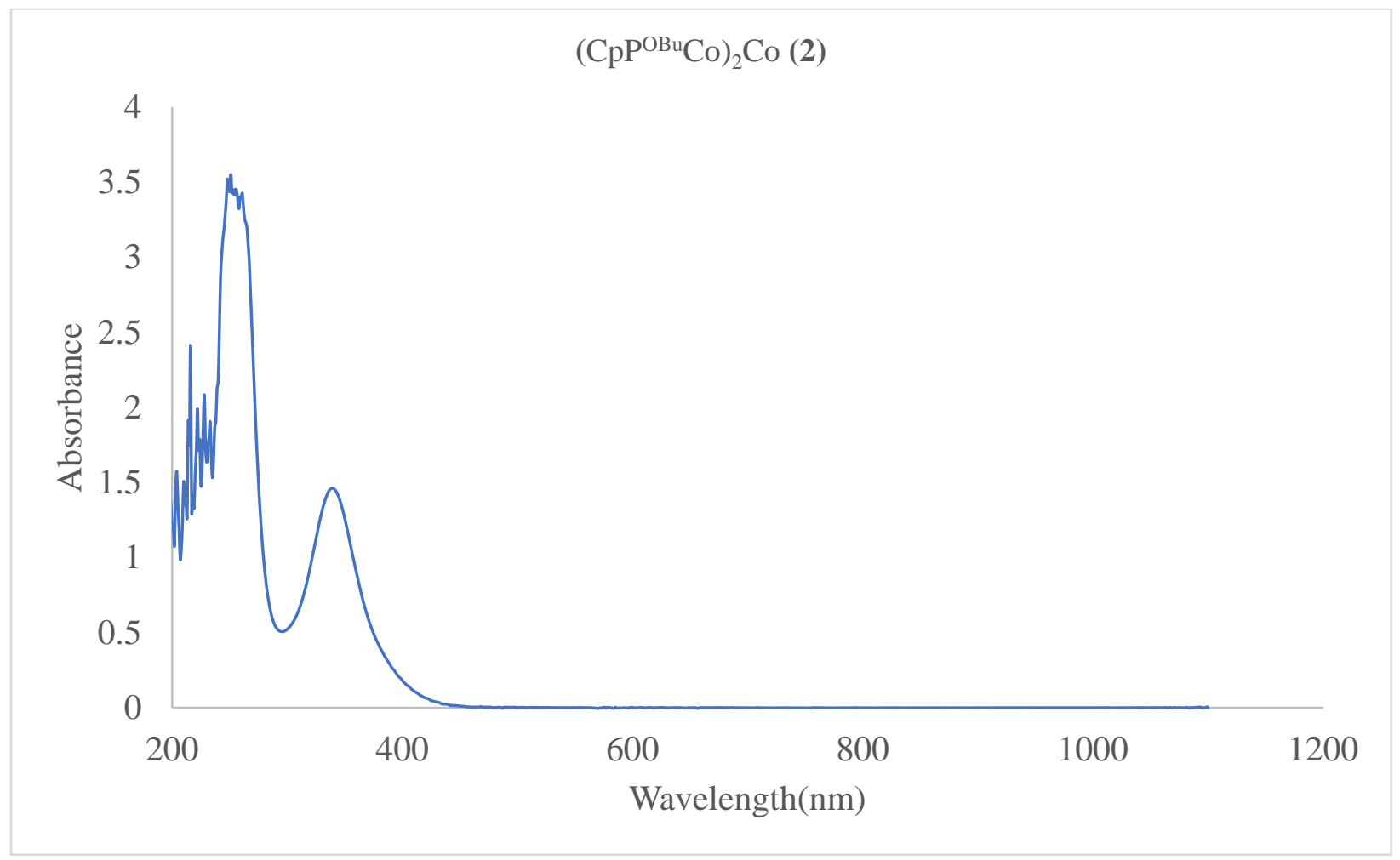

Figure D2. UV-Vis Spectrum of $\left(\mathrm{CpP}{ }^{\mathrm{OBu}} \mathrm{Co}\right)_{2} \mathrm{Co}(2)$ in $\mathrm{CHCl}_{3}$. 


$$
\mathrm{Na}\left(\mathrm{CpP}{ }^{\mathrm{OEt}} \mathrm{Co}\right) \text { (3) }
$$

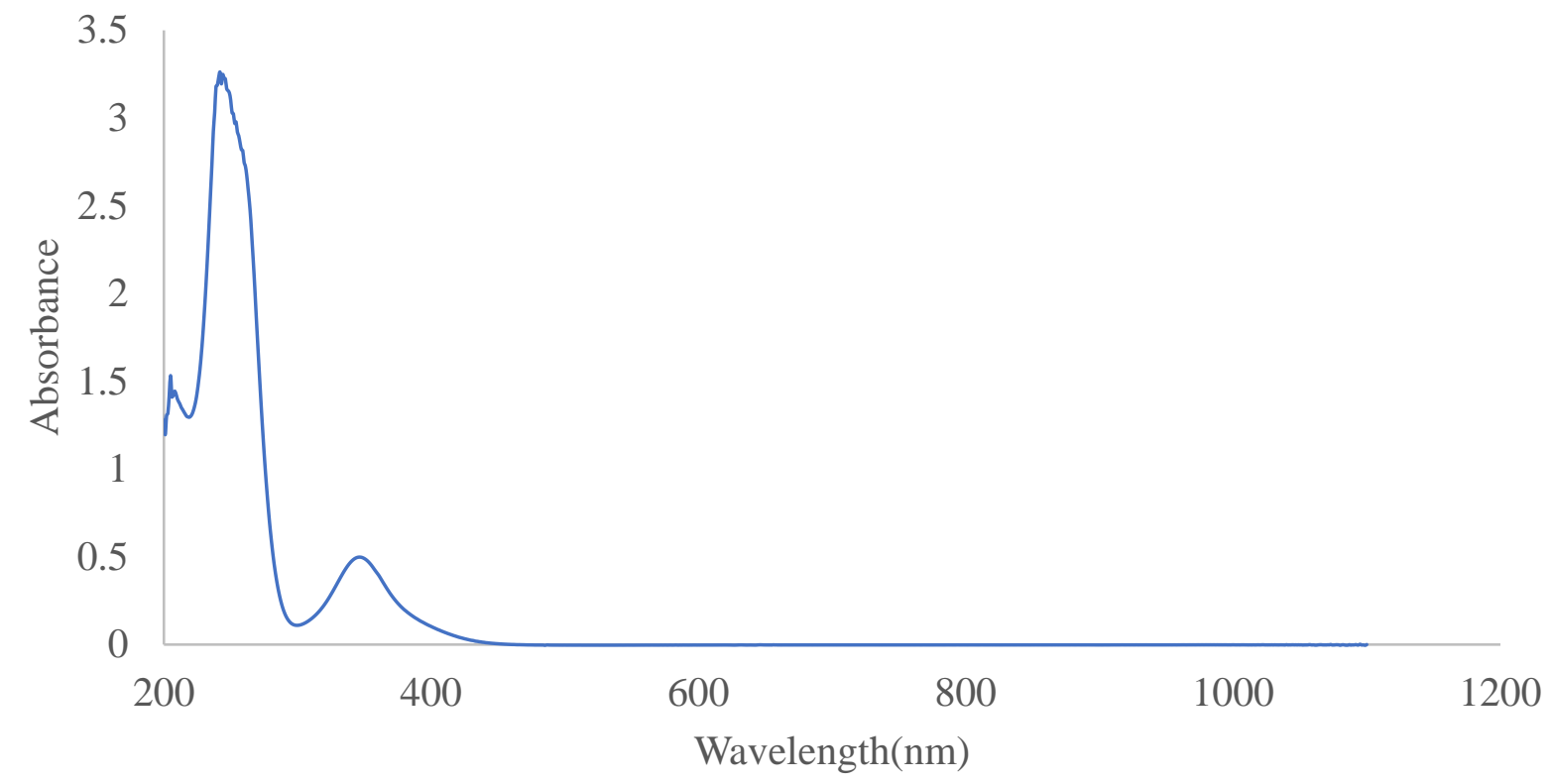

Figure D3. UV-Vis Spectrum of $\mathrm{Na}\left(\mathrm{CpP}^{\mathrm{OEt}} \mathrm{Co}\right)$ (3) in $\mathrm{CHCl}_{3}$.



Figure D4. UV-Vis Spectrum of $\mathrm{Na}\left(\mathrm{CpP}{ }^{\mathrm{OBu}} \mathrm{Co}\right)$ (4) in $\mathrm{CHCl}_{3}$. 
$\left[\mathrm{CpP}^{\mathrm{OBu}} \mathrm{CoVOCl}\right]_{2}(\mathbf{8})$

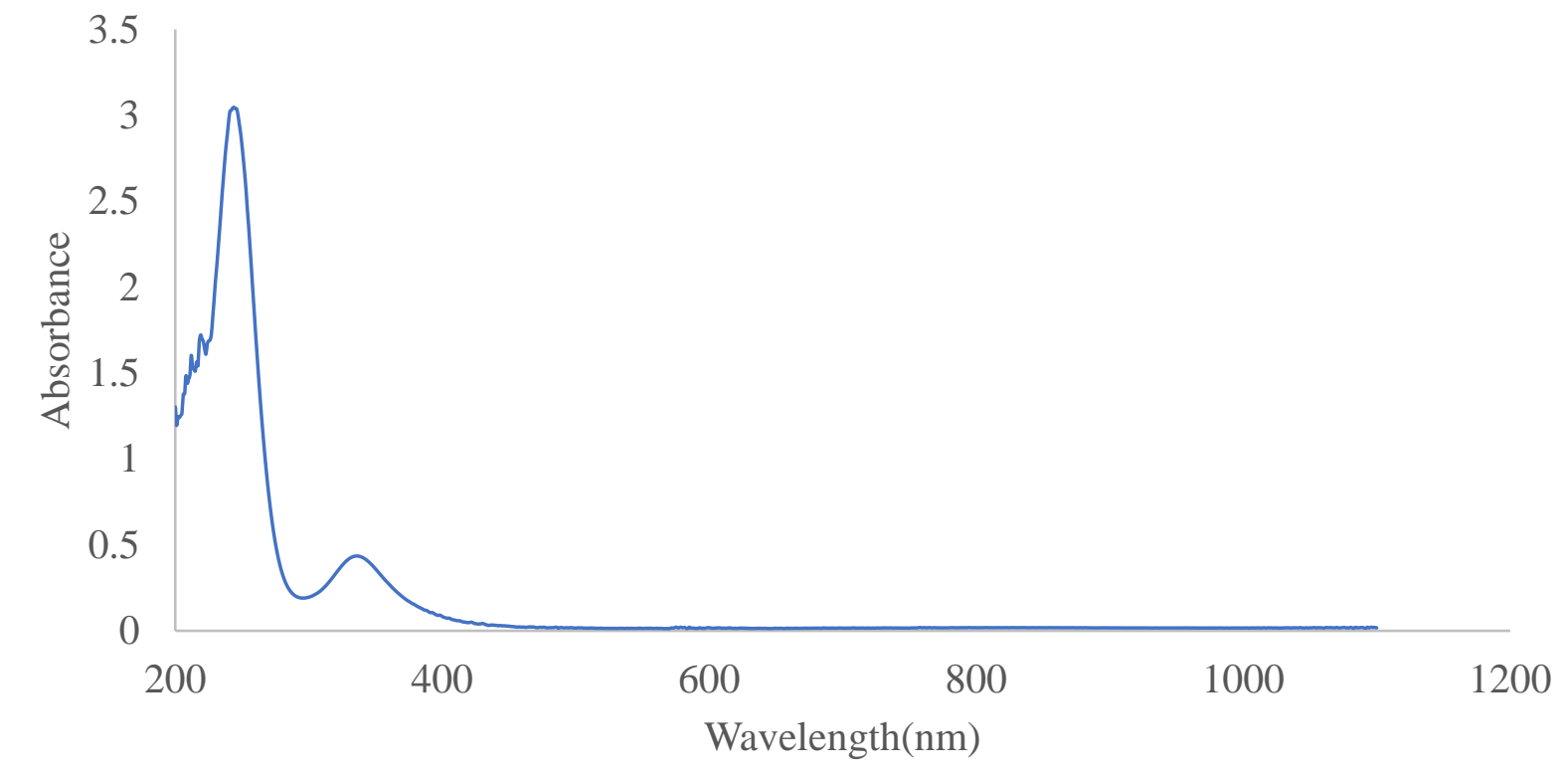

Figure D5. UV-Vis Spectrum of $\left[\mathrm{CpP}^{\mathrm{OBu}} \mathrm{CoVOCl}_{2}(\mathbf{8})\right.$ in $\mathrm{CHCl}_{3}$.

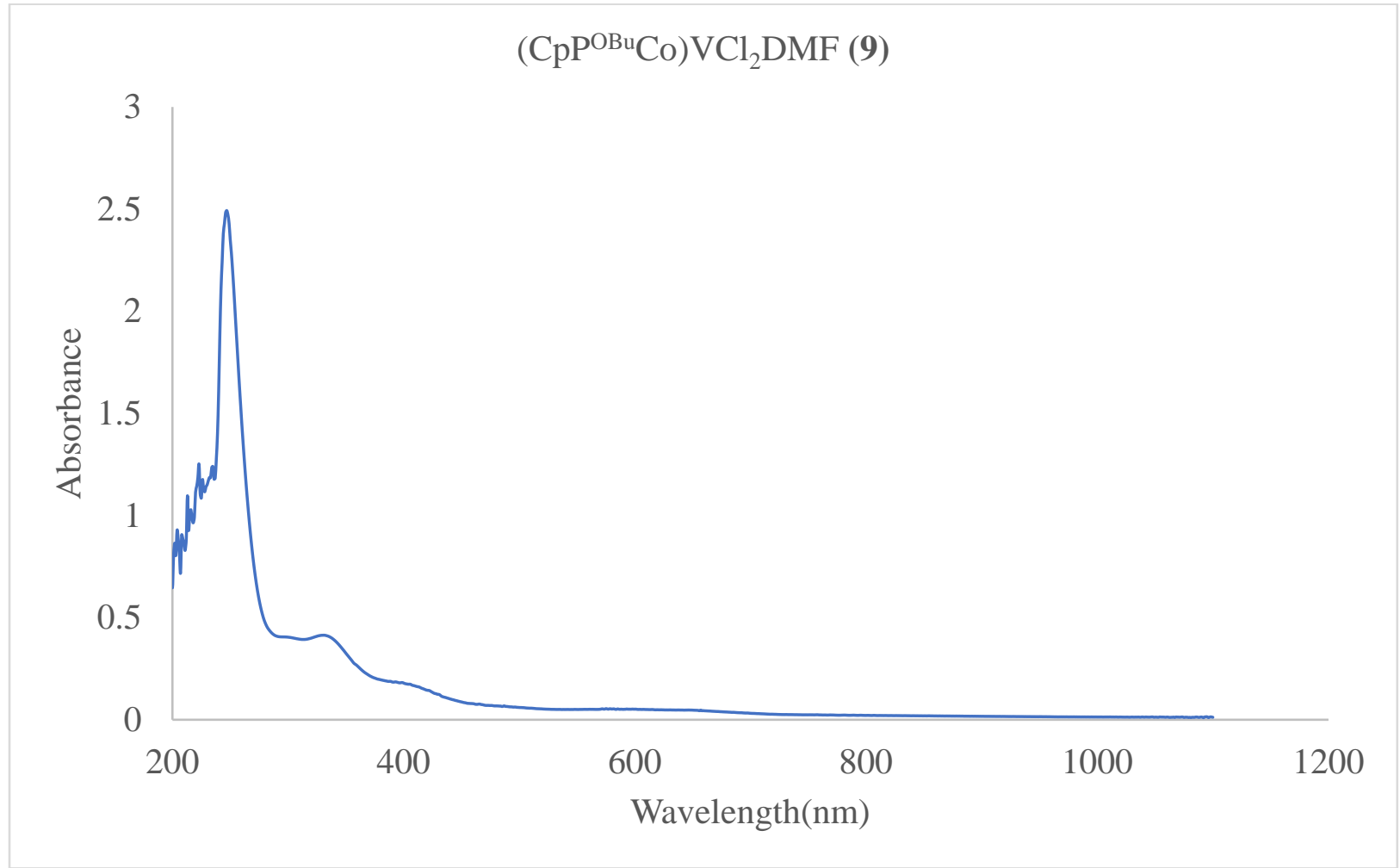

Figure D6. UV-Vis Spectrum of $\left(\mathrm{CpP}^{\mathrm{OBu}} \mathrm{Co}\right) \mathrm{VCl}_{2} \mathrm{DMF}$ (9) in $\mathrm{CHCl}_{3}$. 
(CpP $\left.{ }^{\mathrm{OBu}} \mathrm{Co}\right) \mathrm{VO}($ acac) (10)



Figure D7. UV-Vis Spectrum of $\left(\mathrm{CpP}^{\mathrm{OBu}} \mathrm{Co}\right) \mathrm{VO}(\mathrm{acac})(\mathbf{1 0})$ in $\mathrm{CHCl}_{3}$.

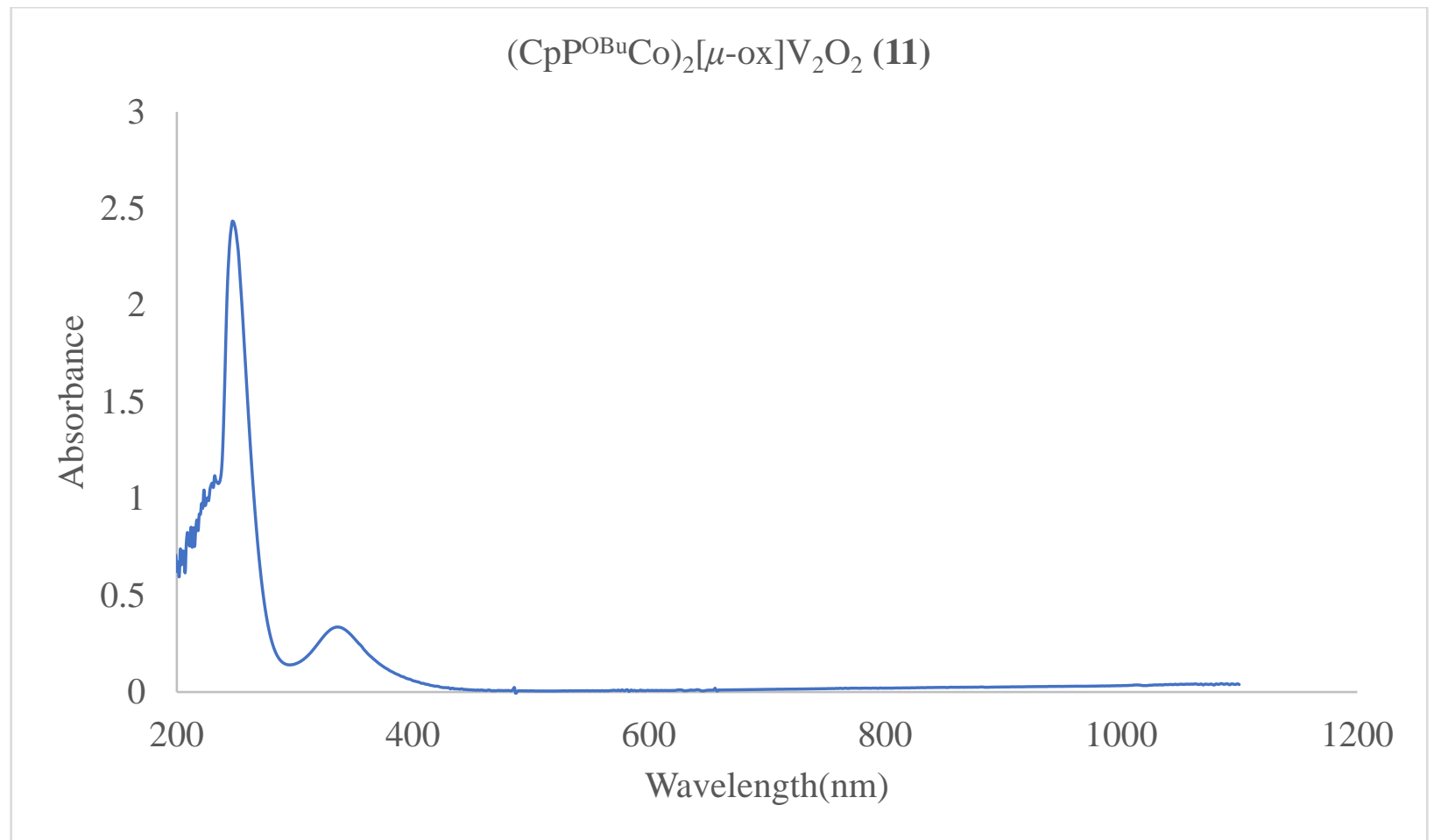

Figure D8. UV-Vis Spectrum of $\left(\mathrm{CpP}^{\mathrm{OBu}} \mathrm{Co}\right)_{2}[\mu-\mathrm{ox}] \mathrm{V}_{2} \mathrm{O}_{2}$ (11) in $\mathrm{CHCl}_{3}$. 


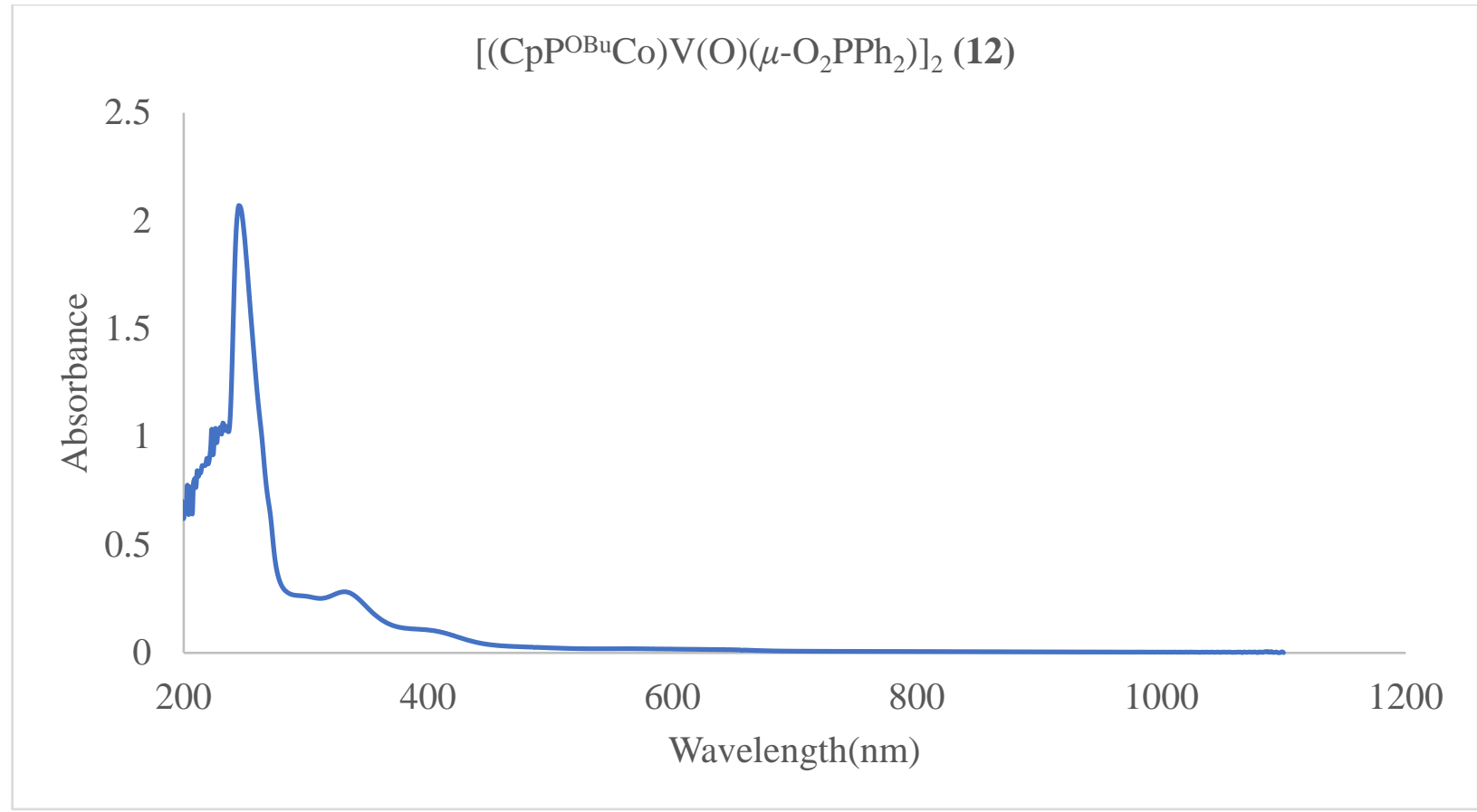

Figure D9. UV-Vis Spectrum of $\left[\left(\mathrm{CpP}^{\mathrm{OBu}} \mathrm{Co}\right) \mathrm{V}(\mathrm{O})\left(\mu-\mathrm{O}_{2} \mathrm{PPh}_{2}\right)\right]_{2}$ (12) in $\mathrm{CHCl}_{3}$. 